\title{
Advanced Vehicle Testing and Evaluation
}

\section{Final Report \\ October 1, 2005-March 31, 2013}

\author{
Prepared for \\ us ocesarmeter of \\ ERGY \\ US Department of Energy \\ Vehicle Technologies Office
}

\author{
Prepared by \\ Clarity Group, Inc. \\ Principal Investigator \\ Thomas Garetson
}

Contract DE-FC26-05NT42486 


\section{DISCLAIMER}

This report was prepared as an account of work sponsored by an agency of the United States Government. Neither the United States Government nor any agency thereof, nor any of their employees, makes any warranty, express or implied, or assumes any legal liability or responsibility for the accuracy, completeness, or usefulness of any information, apparatus, product, or process disclosed, or represents that its use would not infringe privately owned rights. Reference herein to any specific commercial product, process, or service by trade name, trademark, manufacturer, or otherwise does not necessarily constitute or imply its endorsement, recommendation, or favoring by the United States Government or any agency thereof. The views and opinions of authors expressed herein do not necessarily state or reflect those of the United States Government or any agency thereof.

\section{ecotality}

NORTH AMERICA

Clarity Group, Inc. DBA ECOtality North America 430 S. $2^{\text {nd }}$ Avenue Phoenix, Arizona 85003 (602) 716-9576 


\section{Table of Contents}

Executive Summary ...................................................................1

Approach ...........................................................................................3

Discussion of Results................................................................6

Task 1 - Procedure Development ...........................................................................6

Task 1.a: Airport Ground Support Equipment (GSE) Baseline Test Procedures ..................6 6

Task 1.01: Hybrid Electric Vehicle (HEV) Battery Test Procedures............................... 6

Task 1.02: Plug-In HEV Baseline Test Procedure ............................................... 7

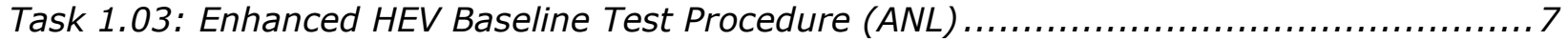

Task 1.04: Enhanced HEV Fleet Test Procedure............................................... 7

Task 1.05: 2007 Procedure Updates \& Revisions ............................................ 8

Task 1.06: 2008 Procedure Updates \& Revisions ............................................... 8

Task 1.07: 2009 Procedure Updates \& Revisions ........................................... 8

Task 1.08: (Added in A015) 2010 Procedure Updates and Revisions ............................ 8

Task 1.09: 2011 \& 2012 Procedure Updates and Revisions .................................9

Task 2 - Baseline Performance Testing .............................................................10

Task 2.a: HICE F-150 4V Baseline Test .................................................. 10

Task 2.b: GSE Baseline Testing - FMC Pushback Tractor................................. 11

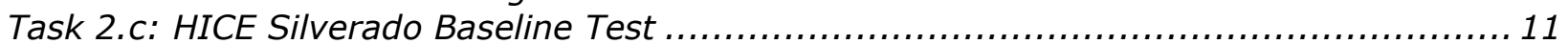

Task 2.d: Neighborhood Electric Vehicle (NEV) Roush Electric Vehicle Baseline Test.......... 12

Task 2.01: HEV Highlander Baseline Testing (1 Baseline Test w/ANL Dyno and 2 Battery

Pre-Tests)................................................................... 12

Task 2.02: 2 HEV Highlander End-of-Life Baseline Testing (Battery Post Test) ................ 13

Task 2.04: 2 HEV Prius End-of-Life Baseline Testing (Battery Post Test)....................... 14

Task 2.05: 2 HEV Honda Accord End-of-Life Baseline Testing (Battery Post Test) .............. 15

Task 2.06: 2 HEV Escape End-of-Life Baseline Testing (Battery Post Test).....................16

Task 2.07: 2 HEV Silverado End-of-Life Baseline Testing (Battery Post Test)...................17

Task 2.08: 2 HEV 400h Lexus End-of-Life Baseline Testing (Battery Post Test) ................ 18

Task 2.09 (Added per A003, April 2006): HEV Lexus 400h Baseline Testing (1 Baseline Test

W/ANL Dyno and 2 Battery Pre-Tests) ........................................ 19

Task 2.10: PHEV Baseline Testing (4 Baseline w/ANL Dyno) ..................................20

Task 2.11: NYSERDA PHEV End-of-Life Baseline Testing (4 Battery Post Test) ................ 21

Task 2.12: PHEV Energy CS Prius Baseline Testing (1 Baseline Test w/ANL Dyno) .............2 21

Task 2.13: PHEV Energy CS Prius End-of-Life Testing (1 Battery Post Test/ End of Life) .... 22

Task 2.14: Gen II Civic HEV Baseline Testing (1 Baseline Test w/ANL Dyno and 2 Battery

Pre-Tests)..................................................................... 22

Task 2.15: 2 HEV Civic End-of-Life Baseline Testing (2 Battery Post Test) ................... 23

Task 2.16: Toyota Camry Baseline Testing (1 Baseline Test w/ANL Dyno and 2 Battery Pre-

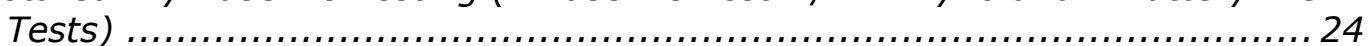

Task 2.17: 2 HEV Camry End-of-Life Baseline Testing (2 Battery Post Test)................. 25

Task 2.20: NYSERDA PHEV Battery Baseline Pre-Tests (2 Battery Pre-Tests) .................. 26

Task 2.21: NYSERDA PHEV Battery Baseline Post-Tests (2 Battery Post-Tests) ................ 26

Task 2.22: Saturn VUE Baseline Testing (1 Baseline Test w/ANL Dyno and 2 Battery Pre-

Tests) ...................................................................... 26

Task 2.23: Saturn VUE End-of-Life Baseline Testing (2 Battery Post Test) .................... 27

Task 2.24: Nissan Altima Baseline Testing (1Baseline w/ANL Dyno and 2 Battery Pre-test) 27

Task 2.25: Nissan Altima End-of-Life Baseline Testing (2 Battery Post Test) ................... 28 
Task 2.28: HEV Chevy Tahoe Baseline Testing (1 Baseline w/ANL Dyno and 2 Battery Pretest)........................................................................... 29

Task 2.29: HEV Chevy Tahoe End-of-Life Baseline Testing (2 Battery Post Test) ............. 30 Task 2.30: GEM NEV (Neighborhood Electric Vehicle) Baseline Testing (2 Vehicles) ........... 31 Task 2.31: Mercedes S400 HEV Baseline Testing (1 Baseline Test w/ANL Dyno and 2 Battery Pre-Tests) 32

Task 2.32: Honda Insight Baseline Testing (1 Baseline w/ANL Dyno and 2 Battery Pre-Test)32 Task 2.33: Honda Insight HEV End-of-Life Baseline Testing (2 Battery Post Test)............. 33 Task 2.34: (Added in A014) Mini E Baseline Testing (1 ANL Dyno and 1 Battery Pre-Test). 34 Task 2.35: RESERVED ..................................................................... 34

Task 2.36: Ford Fusion HEV Baseline Testing (1 ANL Dyno and 2 Battery Pre-Test) .......... 35

Task 2.37: Ford Fusion HEV End-of-Life Baseline Testing (2 Battery Post Test) ................ 36 Task 2.38: (Added in A014) Gen 2 HyMotion Prius PHEV Baseline Testing (1 Baseline Test w/ANL Dyno).................................................................. 36

Task 2.39: (Added in A014) Gen 2 HyMotion Prius PHEV End-of-Life Testing (1 Battery Post Test/End of Life) .............................................................. 37

Task 2.40: (Added in A014) Ford Escape Gasoline PHEV Baseline Testing (1 Baseline Test)37 Task 2.41: (Added in A014) Ford Escape Gasoline PHEV End-of-Life Testing (1 Battery Post Test/End of Life) ............................................................. 38

Task 2.42: (Added in A014) Gen 3 Prius HEV Baseline Testing (1 ANL Dyno and 1 Battery Pre-Test) .................................................................... 38

Task 2.43: Gen 3 Prius HEV End-of-Life Baseline Testing (2 Battery Post Test) .............. 39

Task 2.44: Reserved....................................................................... 39

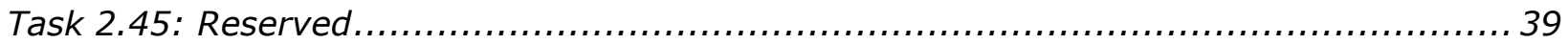

Task 2.46: Kangoo Baseline Testing (1 Baseline Test w/ANL Dyno) .........................40 40

Task 2.47: Gen 1 HyMotion Prius PHEV Baseline Testing (1 Baseline Test w/ANL Dyno) .... 40

Task 2.48: Baseline Testing of 4 NEVs ...................................................... 41

Task 2.49: Mercedes S400 HEV End-of-Life Baseline Testing (Battery Post Test) ............. 42

Task 2.50: Gen 1 HyMotion Prius PHEV End-of-Life Testing (1 Battery Post Test/End of Life) 43

Task 2.51: (Added January 2010) Diesel Volkswagen Golf Idle-Stop Technology Vehicle Baseline Testing (1 Baseline Test w/ANL Dyno) ................................43 43

Task 2.52: (Added January 2010) Mazda3 I-stop Idle-Stop Technology Vehicle Baseline Testing (1 Baseline Test w/ANL Dyno) ........................................4 44

Task 2.53: (Added January 2010) Smart mhd fortwo Idle-Stop Technology Vehicle Baseline Testing (1 Baseline Test w/ANL Dyno and 2 Battery Pre-Test) .................44 44

Task 2.54: (Added January 2010) Diesel Volkswagen Golf Idle-Stop Vehicle Technology Endof-Life Testing (2 Battery Post Test) .......................................... 45

Task 2.55: (Added January 2010) Mazda3 I-stop Idle-Stop Vehicle Technology End-of-Life Testing (2 Battery Post Test)................................................. 45

Task 2.56: (Added January 2010) Smart mhd fortwo Idle-Stop Vehicle Technology End-ofLife Testing (2 Battery Post Test)............................................ 45

Task 2.57: (Added January 2010) Hyundai Sonata Hybrid (1 Baseline Test w/ANL Dynamometer and 2 Battery Pre-Tests) .................................... 46

Task 2.58: (Added January 2010) Hyundai Sonata Hybrid End-of-Life Testing (2 Battery Post Test) ...................................................................47

Task 2.59: (Added January 2010) Nissan LEAF BEV Battery Baseline Testing (1 Baseline w/ANL Dyno and Fast Charge and 1 Battery Pre-Test) ......................47

Task 2.60: (Added January 2010) Nissan LEAF BEV End-of-Life Baseline Testing (1 Battery Post Test) .....................................................................48 48

Task 2.61: (Added January 2010) BEV Battery Baseline Testing (1 Baseline w/ANL Dyno and Battery Pre-Test) ............................................................. 48

Task 2.62: (Added January 2010) BEV End-of-Life Baseline Testing (1 Battery Post Test) . 48 
Task 2.63: (Added January 2010) BEV Battery Baseline Testing (1 Baseline w/ANL Dyno \& Battery Pre-Test) ............................................................. 48

Task 2.64: (Added January 2010) BEV End-of-Life Baseline Testing (1 Battery Post Test) . 48 Task 2.65: (Added January 2010) BEV Battery Baseline Testing (1 Baseline w/ANL Dyno and Battery Pre-Test) ............................................................ 48

Task 2.66: (Added January 2010) BEV End-of-Life Baseline Testing (1 Battery Post Test) . 48

Task 2.67: (Added January 2010) BEV Battery Baseline Testing (1 Baseline w/ANL Dyno and Fast Charge and 1 Battery Pre-Test) ........................................ 48

Task 2.68: (Added January 2010) BEV End-of-Life Baseline Testing (1 Battery Post Test) . 49 Task 2.69: (Added January 2010) BEV Battery Baseline Testing (1 Baseline w/ANL Dyno \& Battery Pre-Test) ........................................................... 49

Task 2.70: (Added January 2010) BEV End-of-Life Baseline Testing (1 Battery Post Test) . 49 Task 2.71: (Added January 2010) BEV Battery Baseline Testing (ANL Dynamometer and Battery Pre-Test) ............................................................ 49

Task 2.72: (Added January 2010) BEV End-of-Life Baseline Testing (1 Battery Post Test) . 49 Task 2.73: Honda Civic Ultra-Battery HEV Baseline Testing (1 Baseline Test and Battery PreTest) .......................................................................... 50

Task 2.74: Honda Civic Ultra-Battery HEV End-of-Life Baseline Testing (Battery Post Test) 51 Task 2.75 (Added January 2010) Chevrolet Volt PHEV Baseline Testing (1 Baseline Test w/ANL Dyno and Battery Pre-Test).......................................... 52

Task 2.76: (Added January 2010) Chevrolet Volt PHEV End-of-Life Testing (1 Battery Post Test) ......................................................................... 53

Task 2.77 (Added January 2010) PHEV Baseline Testing (1 Baseline Test w/ANL Dyno) ....53 Task 2.78: (Added January 2010) PHEV End-of-Life Testing (1 Battery Post Test) ............ 53 Task 2.79: (Added January 2010) HEV Baseline Testing (1 Baseline Test w/ANL Dyno \& 2 Battery Pre-Tests)......................................................... 53

Task 2.80: (Added January 2010) HEV End-of-Life Testing (2 Battery Post Test)............. 53 Task 2.81: (Added January 2010) Honda CR-Z HEV Baseline Testing (1 Baseline Test w/ANL Dynamometer and 2 Battery Pre-Tests).................................... 54

Task 2.82: (Added January 2010) Honda CR-Z HEV End-of-Life Testing (2 Battery Post Test)55

Task 2.83: Reserved ......................................................................... 55

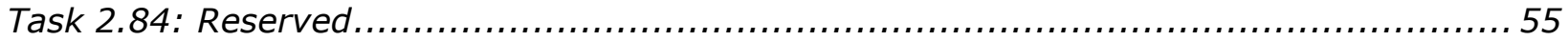

Task 2.85: (Added 2010) BEV Battery Baseline Testing .................................... 55

Task 3 - Accelerated Reliability Testing ...........................................................56

Task 3.a: HICE Ford F-150 2V Accelerated Reliability Test $(6 \mathrm{mo} / 6 \mathrm{~K} \mathrm{mi}) . . . . . . . . . . . . . . . . . . . .56$

Task 3.b: 2 HEV Prius Accelerated Reliability (100K mi) .......................................56

Task 3.01: (Added in A014) Grid-Connected Vehicle Data Collection and Charging Hardware56

Task 3.02: (Added in A014) Smart Grid Communication Interface .............................. 57

Task 3.03: Monitor H2 Station Performance............................................. 57

Task 3.04: PHEV Accelerated Reliability Testing (4 NYSERDA vehicles) (6mo/4,200mi) ..... 57

Task 3.05: HICE Fleet Testing (8 Integrated Waste Hydrogen Utilization Project Vehicles 24 mo/24K mi) .............................................................. 57

Task 3.06: Energy CS Prius Accelerated Reliability Testing $(4,200$ miles)..................... 57

Task 3.07: Future HICE Fleet Testing (3 Vehicles 16 mo/8K mi) ...........................58

Task 3.08: (Added in A003) Kangoo HEV Accelerated Reliability Testing (4,200 miles)...... 58

Task 3.09: (Added per A003) Gen 1 HyMotion Prius PHEV Accelerated Reliability Testing .. 59

Task 3.10: RESERVED ................................................................... 59

Task 3.11: BEV Accelerated Reliability Testing (1 Vehicle 12 months / 12,000 miles)........59

Task 3.12: (Added in A014) Mini E Accelerated Reliability Testing (1 Vehicle 12 months / 12,000 miles) ................................................................... 59

Task 3.13: (Added January 2010) Smart mhd fortwo Idle-Stop Technology Fuel Economy

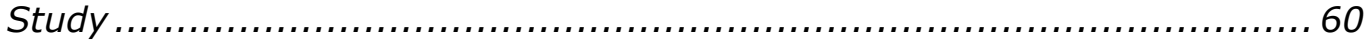


Task 3.14: (Added January 2010) Test Procedure Development for Fast Chargers Utilizing Energy Storage................................................................. 61

Task 3.15: (Added January 2010) DCFC Battery Test Procedure Development ................ 62

Task 3.16: (Added January 2010) Support SAE Level 3 Communication Standard Development..................................................................6 62

Task 3.17: (added January 2010) Advanced Material Handling Electrification Evaluation ... 63

Task 3.18: Conduct USPS Factory Tests (5 vehicles) ........................................ 64

Task 3.19: Develop USPS Baseline Test Procedures ....................................... 64

Task 3.20: Conduct USPS Baseline Testing (5 vehicles)................................... 64

Task 3.21: Develop USPS Accelerated Reliability Test Procedures ............................6. 64

Task 3.22: Conduct USPS Accelerated Reliability Testing (5 vehicles) .........................6. 64

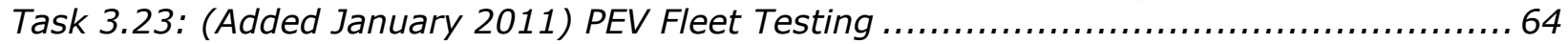

Task 4 - Fleet Testing ....................................................................................65

Task 4.a: Fleet Test 8 HCNG Vehicles ....................................................... 65

Task 4.b: Extended HEV Fleet Testing (2-Silverado, 2-Escape \& 2 Lexus 400h)............... 65

Task 4.c: 2 Accord Fleet Testing $(100 \mathrm{~K}$ mi) .................................................. 65

Task 4.d: Roush HICE Silverado Fleet Testing $(12 \mathrm{mo} / 12 \mathrm{~K} \mathrm{mi})$..............................66 66

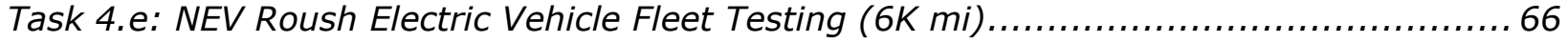

Task 4.f: GSE Life Cycle Cost Study ..................................................... 66

Task 4.01: HEV Highlander Fleet Testing (2 New Vehicles 36mo/160K mi) ................... 66

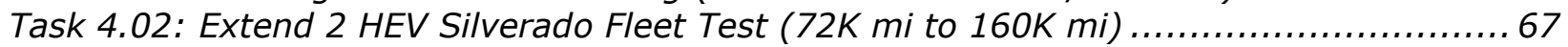

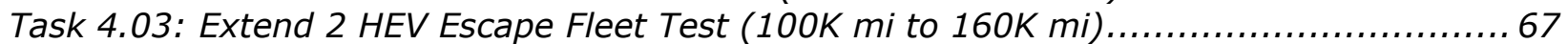

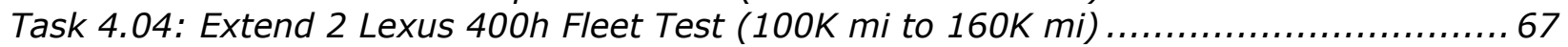

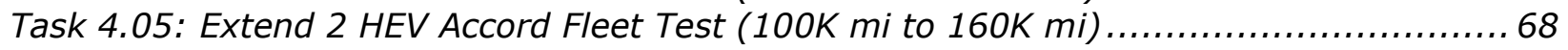

Task 4.06: Monitor HICE National Fleet Status ............................................. 68

Task 4.07: Gen II Civic Fleet Testing (2 Vehicles 36mo/160K mi) ...........................68

Task 4.08: Toyota Camry HEV Fleet Testing (2 Vehicles 36mo/160K mi) .....................6 68

Task 4.09: Lexus 400H 2WD HEV Fleet Testing (1 Vehicles 36mo/36K mi) ...................6 69

Task 4.10: Future PHEV Fleet Testing (20 NYSERDA Vehicles) .................................69

Task 4.11: Saturn VUE HEV Fleet Testing (2 Vehicles 36mo/160K mi) .........................6 69

Task 4.12: Nissan Altima HEV Fleet Testing (2 Vehicles 36mo/160K mi) .......................69 69

Task 4.14: Chevy Tahoe HEV Fleet Testing (2 Vehicles 36mo/160K mi) ........................ 70

Task 4.16: Honda Insight Fleet Testing (2 Vehicles 36mo/160K mi).......................... 70

Task 4.17: PHEV Fleet Testing (6 vehicles 12 months) .................................... 70

Task 4.18: Ford Fusion HEV Fleet Testing (2 Vehicles 36mo/160K mi) ......................... 71

Task 4.19: (Added in A014) HyMotion Gen II PHEV Accelerated Reliability Testing (6 months / 5,400 miles) .................................................................... 71

Task 4.21: Mercedes Benz HEV Fleet Testing (2 Vehicles / 36 months / 160K mi) ........... 72 Task 4.22: (Added in A014) Gen 3 Prius HEV Fleet Testing (2 Vehicles / 36mo/160K mi) .. 72 Task 4.23 (Added in A003): Extend 2 HEV GEN II Prius Fleet Test (100K mi to 160K mi) .. 72 Task 4.24: (Added January 2010) Diesel Volkswagen Golf Idle-Stop Technology Fleet Testing (2 Vehicles 36 mo/160K mi)...................................... 73

Task 4.25: (Added January 2010) Mazda3 I-stop Idle-Stop Technology Fleet Testing (2 Vehicles 36 mo/160K mi).................................................. 73

Task 4.26: (Added January 2010) Smart mhd fortwo Idle-Stop Technology Fleet Testing (2 Vehicles 36 mo/160K mi).................................................. 74

Task 4.27: (Added January 2010) Hyundai Sonata Hybrid HEV Fleet Testing (2 Vehicles 36 mo/160K mi)................................................................. 74

Task 4.28: (Added January 2010) Future HEV Fleet Testing (2 Vehicles 36 mo/160K mi) .. 74 Task 4.29: (Added January 2010) Honda CR-Z HEV Fleet Testing (2 Vehicles 36 mo/160K

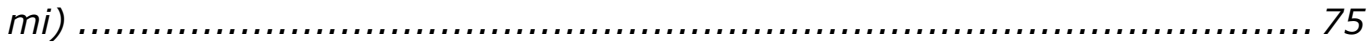

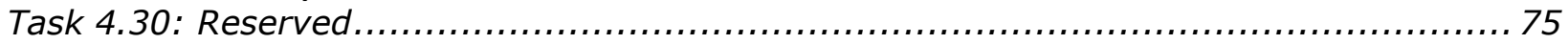


Task 4.31: (Added January 2010) Nissan LEAF BEV Fleet Testing (1 Vehicle, 12 mo / 12k mi) ........................................................................... 75

Task 4.32: (Added January 2010) BEV Accelerated Reliability Testing (1 Vehicle, 12 mo /

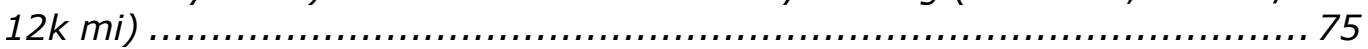

Task 4.33: (Added January 2010) BEV Accelerated Reliability Testing (1 Vehicle, 12 mo /

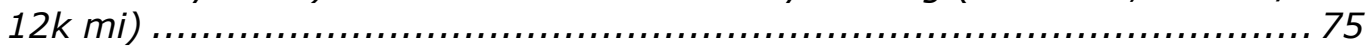

Task 4.34: (Added January 2010) BEV Accelerated Reliability Testing (1 Vehicle, 12 mo /

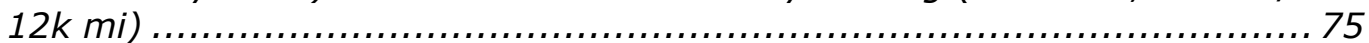

Task 4.35: (Added January 2010) BEV Accelerated Reliability Testing (1 Vehicle, 12 mo / $12 \mathrm{k} \mathrm{mi})$...................................................................... 75

Task 4.36: (Added January 2010) BEV Accelerated Reliability Testing (1 Vehicle, 12 mo / $12 k \mathrm{mi})$....................................................................... 75

Task 4.37: (Added January 2010) BEV Accelerated Reliability Testing (1 Vehicle, 12 mo /

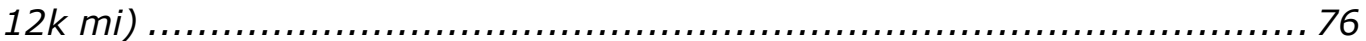

Task 4.38: (Added January 2010) Honda Civic Ultra-Battery HEV Fleet Testing (1 Vehicle, 24 mo / $100 \mathrm{k} \mathrm{mi}$................................................................. 76

Task 4.39: (Added January 2010) Chevrolet Volt PHEV Fleet Testing (12 mo / 12k mi ) .... 76

Task 4.40: (Added January 2010) Plug-In Gasoline HEV Accelerated Reliability Testing (6

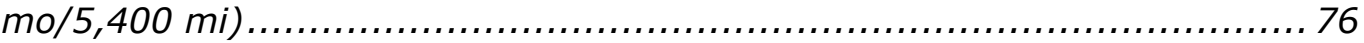

Task 4.41: (Added January 2011) Evaluation of Federal Fleets................................ 76

Task 4.42: (Added January 2011) PHEV Fleet Testing ..................................... 77

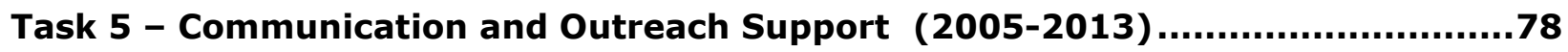

Task 5.a (Added in A003): Model NEV Program ............................................ 78

Task 5.01 (Added in A003): 2006 DOE Ad Hoc Requests for Data, Analysis, and Reports .. 78

Task 5.02 (Added in A003): 2007 DOE Ad Hoc Requests for Data, Analysis, and Reports .. 78

Task 5.03 (Added in A003): 2008 DOE Ad Hoc Requests for Data, Analysis, and Reports .. 78

Task 5.04 (Added in A003): 2009 DOE Ad Hoc Requests for Data, Analysis, and Reports .. 79

Task 5.05 (Added in A003): 2010-2013 DOE Ad Hoc Requests for Data, Analysis, and

Reports ....................................................................... 80

Task 5.062006 DOE Administrative Tasks................................................ 80

Task 5.072007 DOE Administrative Tasks.................................................. 80

Task 5.082008 DOE Administrative tasks ................................................. 81

Task 5.092009 DOE Administrative tasks .................................................. 81

Task 5.10 2010-2013 DOE Administrative Tasks .......................................... 82

Task 5.11 Support Chinese Battery \& Vehicle Manufacturer Interface.......................... 82

Task 5.12 Support Chinese Sister Cities ...................................................... 82

Accomplishments .....................................................................83

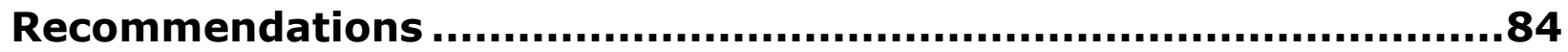

\section{List of Tables}

Table 1- Fleet Vehicle Final Status, October 1, 2005 - March 31, 2013.................................... 2

Table 2 - Kangoo HEV Accelerated Reliability Testing Results.............................................. 58

Table 3 - Gen 1 HyMotion Prius PHEV Accelerated Reliability Testing Results .......................... 59

Table 4 - Mini E Accelerated Reliability Testing Results .................................................... 59

Table 5 - PHEV Ford Escape Accelerated Reliability Testing Results ...................................... 71 


\section{Executive Summary}

The objective of the United States (U.S.) Department of Energy's (DOEs) Advanced Vehicle Testing and Evaluation (AVTE) project, part of the Vehicle Technologies Office, contract DEFC26-05NT42486, was to provide test and evaluation services for advanced technology vehicles, to establish a performance baseline, to determine vehicle reliability, and to evaluate vehicle operating costs in fleet operations.

Vehicles tested include light and medium-duty vehicles in conventional, hybrid, and allelectric configurations using conventional and alternative fuels, including hydrogen in internal combustion engines. Vehicles were tested on closed tracks and chassis dynamometers, as well as operated on public roads, in fleet operations, and over prescribed routes. All testing was controlled by procedures developed specifically to support such testing. Testing and evaluations were conducted in the following phases:

- Development of test procedures, which established testing procedures;

- Baseline performance testing, which established a performance baseline;

- Accelerated reliability testing, which determined vehicle reliability;

- Fleet testing, used to evaluate vehicle economics in fleet operation, and

- End of test performance evaluation.

Test results are reported by two means and posted by Idaho National Laboratory (INL) to their website: quarterly progress reports, used to document work in progress; and final test reports. This final report documents work conducted for the entirety of contract DE-FC2605NT42486 by the Clarity Group, Inc., doing business as ECOtality North America (ECOtality).

The contract was performed from 1 October 2005 through 31 March 2013, and includes 19 amendments to the original award with the most recent Amendment 019 dated 31 March 2012.

The final budget for the AVTA project totaled $\$ 10,797,679$. As a cooperative agreement, Clarity Group, Inc. was to provide cost share of $\$ 2,138,585$, leaving $\$ 8,659,094$ as the Federal share of the agreement.

Actual total expenditure for the AVTA project was $\$ 11,147,952$. The full $\$ 8,659,094$ Federal share was expended and $\$ 2,488,858$ of cost share was provided by Clarity Group, Inc. This resulted in an over-share of $\$ 350,273$.

There were 113 light-duty on-road (95), off-road (3) and low speed (15) vehicles tested. The breakdown of these vehicles is shown in Table 1. 
Table 1- Fleet Vehicle Final Status, October 1, 2005 - March 31, 2013

\begin{tabular}{|c|c|c|c|c|c|c|c|c|c|c|c|c|}
\hline $\begin{array}{r}\text { Vehicle } \\
\text { Count }\end{array}$ & VIN\# & Vehicle & Vehicle Type & Task 2 & Task 3/4 & $\begin{array}{c}\text { Initial } \\
\text { Mileage }\end{array}$ & End Mileage & $\begin{array}{c}\text { Total Miles } \\
\text { Accumulated }\end{array}$ & $\begin{array}{c}\text { Average Fuel } \\
\text { Economy } \\
(\mathrm{mpg})\end{array}$ & \begin{tabular}{|c|} 
Baseline \\
Data \\
Sheet \\
Published \\
\end{tabular} & \begin{tabular}{|c} 
Battery \\
Beg of Life \\
Published \\
\end{tabular} & $\begin{array}{c}\text { Battery } \\
\text { End of Life } \\
\text { Published }\end{array}$ \\
\hline 1 & $\# 8237$ & 2005 Escape Hybrid & HEV & 2.06 & 4.03 & 0 & \begin{tabular}{|l|}
160,274 \\
\end{tabular} & 160,274 & 26.2 & 2006 & $\sum$ & Jul-09 \\
\hline 2 & $\# 5881$ & 2005 Escape Hybrid & HEV & 2.06 & 4.03 & 0 & 160,000 & 160,000 & 27.9 & $\sum$ & $3<$ & Jul-09 \\
\hline 3 & $\# 1096$ & 2005 Accord Hybrid & HEV & 2.05 & 4.05 & 0 & 160,093 & 160,093 & 27.7 & 2005 & 2006 & Jul-09 \\
\hline 4 & $\# 0657$ & 2005 Accord Hybrid & HEV & 2.05 & 4.05 & 0 & 160,166 & 160,166 & 28.5 & $\sum<$ & 2006 & Jul-09 \\
\hline 5 & $\# 5681$ & 2006 Highlander Hybrid & HEV & $2.01,2.02$ & 4.01 & 0 & 159,888 & 159,888 & 23.8 & Feb-07 & Feb-10 & Feb-10 \\
\hline 6 & $\# 6395$ & 2006 Highlander Hybrid & HEV & 2.02 & 4.01 & 0 & 160,344 & 160,344 & 24.9 & $\sum<$ & Feb-10 & Feb-10 \\
\hline 7 & $\# 3344$ & 2007 Saturn Vue Hybrid & HEV & 2.23 & 4.11 & 0 & 152,280 & 152,280 & 25.7 & $\sum<$ & 2008 & $\mathrm{n} / \mathrm{a}$ \\
\hline 8 & $\# 8122$ & 2007 Saturn Vue Hybrid & HEV & $2.22,2.23$ & 4.11 & 0 & 102,934 & 102,934 & 27.1 & Jun-07 & 2008 & $\mathrm{n} / \mathrm{a}$ \\
\hline 9 & $\# 9329$ & 2006 Honda Civic Hybrid & HEV & 2.15 & 4.07 & 0 & 160,835 & 160,835 & 38.9 & Feb-07 & $\sum$ & Jul-09 \\
\hline 10 & $\# 8725$ & 2006 Honda Civic Hybrid & HEV & 2.15 & 4.07 & 0 & 160,711 & 160,711 & 39.2 & $2<$ & $2<$ & Jan-09 \\
\hline 11 & \#9664 & 2005 Silverado 4WD Hybrid & HEV & 2.07 & 4.02 & 0 & 160,037 & 160,037 & 17.8 & 2005 & 2006 & 2008 \\
\hline 12 & \#9284 & 2005 Silverado 2WD Hybrid & HEV & 2.07 & 4.02 & 0 & 160,539 & 160,539 & 18.0 & $\sum$ & 2006 & 2008 \\
\hline 13 & $\# 2575$ & 2006 Lexus 400H AWD & HEV & $2.08,2.09$ & 4.04 & 0 & 160,111 & 160,111 & 23.1 & $2<$ & Feb-10 & Feb-10 \\
\hline 14 & $\# 4807$ & 2006 Lexus $400 \mathrm{H}$ AWD & HEV & 2.08 & 4.04 & 0 & 160,531 & 160,531 & 23.1 & $\operatorname{Jan}-07$ & Feb-10 & Feb-10 \\
\hline 15 & $\# 6330$ & 2007 Camry Hybrid & HEV & 2.17 & 4.08 & 0 & 160,035 & 160,035 & 34.1 & Feb-07 & Feb-10 & Feb-10 \\
\hline 16 & $\# 7129$ & 2007 Camry Hybrid & HEV & $2.16,2.17$ & 4.08 & 0 & 160,231 & 160,231 & 34.1 & $2<$ & Feb-10 & Feb-10 \\
\hline 17 & $\# 0301$ & 2006 Lexus 400H FWD & HEV & 3 & 4.09 & 32,024 & 36,362 & 4,338 & 26.5 & $\mathrm{n} / \mathrm{a}$ & $\mathrm{n} / \mathrm{a}$ & $\mathrm{n} / \mathrm{a}$ \\
\hline 18 & $\# 1052$ & 2004 Prius & HEV & 2.04 & 4.23 & 0 & 160,274 & 160,274 & 44.8 & 2004 & $\sum$ & Jul-09 \\
\hline 19 & $\# 2721$ & 2004 Prius & HEV & 2.04 & 4.23 & 0 & 160,115 & 160,115 & 43.8 & $\sum$ & 26 & Jul-09 \\
\hline 20 & $\# 2351$ & 2007 Altima Hybrid & HEV & 2.25 & 4.12 & 0 & 160,633 & 160,633 & 29.8 & $\sum$ & Mar-10 & Mar-10 \\
\hline 21 & $\# 7982$ & 2007 Altima Hybrid & HEV & $2.24,2.25$ & 4.12 & 0 & 161,596 & 161,596 & 29.7 & May-08 & Mar-10 & Mar-10 \\
\hline 22 & $\# 5170$ & 2008 Tahoe Hybrid & HEV & 2.29 & 4.14 & 0 & 160,069 & 160,069 & 21.7 & Oct-08 & Jul-09 & Apr-12 \\
\hline 23 & $\# 7400$ & 2008 Tahoe Hybrid & HEV & $2.28,2.29$ & 4.14 & 0 & 160,124 & 160,124 & 21.4 & Oct-08 & Jul-09 & Apr-12 \\
\hline 24 & $\# 5670$ & 2008 BMW Mini-E & BEV & $2.34,2.35$ & 3.12 & 0 & 3,686 & 3,686 & \begin{tabular}{|c|}
$104.1 \mathrm{miles}$ \\
$@ 65 \mathrm{mph}^{* *}$
\end{tabular} & Mar-10 & $n / a$ & $\mathrm{n} / \mathrm{a}$ \\
\hline 25 & $\# 1181$ & 2009 Escape PHEV (Ford CRADA) & PHEV & $2.40,2.41$ & 4.20 & 1,826 & 65,423 & 63,597 & 38.0 & $3<$ & 2 & $>$ \\
\hline 26 & $\# 0141$ & 2010 Insight EX & HEV & $2.32,2.33$ & 4.16 & 0 & 160,172 & 160,172 & 40.4 & Dec-09 & Oct-09 & Jan-13 \\
\hline 27 & $\# 1748$ & 2010 Insight LX & HEV & $2.32,2.34$ & 4.16 & 0 & 160,015 & 160,015 & 39.5 & Dec-09 & Oct-09 & Jan-13 \\
\hline 28 & $\# 4699$ & 2010 Ford Fusion Hybrid & HEV & 2.36 & 4.18 & 0 & 74,964 & 74,964 & 33.8 & Dec-09 & Nov-09 & $\mathrm{n} / \mathrm{a}$ \\
\hline 29 & $\# 4757$ & 2010 Ford Fusion Hybrid & HEV & 2.36 & 4.18 & 0 & 160,110 & 160,110 & 35.5 & Dec-09 & Sep-09 & Jan-13 \\
\hline 30 & $\# 0462$ & 2010 Prius & HEV & 2.42 & 4.22 & 0 & 160,150 & 160,150 & 45.4 & Dec-09 & Oct-09 & Jan-13 \\
\hline 31 & $\# 6063$ & 2010 Prius & HEV & 2.42 & 4.22 & 0 & 160,160 & 160,160 & 43.1 & Dec-09 & Oct-09 & Jan-13 \\
\hline 32 & $\# 6231$ & 2010 Merc. $\$ 400$ Hybrid* & HEV & 2.49 & 4.21 & 21 & 132,123 & 132,102 & 26.1 & Mar-10 & 26 & 2 \\
\hline 33 & $\# 5883$ & 2011 Merc. S400 Hybrid & HEV & 2.49 & 4.21 & 23 & 160,478 & 160,455 & 25.6 & Mar-10 & 2 & $2<$ \\
\hline 34 & $\# 5577$ & 2010 Honda Civic (UBC) & HEV & $2.73,2.74$ & 4.38 & 11 & 97,875 & 97,864 & $\mathrm{n} / \mathrm{a}$ & May-12 & Sep-12 & Jun-13 \\
\hline 35 & $\# 2982$ & 2011 Honda CR-Z Hybrid & HEV & $2.81,2.82$ & 4.29 & 72 & 121,783 & 121,711 & 35.4 & May-12 & Sep-12 & DE-EE0005501 \\
\hline 36 & $\# 4466$ & 2011 Honda CR-Z Hybrid & HEV & $2.81,2.82$ & 4.29 & 52 & 129,551 & 129,499 & 37.1 & May-12 & Sep-12 & DE-EE0005501 \\
\hline 37 & $\# 5777$ & 2010 Volkswagen Golf Diesel & $\mathrm{s} / \mathrm{s}$ & $2.51,2.54$ & 4.24 & 24 & 103,642 & 103,618 & 43.5 & May-12 & $\mathrm{n} / \mathrm{a}$ & $n / a$ \\
\hline 38 & $\# 8111$ & 2010 Volkswagen Golf Diesel & $s / \mathrm{s}$ & $2.51,2.54$ & 4.24 & 11 & 99,036 & 99,025 & 42.9 & May-12 & $\mathrm{n} / \mathrm{a}$ & $\mathrm{n} / \mathrm{a}$ \\
\hline 39 & $\# 1865$ & 2010 Mazda3 Hatchback & $s / \mathrm{s}$ & $2.52,2.55$ & 4.25 & 19 & 108,787 & 108,768 & 28.8 & May-12 & $\mathrm{n} / \mathrm{a}$ & $\mathrm{n} / \mathrm{a}$ \\
\hline 40 & $\# 2736$ & 2010 Mazda3 Hatchback & $s / \mathrm{s}$ & $2.52,2.55$ & 4.25 & 29 & 116,785 & 116,757 & 28.2 & May-12 & $\mathrm{n} / \mathrm{a}$ & $\mathrm{n} / \mathrm{a}$ \\
\hline 41 & $\# 6644$ & 2010 Smart4Two * & $s / \mathrm{s}$ & $2.53,2.56$ & 4.26 & 9 & 58,876 & 58,867 & 36.3 & May-12 & $\mathrm{n} / \mathrm{a}$ & $\mathrm{n} / \mathrm{a}$ \\
\hline 42 & $\# 6659$ & 2010 Smart4Two * & $s / \mathrm{s}$ & $2.53,2.56$ & 4.26 & 9 & 49,578 & 49,570 & 36.8 & May-12 & $\mathrm{n} / \mathrm{a}$ & $\mathrm{n} / \mathrm{a}$ \\
\hline 43 & $\# 6476$ & 2010 Smart4Two & $s / s$ & 3 & 3.13 & 6 & 42,760 & 42,754 & 37.0 & May-12 & $\mathrm{n} / \mathrm{a}$ & $\mathrm{n} / \mathrm{a}$ \\
\hline 44 & $\# 0178$ & 2011 Nissan Leaf-HQ & BEV & $\sum$ & 3.23 & 12 & 15,187 & 15,175 & $\mathrm{n} / \mathrm{a}$ & $\mathrm{n} / \mathrm{a}$ & $\mathrm{n} / \mathrm{a}$ & $\mathrm{n} / \mathrm{a}$ \\
\hline 45 & $\# 0356$ & 2011 Nissan Leaf & BEV & $2.59,2.60$ & 4.31 & 3 & 22,606 & 22,603 & $\begin{array}{l}65.3 \text { miles } \\
@ 60 \mathrm{mph}^{* *}\end{array}$ & Jan-13 & Jan-13 & Jun-13 \\
\hline 46 & $\# 0815$ & 2011 Chevy Volt & PHEV & $2.75,2.76$ & 4.39 & 25 & 26,898 & 26,873 & \begin{tabular}{|l}
$31.0 \mathrm{miles}$ \\
$@ 60 \mathrm{mph}^{* *}$
\end{tabular} & Jan-13 & Jan-13 & Jun-13 \\
\hline 47 & $\# 0914$ & 2011 Chevy Volt-HQ & PHEV & $><$ & 3.23 & 25 & 27,705 & 27,680 & $\mathrm{n} / \mathrm{a}$ & $n / a$ & $\mathrm{n} / \mathrm{a}$ & $\mathrm{n} / \mathrm{a}$ \\
\hline 48 & $\# 3539$ & 2011 Hyundai Sonata Hybrid & HEV & $2.57,2.58$ & 4.27 & 12 & 145,916 & 145,904 & 34.0 & May-12 & Sep-12 & DE-EE0005501 \\
\hline 49 & $\# 4932$ & 2011 Hyundai Sonata Hybrid* & HEV & $2.57,2.58$ & 4.27 & 12 & 120,507 & 120,495 & 33.9 & May-12 & Sep-12 & Jun-13 \\
\hline 50 & $\# 8916$ & IWHUP HICE 5000 & HICE & 3 & $4 d$ & 0 & 31,221 & 31,221 & 13.5 mpgge & $\mathrm{n} / \mathrm{a}$ & $\mathrm{n} / \mathrm{a}$ & $\mathrm{n} / \mathrm{a}$ \\
\hline 51 & $\# 0409$ & IWHUP HICE 5445 & HICE & & 3.05 & 0 & 16417 & 16,417 & $13.5 \mathrm{mpgge}$ & $\mathrm{n} / \mathrm{a}$ & $\mathrm{n} / \mathrm{a}$ & $\mathrm{n} / \mathrm{a}$ \\
\hline 52 & $\# 2843$ & IWHUP HICE 5561 & HICE & & 3.05 & 0 & 13458 & 13,458 & 13.5 mpgge & $\mathrm{n} / \mathrm{a}$ & $\mathrm{n} / \mathrm{a}$ & $\mathrm{n} / \mathrm{a}$ \\
\hline 53 & $\# 1292$ & IWHUP HICE 5562 & HICE & & 3.05 & 0 & 17288 & 17,288 & $13.5 \mathrm{mpgge}$ & $\mathrm{n} / \mathrm{a}$ & $\mathrm{n} / \mathrm{a}$ & $\mathrm{n} / \mathrm{a}$ \\
\hline 54 & $\# 5684$ & IWHUP HICE 5563 & HICE & 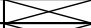 & 3.05 & 0 & 25373 & 25,373 & 13.5 mpgge & $\mathrm{n} / \mathrm{a}$ & $\mathrm{n} / \mathrm{a}$ & $\mathrm{n} / \mathrm{a}$ \\
\hline 55 & $\# 1319$ & IWHUP HICE 5564 & HICE & & 3.05 & 0 & 11550 & 11,550 & 13.5 mpgge & $\mathrm{n} / \mathrm{a}$ & $\mathrm{n} / \mathrm{a}$ & $\mathrm{n} / \mathrm{a}$ \\
\hline 56 & $\# 0975$ & IWHUP HICE 5565 & HICE & & 3.05 & 0 & 18064 & 18,064 & $13.5 \mathrm{mpgge}$ & $\mathrm{n} / \mathrm{a}$ & $\mathrm{n} / \mathrm{a}$ & $\mathrm{n} / \mathrm{a}$ \\
\hline 57 & $\# 1945$ & IWHUP HICE 5566 & HICE & C & 3.05 & 0 & 15278 & 15,278 & 13.5 mpgge & $\mathrm{n} / \mathrm{a}$ & $\mathrm{n} / \mathrm{a}$ & $\mathrm{n} / \mathrm{a}$ \\
\hline 58 & $\# 0945$ & IWHUP HICE 5567 & HICE & & 3.05 & 0 & 18087 & 18,087 & $13.5 \mathrm{mpgge}$ & $\mathrm{n} / \mathrm{a}$ & $\mathrm{n} / \mathrm{a}$ & $\mathrm{n} / \mathrm{a}$ \\
\hline 59 & $\# 9148$ & HICE-SC Truck & HICE & $>$ & 3.07 & 0 & 8,472 & 8,472 & $13.5 \mathrm{mpgge}$ & $\mathrm{n} / \mathrm{a}$ & $\mathrm{n} / \mathrm{a}$ & $\mathrm{n} / \mathrm{a}$ \\
\hline 60 & $\# 5823$ & HICE-NY RED & HICE & S & 3.07 & 0 & 26417 & 26,417 & 13.5 mpgge & $\mathrm{n} / \mathrm{a}$ & $\mathrm{n} / \mathrm{a}$ & $\mathrm{n} / \mathrm{a}$ \\
\hline 61 & $\# 7156$ & HICE-NY BLUE & HICE & $3<$ & 3.07 & 0 & 14096 & 14,096 & $13.5 \mathrm{mpgge}$ & $\mathrm{n} / \mathrm{a}$ & $\mathrm{n} / \mathrm{a}$ & $\mathrm{n} / \mathrm{a}$ \\
\hline 62 & $\# 8841$ & 2006 Energy CS PHEV & PHEV & $\begin{array}{c}2.10,2.12 \\
2.13\end{array}$ & 3.06 & 0 & 17,330 & 17,330 & $51.0^{* * *}$ & Jun-07 & $\mathrm{n} / \mathrm{a}$ & $\mathrm{n} / \mathrm{a}$ \\
\hline 63 & \#9616 & 2003 Kangoo PHEV & PHEV & 2.46 & 3.08 & 0 & 14,207 & 14,207 & $42.4^{* * *}$ & May-08 & $\mathrm{n} / \mathrm{a}$ & $\mathrm{n} / \mathrm{a}$ \\
\hline 64 & $\# 8820$ & 2007 HyMotion Prius Gen I PHEV & PHEV & $3<$ & 3.09 & 0 & 9,344 & 9,344 & $79.5^{* * *}$ & Jun-07 & $\mathrm{n} / \mathrm{a}$ & $\mathrm{n} / \mathrm{a}$ \\
\hline & $\# 8820$ & 2007 HyMotion Prius Gen II PHEV & PHEV & 2.11 & 3.09 & 9,344 & 18,698 & 9,354 & $48.0^{* * *}$ & Dec-09 & $\mathrm{n} / \mathrm{a}$ & $\mathrm{n} / \mathrm{a}$ \\
\hline 65 & $\# 0175$ & 2007 HyMotion Escape PHEV & PHEV & 2.10 & 3.04 & 0 & 18,038 & 18,038 & $42.5^{* * *}$ & Dec-08 & $\mathrm{n} / \mathrm{a}$ & $\mathrm{n} / \mathrm{a}$ \\
\hline 66 & \#7842 & 2007 Electrovaya Escape PHEV & PHEV & $2.10,2.11$ & 3.04 & 0 & 14,121 & 14,121 & $36.7^{* * *}$ & May-08 & $\mathrm{n} / \mathrm{a}$ & $\mathrm{n} / \mathrm{a}$ \\
\hline 67 & $\# 8810$ & 2007 Hybrids Plus Escape PHEV & PHEV & $2.10,2.12$ & 3.04 & 0 & 6,455 & 6,455 & $38.0^{* * *}$ & Jul-09 & $\mathrm{n} / \mathrm{a}$ & $\mathrm{n} / \mathrm{a}$ \\
\hline 68 & $\# 2610$ & 2007 E-85 Hybrid Escape & HEV & 1 & 5.03 & 0 & 2,362 & 2,362 & $\mathrm{n} / \mathrm{a}$ & $\mathrm{n} / \mathrm{a}$ & $\mathrm{n} / \mathrm{a}$ & $\mathrm{n} / \mathrm{a}$ \\
\hline 72 & 4 & HCNG Fleet & CNG & $\sum$ & $4 a$ & 0 & 158,223 & 158,223 & $\mathrm{n} / \mathrm{a}$ & $\mathrm{n} / \mathrm{a}$ & $\mathrm{n} / \mathrm{a}$ & $\mathrm{n} / \mathrm{a}$ \\
\hline 73 & $\# 1505$ & 2006 Roush REV Truck & BEV & $\sum$ & $4 \mathrm{e}$ & 0 & 8,068 & 8,068 & $\mathrm{n} / \mathrm{a}$ & $\mathrm{n} / \mathrm{a}$ & $\mathrm{n} / \mathrm{a}$ & $\mathrm{n} / \mathrm{a}$ \\
\hline 74 & $\# 4601$ & F-150 with 2 Valve HICE Engine & HICE & 3 & $3 a$ & 0 & 15,181 & 15,181 & $\mathrm{n} / \mathrm{a}$ & 2005 & $\mathrm{n} / \mathrm{a}$ & $\mathrm{n} / \mathrm{a}$ \\
\hline 75 & $\# 0528$ & F-150 with 4 Valve HICE Engine & HICE & $2 . a$ & $3 c$ & 0 & 12,791 & 12,791 & $12.3 \mathrm{mpgge}$ & $\mathrm{n} / \mathrm{a}$ & $\mathrm{n} / \mathrm{a}$ & $\mathrm{n} / \mathrm{a}$ \\
\hline 85 & 10 & NEVs & NEV & 2.48 & $x_{1}$ & 0 & 0 & 0 & $\mathrm{n} / \mathrm{a}$ & $\mathrm{n} / \mathrm{a}$ & $\mathrm{n} / \mathrm{a}$ & $\mathrm{n} / \mathrm{a}$ \\
\hline 90 & 5 & USPS Vehicles & BEV & & 3.20 & 0 & 0 & 0 & $\mathrm{n} / \mathrm{a}$ & $\mathrm{n} / \mathrm{a}$ & $\mathrm{n} / \mathrm{a}$ & $\mathrm{n} / \mathrm{a}$ \\
\hline 110 & 20 & SCAQMD Quantum Escape Fleet & PHEV & & 4.42 & 0 & 150,068 & 150,068 & 35.0 & $\mathrm{n} / \mathrm{a}$ & $\mathrm{n} / \mathrm{a}$ & $\mathrm{n} / \mathrm{a}$ \\
\hline 111 & 1 & eGSE Pushback Tractor & eGSe & $>$ & $2 . b$ & 0 & 0 & 0 & $\mathrm{n} / \mathrm{a}$ & $\mathrm{n} / \mathrm{a}$ & $\mathrm{n} / \mathrm{a}$ & 2006 \\
\hline 113 & 2 & eGSE Demonstration Project & eGSE & 2 & 3.17 & 0 & 0 & 0 & $\mathrm{n} / \mathrm{a}$ & $\mathrm{n} / \mathrm{a}$ & $\mathrm{n} / \mathrm{a}$ & $\mathrm{n} / \mathrm{a}$ \\
\hline & & $\begin{array}{l}\text { Vehicle engine/battery } \\
\text { failure/removed from testing }\end{array}$ & & & & & TOTAL: & $6,639,994$ & & & & \\
\hline & ** & Charge-Depleting Electric Range & & & & & & & & & & \\
\hline & ${ }^{* * *}$ & Accelerated Testing Only & & & & & & & & & & \\
\hline
\end{tabular}




\section{Approach}

The AVTA requirements included detailed evaluations of advanced vehicles and technologies, as well as coordinated and participated in demonstrations of specific advanced vehicles. The period of performance for this cooperative agreement was from October 2005 through March 2013

Each AVTA vehicle evaluation consists of following tasks;

- Baseline Vehicle Performance Testing

- Baseline Battery Performance Testing

- $\quad$ Fleet Vehicle Testing

- Accelerated Vehicle Testing

- Final Battery Performance Testing

Vehicles evaluated were predominantly HEVs, with an increased emphasis on PHEVs, BEVs and NEVs. This supported of the California Air Resources Board (CARB), which necessitates evaluating these vehicle types, as well. The AVTA also conducted evaluations of HICE vehicles in the fleet evaluation program.

The work program was divided into five tasks:

- Task 1 - Consisted of the development and modification of procedures to support testing

- Over the AVTA period of performance, test procedures utilized for testing advanced vehicle types were created and updated. As technologies advanced in vehicle testing, the procedures to properly test the vehicles were updated, as well. Further refinements to the procedures will occur with AVTE. The AVTA procedures can be found at the bottom of each webpage:

- http://avt.inel.gov/hev.shtml

- http://avt.inel.gov/fsev.shtml

- http://avt.inel.gov/nev.shtml

- http://avt.inel.gov/hydrogen.shtml

- http://avt.inel.gov/pdf/phev/phevtestplan.pdf (procedures listed in the appendix of the weblink)

- $\quad$ http://avt.inel.gov/groundsupport.shtml 
- Task 2 - Consisted of the conduct of baseline testing, including battery capacity

- The baseline vehicle testing is conducted at closed test tracks located near Phoenix, AZ, vehicle fuel economy testing at Argonne National Laboratory on their chassis dyno, battery capacity testing at Clarity Group, Inc., fleet testing in a local Phoenix courier delivery fleet, and end-of-life testing at Clarity Group, Inc.

- Closed test track testing consists of the following test procedures (the hybrid electric vehicle procedures are shown below):

- http://avt.inel.gov/pdf/hev/htp001r2.pdf

- http://avt.inel.gov/pdf/hev/htp002ra.pdf

- http://avt.inel.gov/pdf/hev/htp003ra.pdf

- http://avt.inel.gov/pdf/hev/htp004r1.pdf

- http://avt.inel.gov/pdf/hev/htp005ra.pdf

- $\quad$ http://avt.inel.gov/pdf/hev/htp006r2.pdf

- http://avt.inel.gov/pdf/hev/htp007ra.pdf

- $\quad$ http://avt.inel.gov/pdf/hev/htp008r1.pdf

- http://avt.inel.gov/pdf/hev/htp009ra.pdf

- http://avt.inel.gov/pdf/hev/htp010ra.pdf

- http://avt.inel.gov/pdf/hev/htp011r1.pdf

- http://avt.inel.gov/pdf/hev/htp012ra.pdf

- http://avt.inel.gov/pdf/hev/htp013r0.pdf

- Vehicle dynamometer testing conducted at Argonne National Laboratory consisted of the following test procedure (the hydrogen internal combustion engine vehicle procedure is shown below):

- http://avt.inel.gov/pdf/hydrogen/hitp03.pdf

- More information on dynamometer fuel economy testing at Argonne National Lab and recent vehicles tested can be found here:

- $\quad$ http://www.transportation.anl.gov/D3/pdfs/ANL APRF DynoTe stingReference April2013.pdf

- http://www.transportation.anl.gov/D3/

- Baseline battery testing conducted at Clarity Group, Inc. and consists of battery capacity and power testing with the following test procedures:

- http://avt.inel.gov/battery/pdf/usabc manual rev2.pdf

- http://avt.inel.gov/energy storage lib.shtml

- End-of-life battery testing conducted at Clarity Group, Inc. and consists of battery capacity and power testing to determine battery degradation over the fleet testing period utilizing the following test procedures:

- http://avt.inel.gov/battery/pdf/usabc manual rev2.pdf

- http://avt.inel.gov/energy storage lib.shtml

- Task 3 - Consisted of the conduct of accelerated testing for vehicles requiring specialized fueling infrastructure

- Accelerated testing is conducted over controlled routes on public roads with Clarity Group, Inc. drivers

- Accelerated fleet testing was conducted over approximately 5,400 miles and in accordance with the schedule shown in tables 2-5. 
- Task 4 - Consisted of the conduct of fleet testing for vehicles using conventional fueling infrastructure.

- Fleet testing is conducted on public roads and in conjunction with a private fleet operator

- Fleet testing accumulates 160,000 miles of real-world use

- While accumulating miles, the fleet testing also collects vehicle fuel use, maintenance, and repair information and costs from the fleet operator

- A Clarity Group, Inc. fleet coordinator utilizes the following procedure to work with the fleet (hybrid example shown):

- http://avt.inel.gov/pdf/hev/fep 001 ro.pdf

- Task 5 - Consisted of the conduct of tasks as assigned by the DOE technical representative or contract manager

Vehicle baseline test and battery test reports were produced and distributed from Baseline Performance Testing. Detailed evaluation reports containing data analysis were produced for Fleet and Accelerated Testing. All AVTA-produced documents were posted to the AVTA website of the INL.

In addition to vehicle testing and evaluation, a limited number of non-vehicle tasks were conducted as part of this cooperative agreement. Those tasks include an advanced battery demonstration project with electric Ground Support equipment (eGSE) and the baseline testing of eGSE. 


\section{Discussion of Results}

\section{Task 1 - Procedure Development}

Task 1.a: Airport Ground Support Equipment (GSE) Baseline Test Procedures Develop test procedures for Baseline Performance Testing of an electric pushback tractor. Testing shall be based upon Vehicle Specifications developed under agreement DE-FC07-00ID13859.

Deliverable: Electronic copy of Electric Pushback Tractor Baseline Test Procedures. Status: This task has been completed. The Procedures have been posted to the AVTA website.

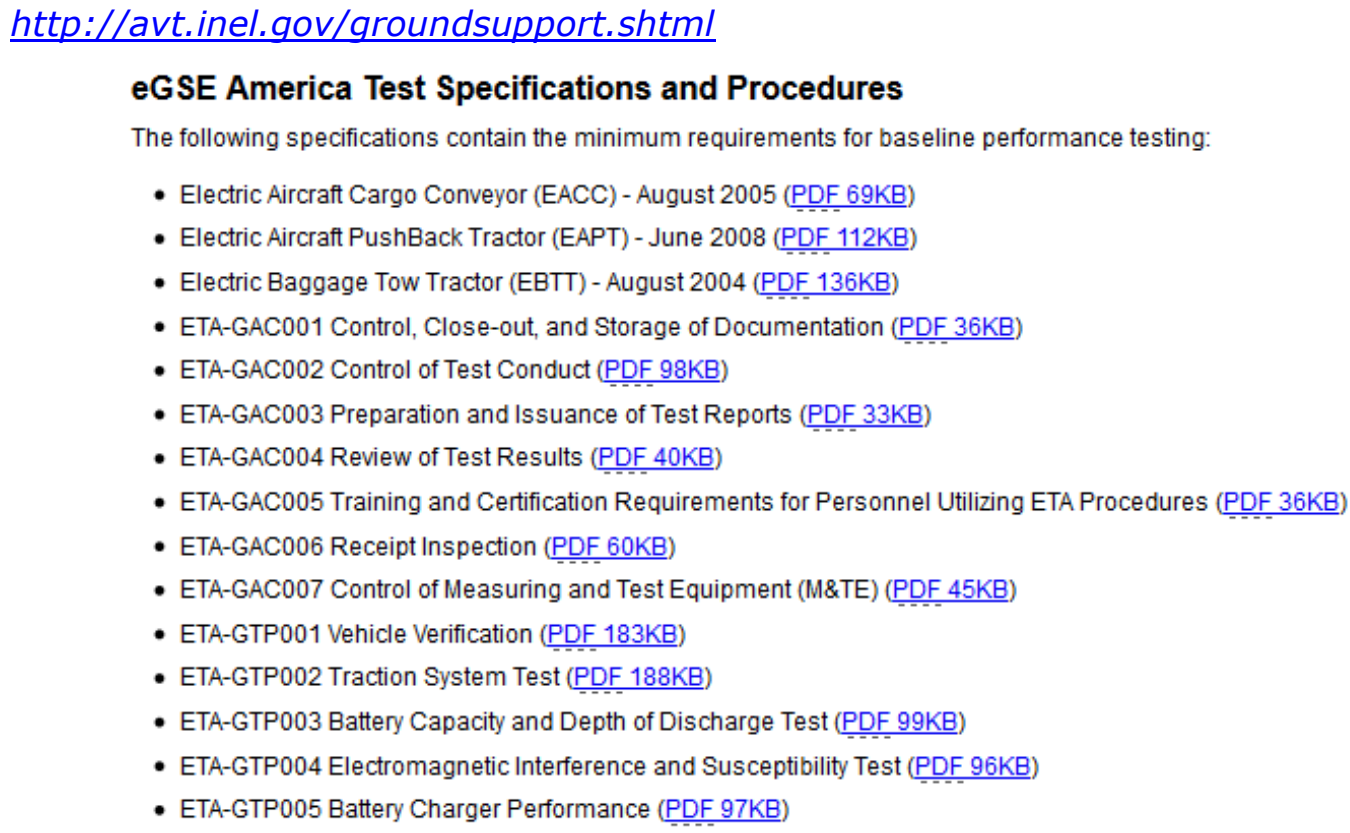

\section{Task 1.01: Hybrid Electric Vehicle (HEV) Battery Test Procedures}

Develop test procedures for HEV battery end-of-life testing. Procedures shall utilize US Advance Battery Consortium (USABC) test guidance as appropriate for capacity and hybrid pulse power test procedure development.

Deliverable: Electronic copy of HEV Battery Test Procedures.

Status: Procedures have been developed and trialed in round-robin testing with INL. Feedback from INL has been incorporated to improve usefulness of results. Revisions incorporated minor changes to static capacity and HPPC testing. PHEV and mild hybrid (42 volt) battery test procedures have been completed. The Procedures have been posted to the AVTA website.

http://avt.inel.gov/energy storage lib.shtml 


\section{Task 1.02: Plug-In HEV Baseline Test Procedure}

Develop vehicle specifications and baseline test procedures to conduct Baseline Performance Testing of a plug-in hybrid electric vehicle (PHEV). Specifications and procedures shall incorporate applicable HEV America requirements.

Deliverable: Electronic copy of plug-in HEV Vehicle Specifications and Baseline Test Procedures.

Status: This task has been completed. The Procedures have been posted to the AVTA website.

http://avt.inel.gov/phev.shtml

\section{Task 1.03: Enhanced HEV Baseline Test Procedure (ANL)}

Revise HEV Baseline Test Procedures to incorporate requirements for dynamometer testing at Argonne National Laboratory (ANL).

Deliverable: Electronic copy of revised HEV Baseline Test Procedures.

Status: This task has been completed. The Procedures have been posted to the AVTA website.

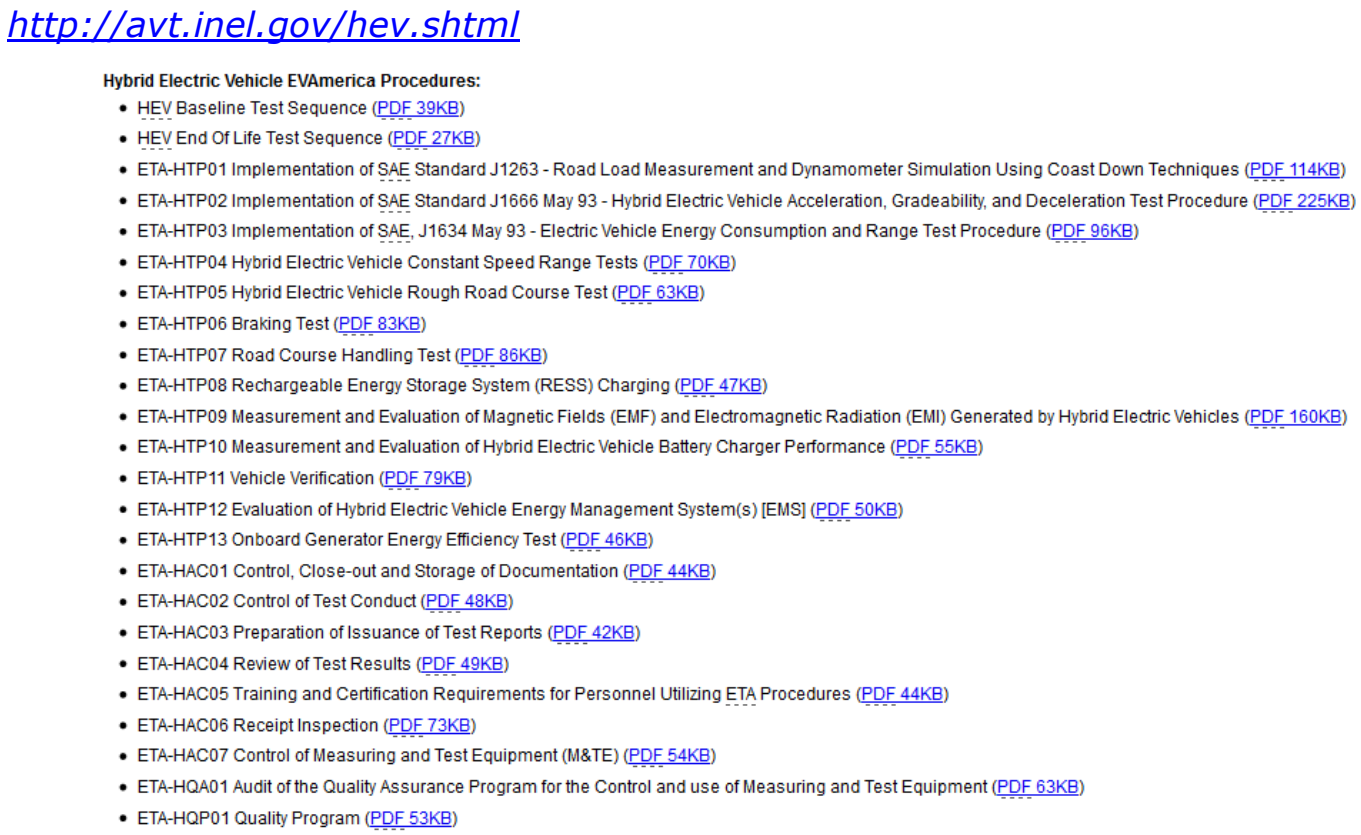

Task 1.04: Enhanced HEV Fleet Test Procedure

Revise HEV Fleet Test Procedures to incorporate requirements for additional data collection to support vehicle modeling conducted by Argonne National Laboratory.

Deliverable: Electronic copy of revised HEV Fleet Test Procedures.

Status: Process updates made previously for AVTA fleet testing were conducted with onboard data loggers. All fleet data was transmitted monthly to INL. The Fleet test procedure will be updated to reflect a new process for future testing. 


\section{Task 1.05: 2007 Procedure Updates \& Revisions}

Update HEV, PHEV, and HICE Vehicle Specifications and Baseline Test Procedures based upon lessons learned from testing conducted in 2007.

Deliverable: Electronic copy of updated Vehicle Specifications and Baseline Test Procedures.

Status: This task has been completed. Work conducted in 2007 includes reformatting HEV procedures to new AVTA format, updating NEV procedures following completion of testing in Task $2 \mathrm{~d}$, and maintaining HEV fleet procedures as data is collected using electronic data recorders. Significant changes to Data Logger procedures include an additional test sequence following installation of the data logger, which validates recorder data by running various vehicle operations under a test sequence to allow for collection and review of "test data" prior to release to fleet with scheduled uploads. A revised NEV Vehicle Specification was prepared and posted to the INL website.

Task 1.06: 2008 Procedure Updates \& Revisions

Update HEV, PHEV, and HICE Vehicle Specifications and Baseline Test Procedures based upon lessons learned from testing conducted in 2008.

Deliverable: Electronic copy of updated Vehicle Specifications and Baseline Test Procedures.

Status: This task is complete. Work conducted in 2008 includes posting reformatted HEV procedures (significant changes to coastdown procedure and deletion of wet braking). HEV procedures were amended to reflect moving to the Volvo proving ground for Baseline Performance testing. NEV procedures have been updated and posted to the INL website.

Task 1.07: 2009 Procedure Updates \& Revisions

Update HEV, PHEV, and HICE Vehicle Specifications and Baseline Test Procedures based upon lessons learned from testing conducted in 2009.

Deliverable: Electronic copy of updated Vehicle Specifications and Baseline Test Procedures.

Status: NEV test procedures have been updated based on recent testing. Changes were updated, reviewed by INL, and posted to the AVTA website.

Task 1.08: (Added in A015) 2010 Procedure Updates and Revisions

Update BEV, HEV, PHEV, and HICE Vehicle Specifications and Baseline Test Procedures based upon lessons learned from testing conducted in 2010.

Deliverable: Electronic copy of updated Vehicle Specifications and Baseline Test Procedures.

Status: This task has been completed. Internal updates to procedures were conducted throughout the year and submitted to INL for posting on the AVTA website. 
Task 1.09: 2011 \& 2012 Procedure Updates and Revisions

Update BEV, HEV, PHEV, and HICE Vehicle Specifications and Baseline Test Procedures based upon lessons learned from testing conducted in 2011.

Deliverable: Electronic copy of updated Vehicle Specifications and Baseline Test Procedures.

Status: BEV, PHEV, HEV, and HICE test procedures have been reorganized and are ready for review and implementation as common procedures for all vehicle types with the AVTE contract. 


\section{Task 2 - Baseline Performance Testing}

Task 2.a: HICE F-150 4V Baseline Test

Conduct Baseline Performance Testing of a Ford F-150 pickup truck equipped with a 4valve HICE engine using Hydrogen Internal Combustion Engine Vehicle (HICEV) America test procedures developed under agreement DE-FC07-00ID13859.

Deliverable: Electronic copy of HICEV America Summary Data Sheet.

Status: This task has been completed. The Summary Data Sheet has been posted to the AVTA website.

http://avt.inel.gov/pdf/hydrogen/f150 32v hice fact.pdf

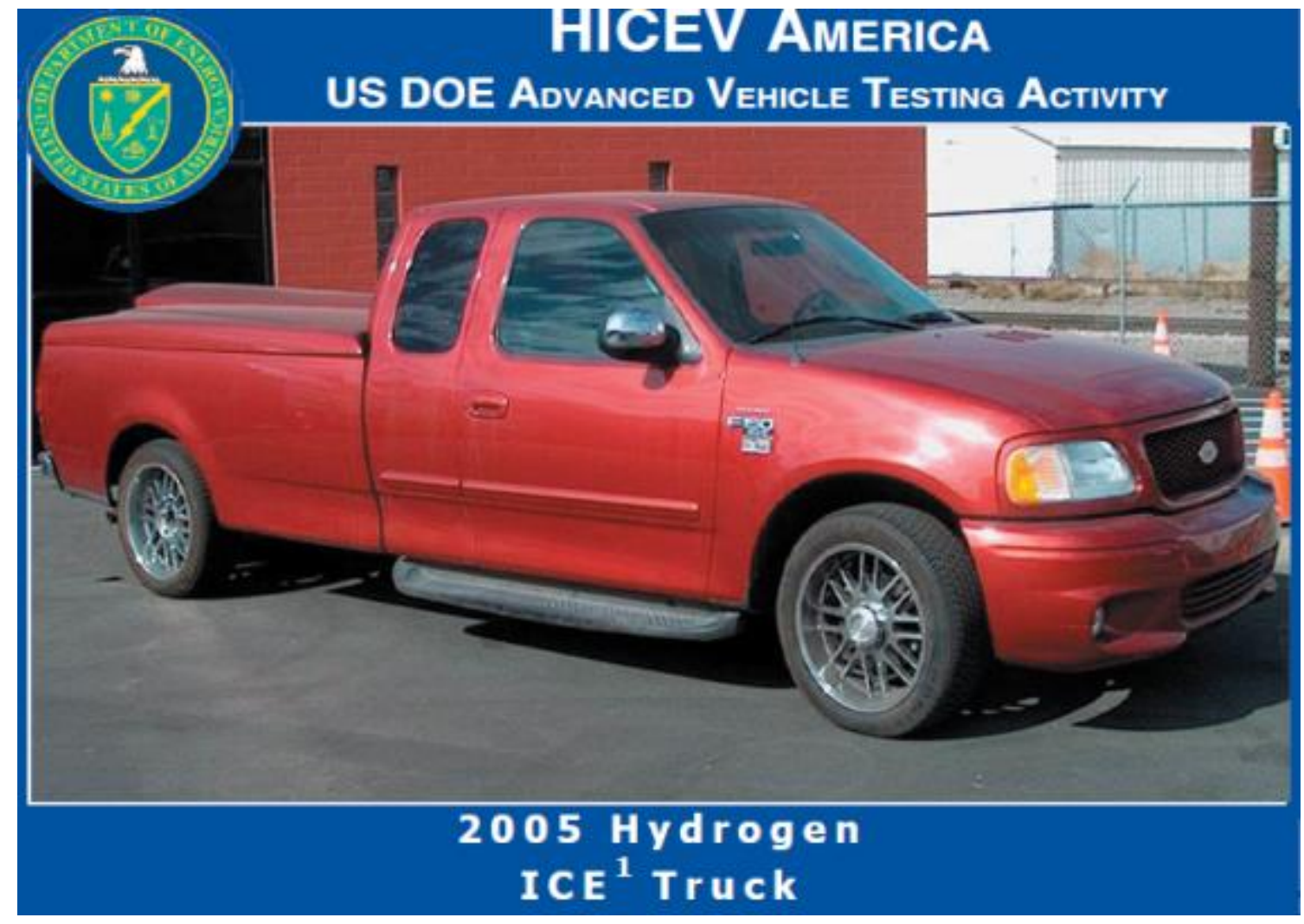


Task 2.b: GSE Baseline Testing - FMC Pushback Tractor

Conduct Baseline Performance Testing of an electric pushback tractor using GSEAmerica test procedures developed under agreement DE-FC07-00ID13859.

Deliverable: Electronic copy of GSEAmerica Summary Performance Data Sheet.

Status: This task has been completed. The Summary Data Sheet has been posted to the AVTA website.

\section{http://avt.inel.gov/pdf/airport/pushbackTractorFactSheet.pdf}

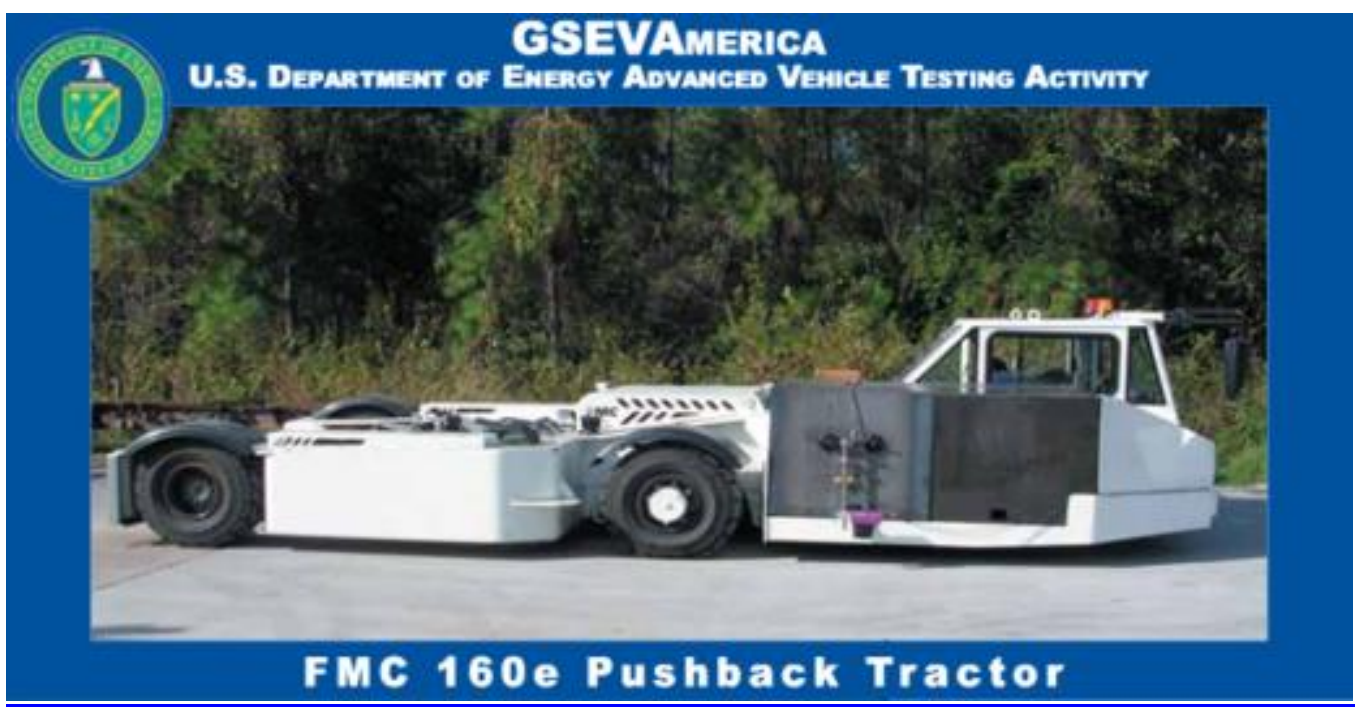

Task 2.c: HICE Silverado Baseline Test

Conduct Baseline Performance Testing of an HICE Chevrolet 3v Roush Silverado pickup truck using HICEVAmerica test procedures developed under agreement DE-FC0700ID13859.

Deliverable: Electronic copy of HICEVAmerica Summary Data Sheet.

Status: This task has been completed. The Summary Data Sheet has been posted to the AVTA website.

\section{http://avt.inel.gov/pdf/hydrogen/roush hev fact.pdf}

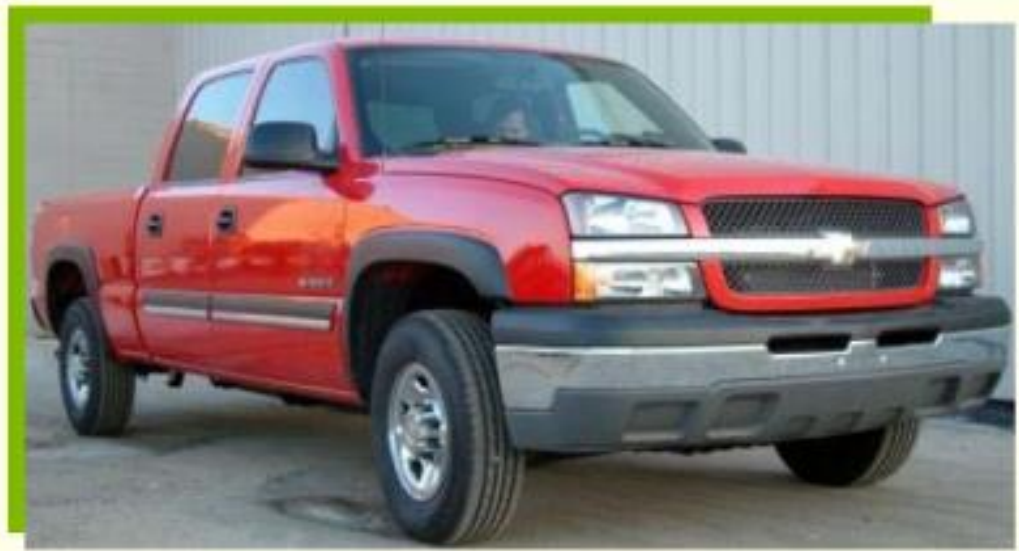

2005 Chevrolet Silverado $1500 \mathrm{HD}$

Hydrogen ICE ${ }^{1}$

Conversion

North American

Fleet Testing

Results to Date

June, 2009 
Task 2.d: Neighborhood Electric Vehicle (NEV) Roush Electric Vehicle Baseline Test Conduct Baseline Performance Testing of a NEV Roush Electric Vehicle using NEVAmerica test procedures developed under agreement DE-FC07-00ID13859.

Deliverable: Electronic copy of NEVAmerica Summary Data Sheet.

Status: This task has been completed. The Summary Data Sheet has been posted to the AVTA website.

http://avt.inel.gov/pdf/nev/roush2008nevamerica.pdf

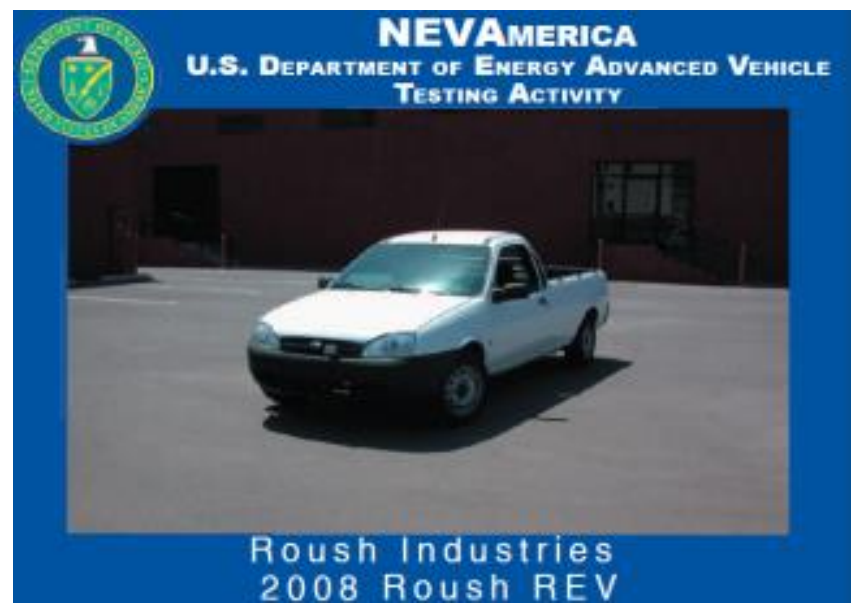

Task 2.01: HEV Highlander Baseline Testing (1 Baseline Test w/ANL Dyno and 2 Battery Pre-Tests)

Conduct Baseline Performance Testing of one Toyota Highlander HEV using previously prepared HEVAmerica test procedures. Dynamometer testing shall be conducted by Argonne National Laboratory. Conduct Battery Baseline Pre-Testing of two Toyota Highlander HEVs.

Deliverable: Electronic copy of HEVAmerica Summary Data Sheet and battery test results.

Status: This task has been completed. The Summary Data Sheet has been posted to the AVTA website. The battery baseline test results are included in the reports located under Task 2.02.

\section{http://avt.inel.gov/pdf/hev/factHighlander2006.pdf}

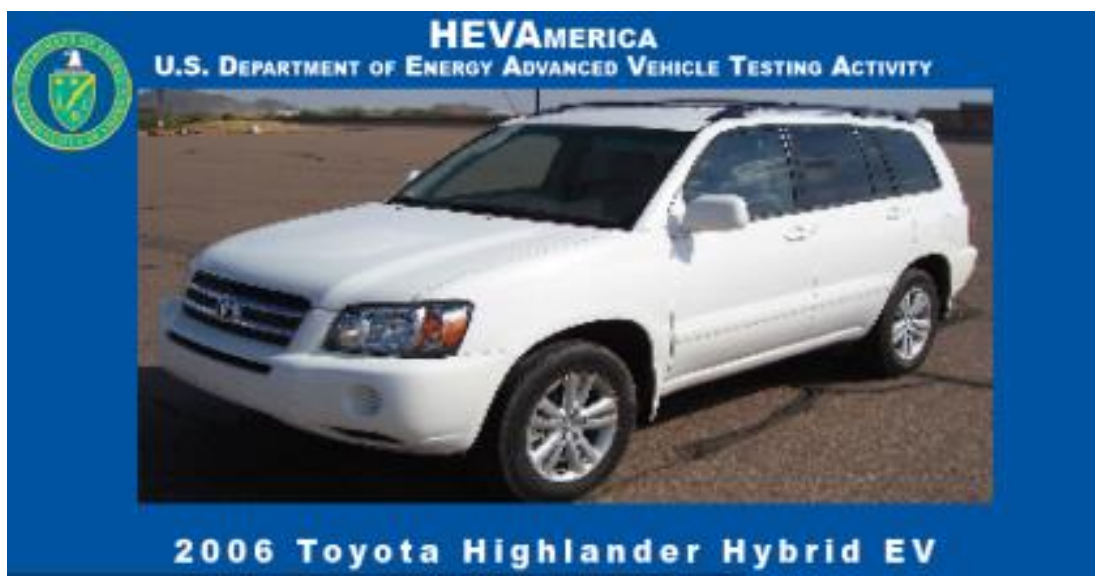


Task 2.02: 2 HEV Highlander End-of-Life Baseline Testing (Battery Post Test) Conduct Battery Baseline Post Testing of two Highlander vehicles. Deliverable: Electronic copy of end-of-life battery test results.

Status: This task has been completed. The Test Results and Summary Data Sheet have been posted to the AVTA website.

http://avt.inel.gov/pdf/hev/batteryhighlander5681.pdf

\section{Toyota Highlander-5681 Hybrid Electric Vehicle Battery Test Results}

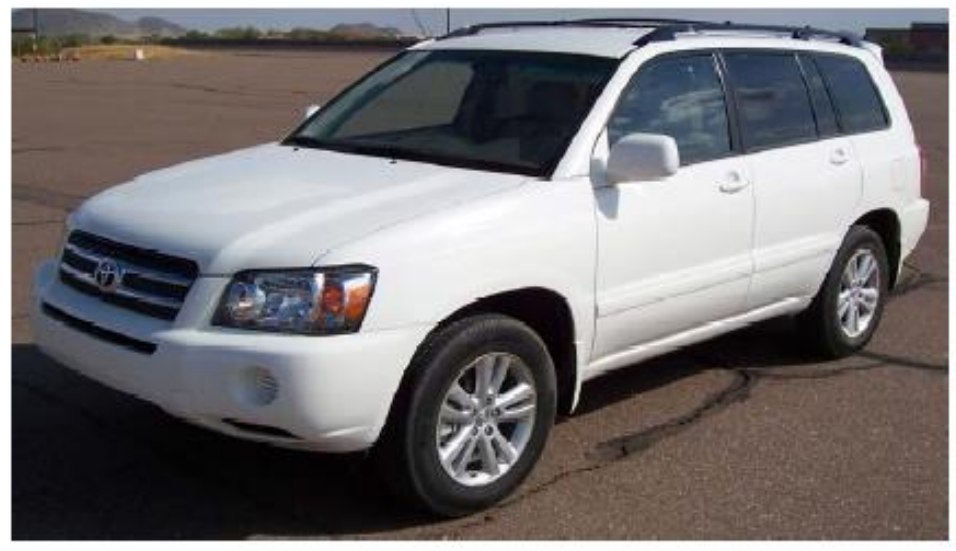

http://avt.inel.gov/pdf/hev/batteryhighlander6395.pdf

2006 Toyota Highlander-6395 Hybrid Electric Vehicle Battery Test Results

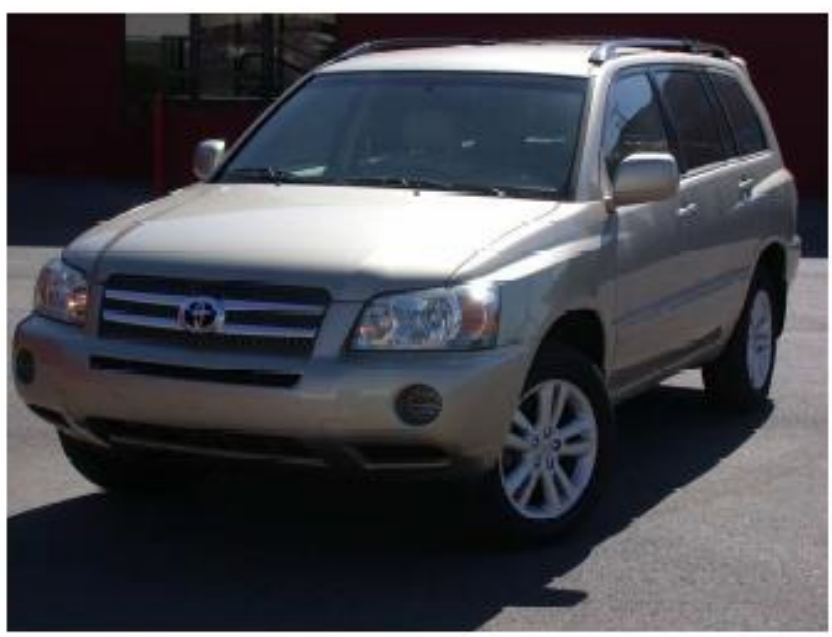




\section{Task 2.04: 2 HEV Prius End-of-Life Baseline Testing (Battery Post Test)}

Conduct Battery Baseline Post Testing of two Hybrid Prius vehicles.

Deliverable: Electronic copy of end-of-life battery test results.

Status: This task has bee completed. The Test Results and Summary Data Sheet have been posted to the AVTA website.

http://avt.inel.gov/pdf/hev/batteryprius1052.pdf

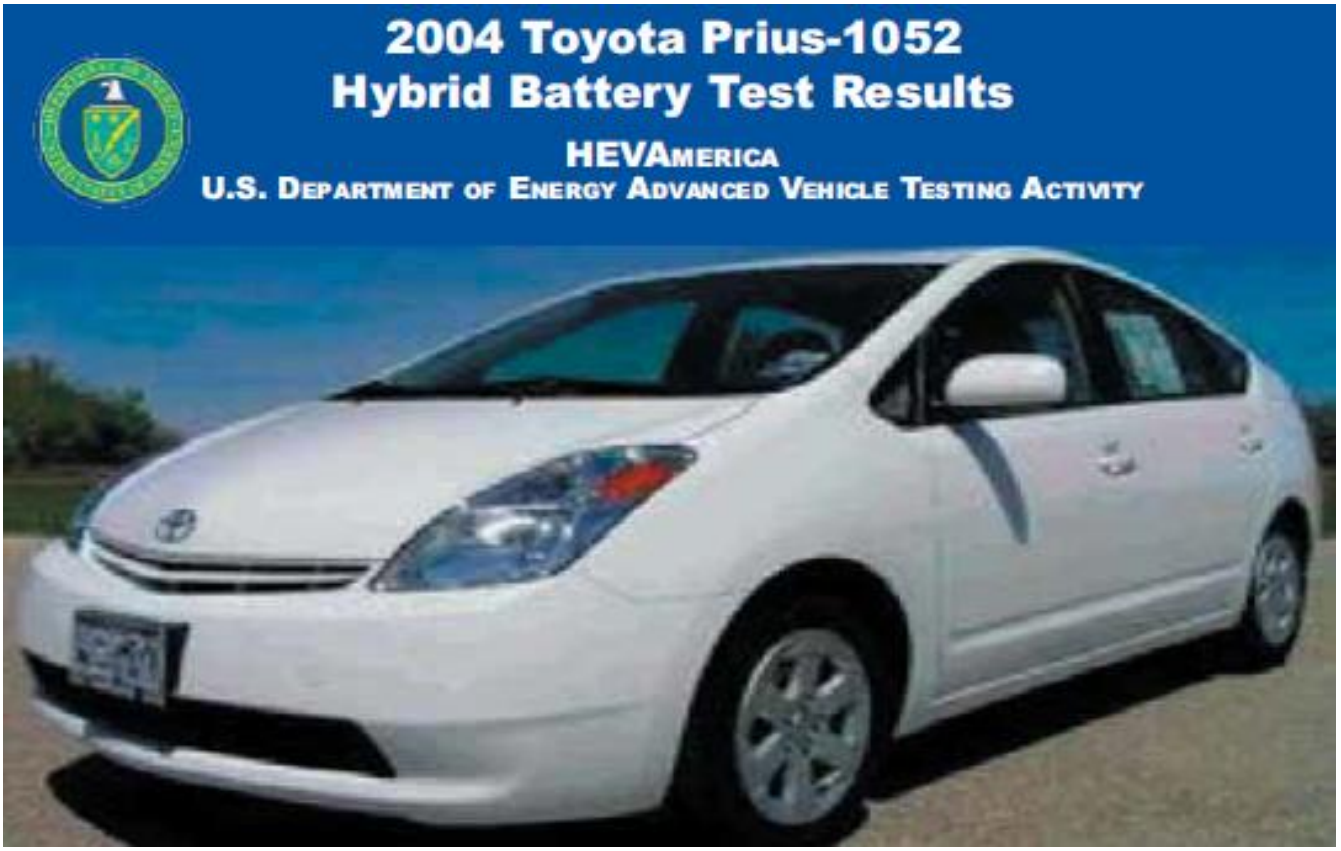

http://avt.inel.gov/pdf/hev/batteryprius2721.pdf

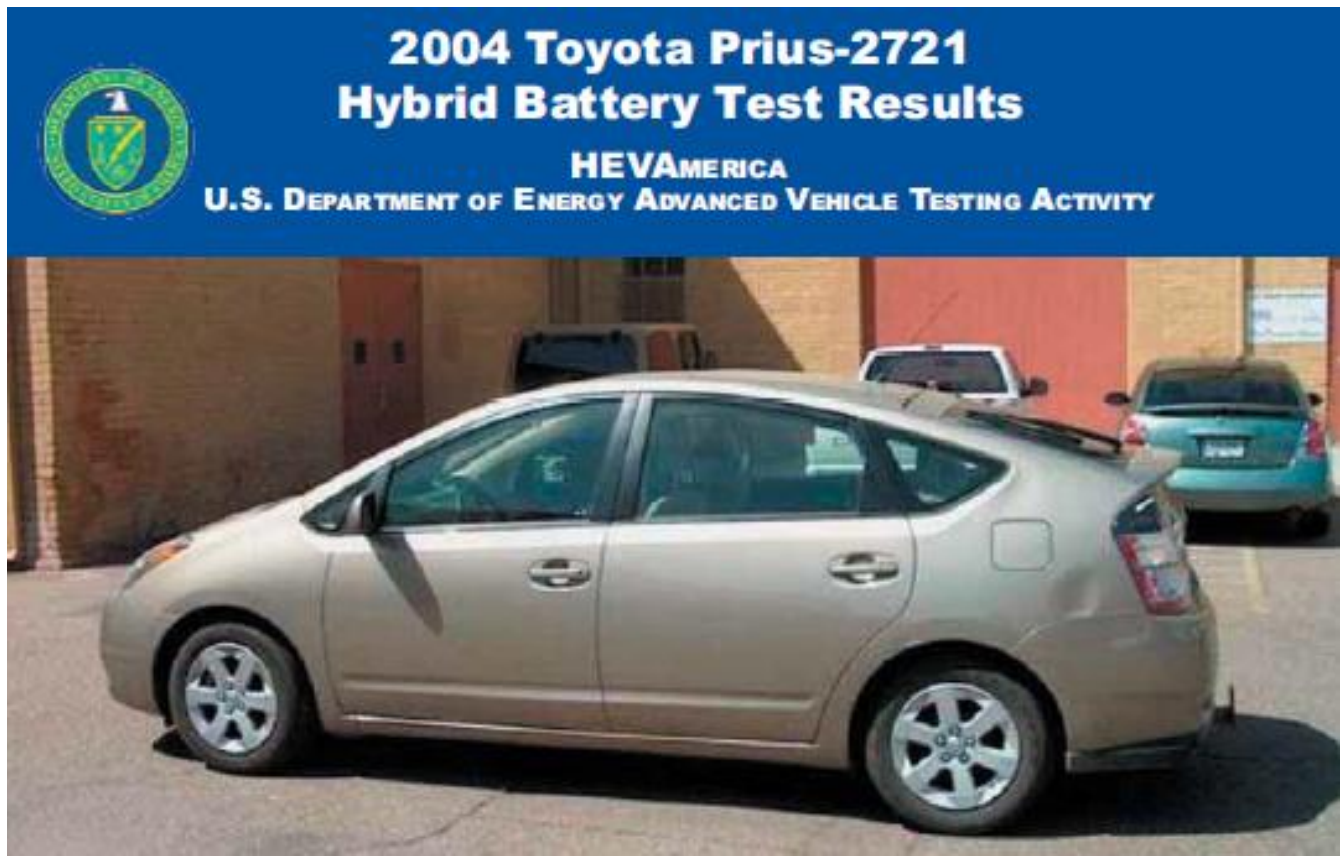


Task 2.05: 2 HEV Honda Accord End-of-Life Baseline Testing (Battery Post Test) Conduct Battery Baseline Post Testing of two Honda Accord vehicles. Deliverable: Electronic copy of end-of-life battery test results.

Status: This task has been completed. The Test Results and Summary Data Sheet have been posted to the AVTA website.

http://avt.inel.gov/pdf/hev/batteryaccord0657.pdf

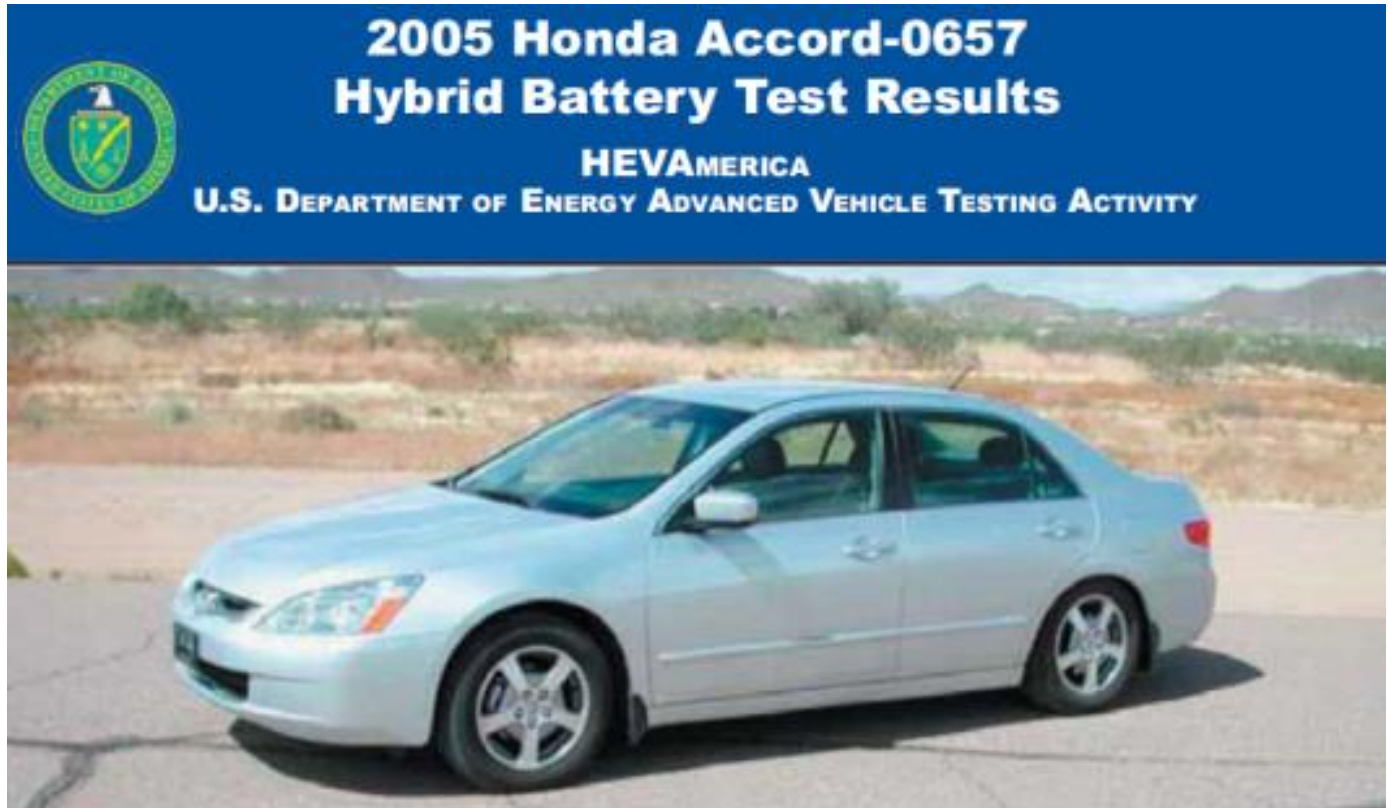

http://avt.inel.gov/pdf/hev/batteryaccord1096.pdf

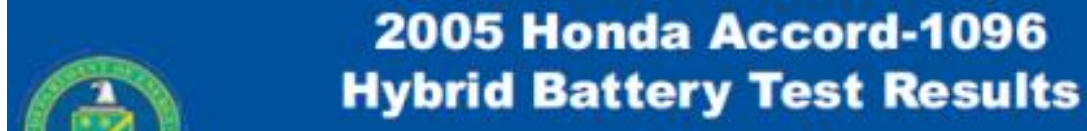

HEVAMERICA

U.S. Department of Energy Advanced Vehicle Testing Activity

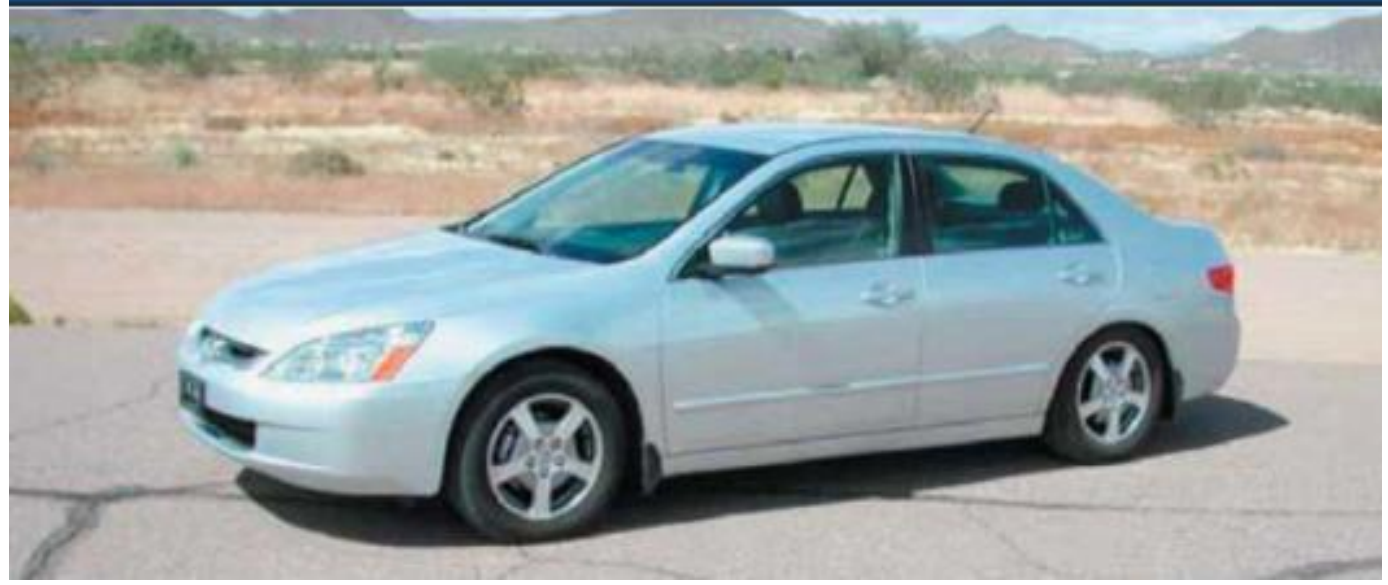


Task 2.06: 2 HEV Escape End-of-Life Baseline Testing (Battery Post Test)

Conduct Battery Baseline Post Testing of two Ford Escape vehicles.

Deliverable: Electronic copy of end-of-life battery test results.

Status: This task has been completed. The Test Results and Summary Data Sheet have been posted to the AVTA website.

http://avt.inel.gov/pdf/hev/batteryescape5881.pdf

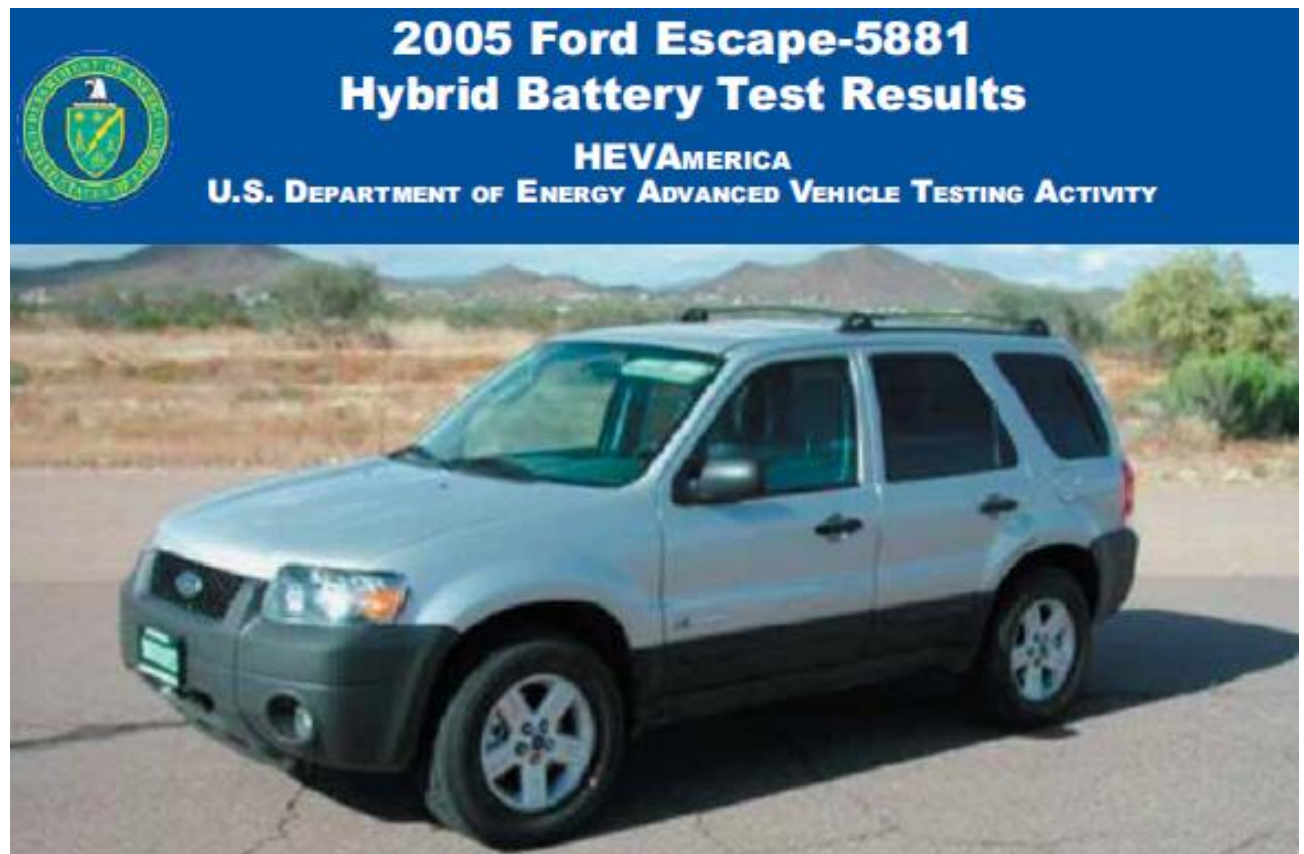

http://avt.inel.gov/pdf/hev/batteryescape8237.pdf

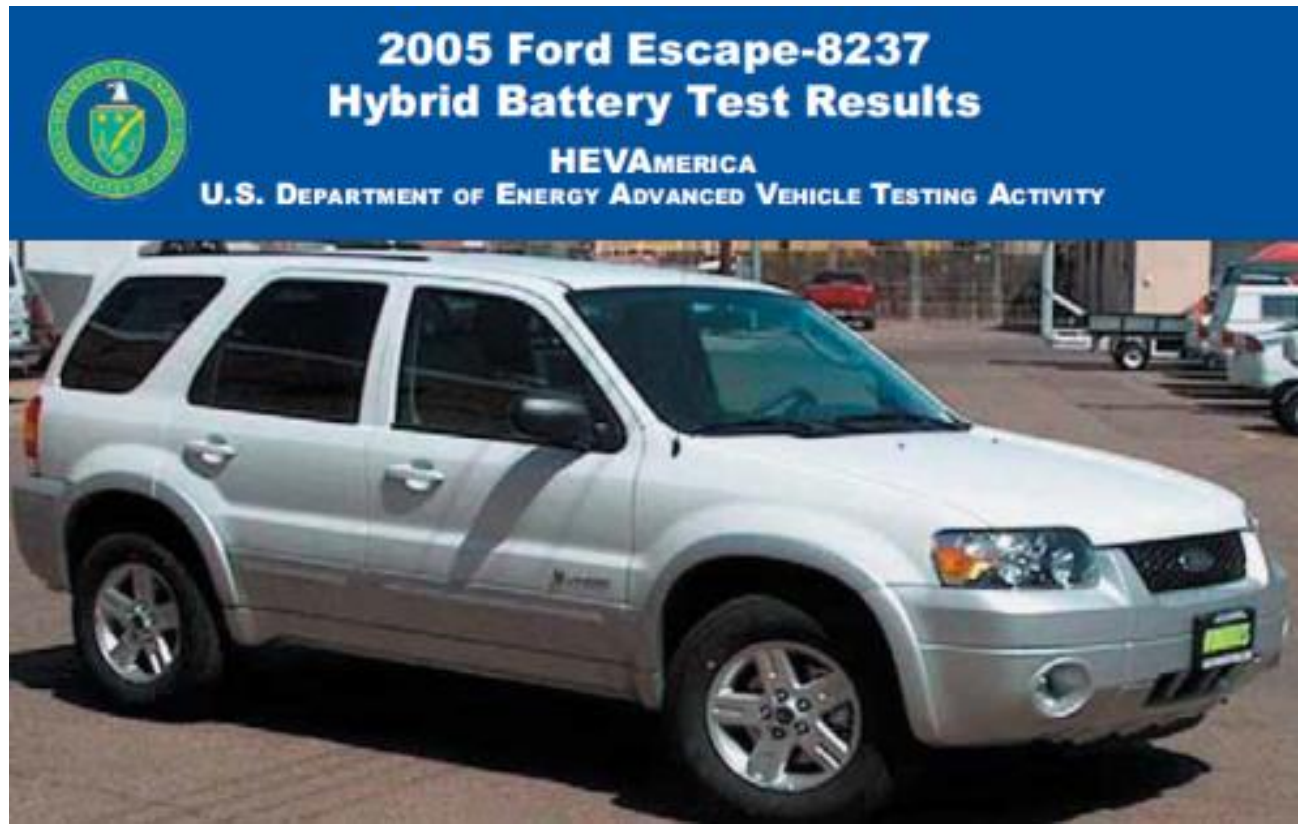


Task 2.07: 2 HEV Silverado End-of-Life Baseline Testing (Battery Post Test) Conduct Battery Baseline Post Testing of two Silverado vehicles. Deliverable: Electronic copy of end-of-life battery test results.

Status: Battery testing data was shown to be invalid due to in-vehicle failures. No report was released due to vehicle failures.

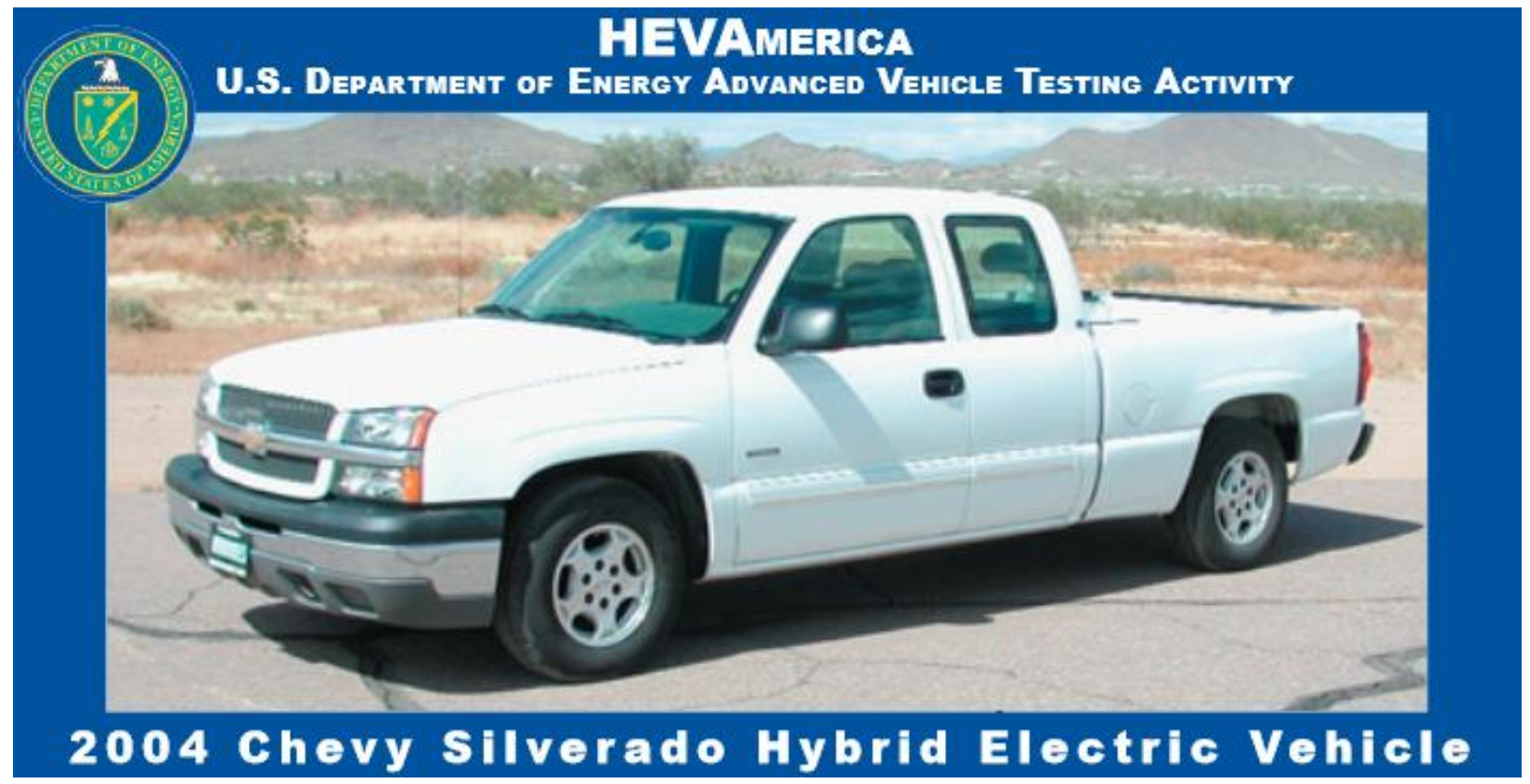


Task 2.08: 2 HEV 400h Lexus End-of-Life Baseline Testing (Battery Post Test) Conduct Battery Baseline Post Testing of two $400 \mathrm{H}$ Lexus vehicles. Deliverable: Electronic copy of end-of-life battery test results.

Status: This task has been completed. The Test Results and Summary Data Sheet have been posted to the AVTA website.

http://avt.inel.gov/pdf/hev/batterylexus2575.pdf

\section{Lexus RX400h-2575 Hybrid Electric Vehicle Battery Test Results}

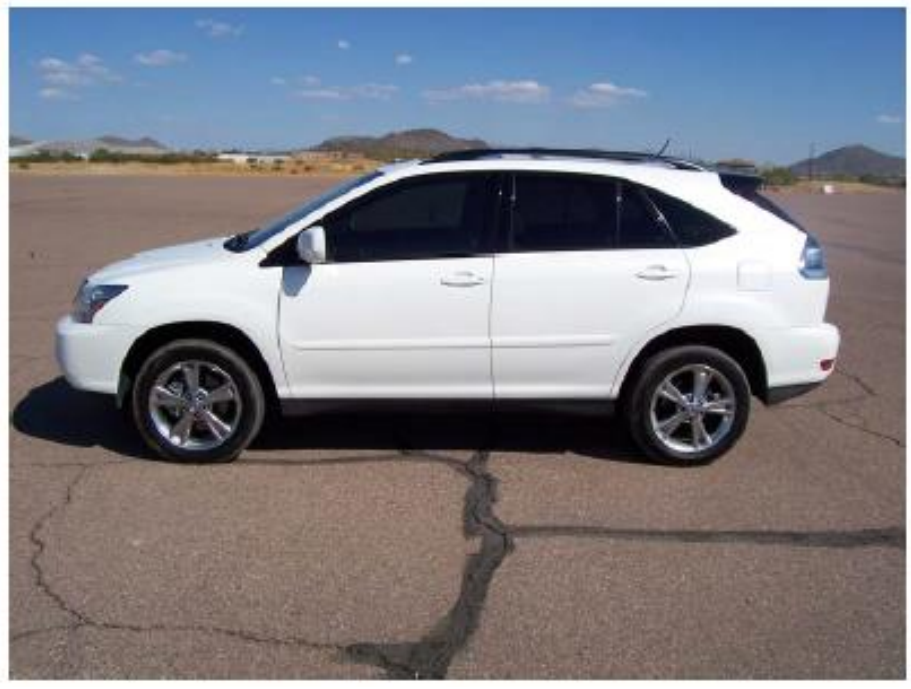

http://avt.inel.gov/pdf/hev/batterylexus4807.pdf

\section{Lexus RX400h-4807 Hybrid Electric Vehicle Battery Test Results}

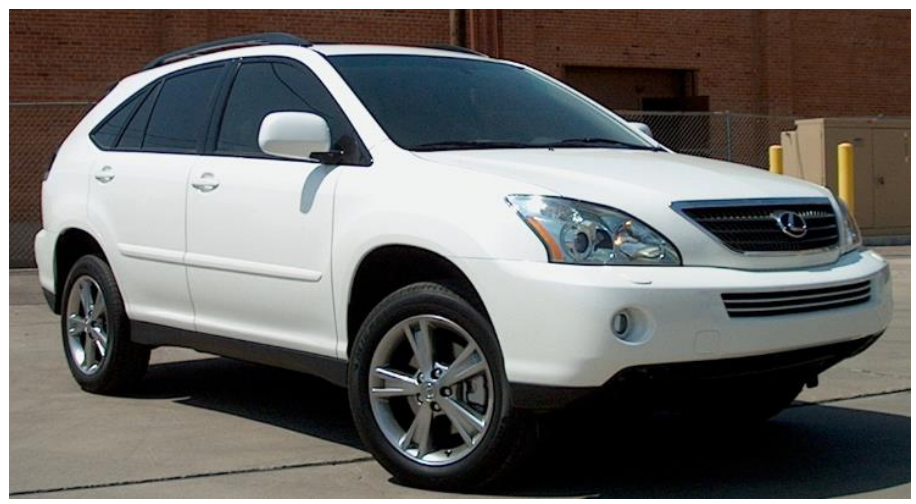


Task 2.09 (Added per A003, April 2006): HEV Lexus 400h Baseline Testing (1 Baseline Test w/ANL Dyno and 2 Battery Pre-Tests)

Conduct Baseline Performance Testing of one Lexus 400h HEV using previously prepared HEVAmerica test procedures. Dynamometer testing shall be conducted by Argonne National Laboratory. Conduct Battery Baseline Pre-Testing of two Lexus 400h HEVs.

Deliverable: Printed and electronic copy of HEVAmerica Summary Data Sheet.

Status: This task has been completed. The Summary Data Sheet has been posted to the AVTA website. The battery baseline test results are included in the reports located under Task 2.08.

http://avt.inel.gov/pdf/hev/lexus2006.pdf

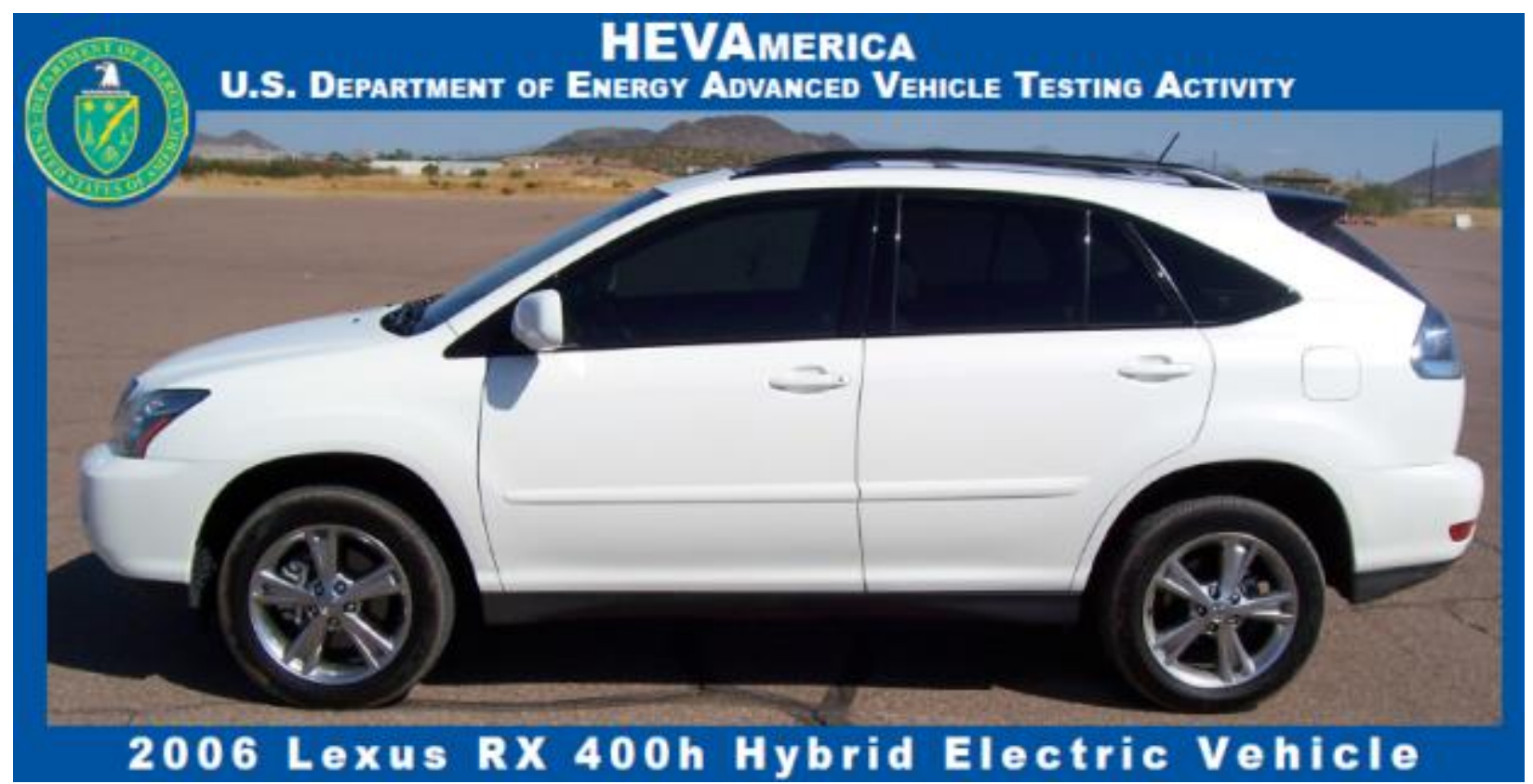


Task 2.10: PHEV Baseline Testing (4 Baseline w/ANL Dyno)

Conduct Baseline Performance Testing of four (4) NYSERDA Plug-in Hybrid Electric Vehicles using test procedures developed in Task 1.2. Dynamometer testing shall be conducted by Argonne National Laboratory.

Deliverable: Electronic copy of PHEVAmerica Summary Data Sheet.

Status: Baseline tests for the Energy CS Prius, HyMotion Prius, Electrovaya Escape, and HyMotion Escape have been completed. The Summary Data Sheets have been posted to the AVTA website. The Hybrids Plus Escape has been returned to Hybrids Plus for repair and did not complete testing.

http://avt.inel.gov/phev.shtml

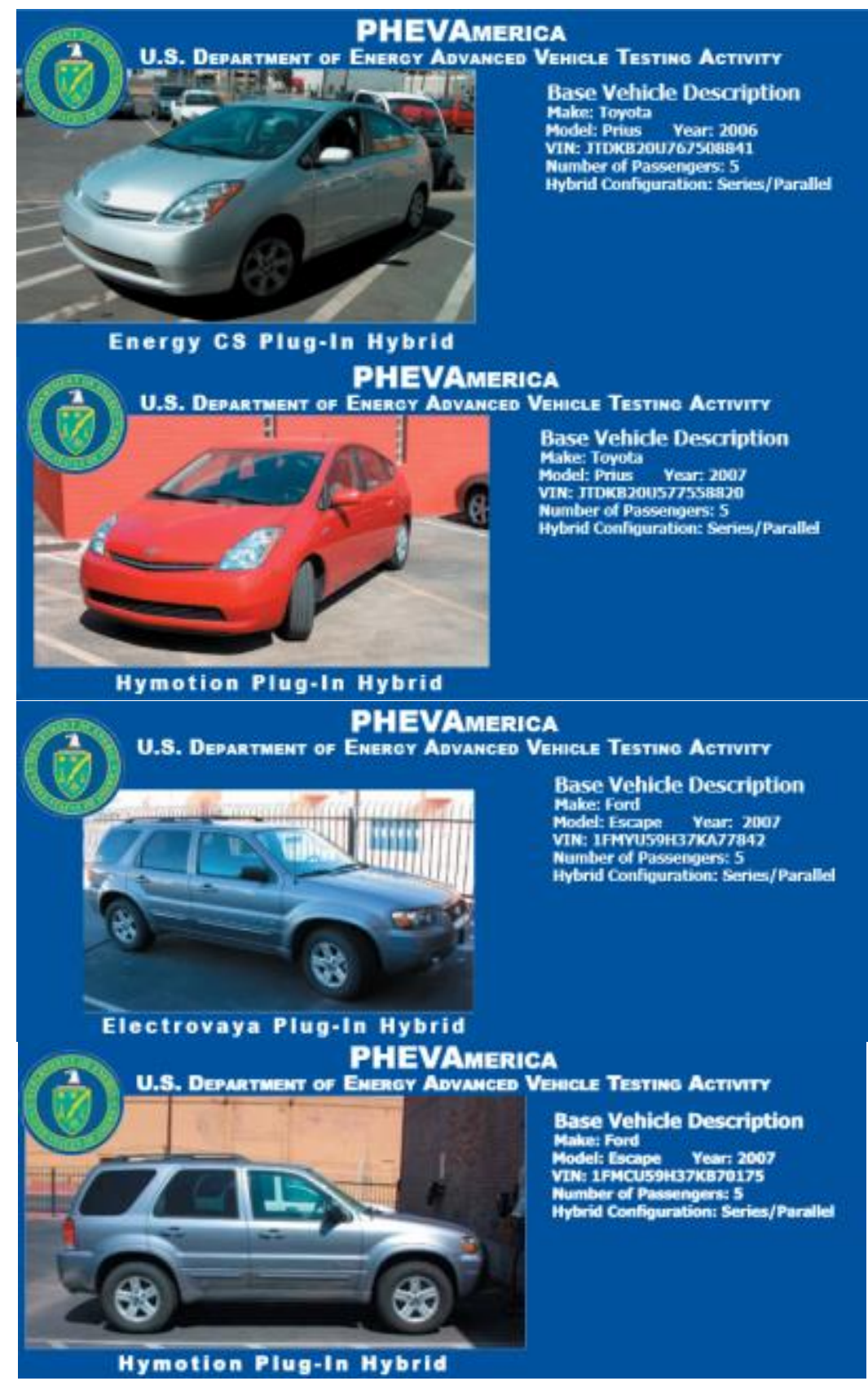




\section{Task 2.11: NYSERDA PHEV End-of-Life Baseline Testing (4 Battery Post Test)}

Conduct Battery Baseline Post Testing of four plug-in hybrid vehicles.

Deliverable: Electronic copy of end-of-life battery test results.

Status: End-of-Life Battery testing for the HyMotion Escape was not conducted as its production was cancelled. The Electrovaya Escape was destroyed by fire before it could be tested. The Hybrids Plus Escape was recalled by Hybrids Plus before completion of accelerated testing. The second generation HyMotion Prius was substituted for the HyMotion Civic. The battery post-test report for the second generation Hymotion Prius conversion was submitted to INL and posted to the AVTA website to satisfy this task.

http://avt.inel.gov/pdf/phev/batterygenIIprius8820.pdf

\section{Toyota Prius 8820 with Gen II Hymotion Prius Conversion Plug-In Hybrid Battery Test Results}

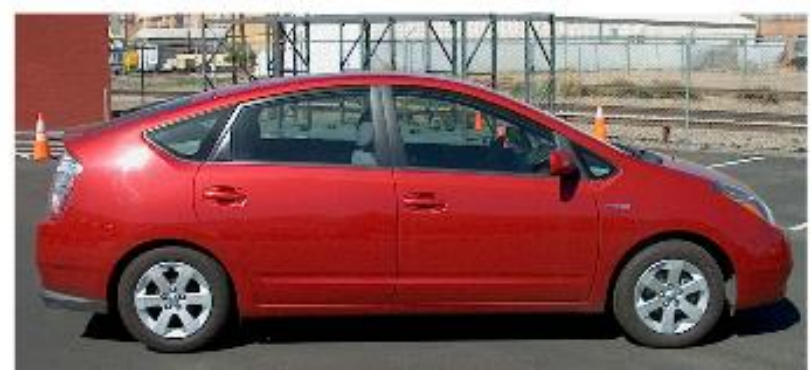

Task 2.12: PHEV Energy CS Prius Baseline Testing (1 Baseline Test w/ANL Dyno) Conduct Baseline Performance Testing of Energy CS Prius hybrid using test procedures developed in Task 1.2. Dynamometer testing shall be conducted by Argonne National Laboratory.

Deliverable: Electronic copy of PHEVAmerica Summary Data Sheet.

Status: This task has been completed. The Summary Data Sheet has been posted to the AVTA website.

\section{http://avt.inel.gov/pdf/phev/toyotaPriusHymotionFact.pdf}

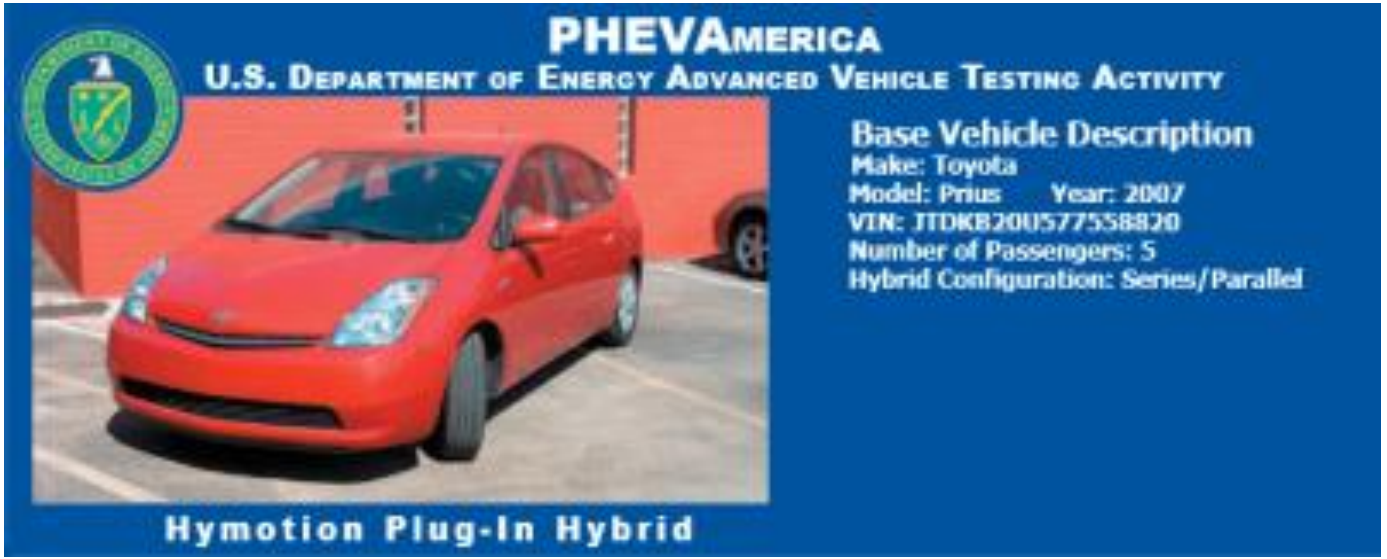


Task 2.13: PHEV Energy CS Prius End-of-Life Testing (1 Battery Post Test/ End of Life)

End-of-life testing following completion of 4,200 urban driving routes. Conduct Battery Testing of Energy CS Prius hybrid using test procedures developed in Task 1.02.

Deliverable: Electronic copy of PHEVAmerica Summary Data Sheet.

Status: This task has been completed. The battery post-test report has been completed, submitted to INL for review, then posted on the AVTA website.

\section{Toyota Prius VIN 8841 with Energy CS \\ Conversion \\ Plug-In Hybrid Battery Test Results}

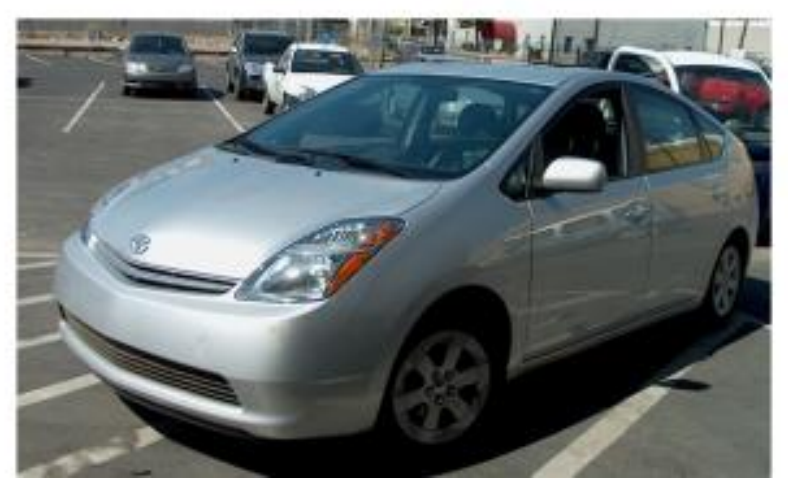

Task 2.14: Gen II Civic HEV Baseline Testing (1 Baseline Test w/ANL Dyno and 2 Battery Pre-Tests)

Conduct Baseline Performance Testing of one future HEV using previously prepared HEVAmerica test procedures. Dynamometer testing shall be conducted by Argonne National Laboratory. Conduct Battery Baseline Pre-Testing of two future HEVs.

Deliverable: Electronic copy of HEVAmerica Summary Data Sheet.

Status: This task has been completed. The Summary Data Sheet has been posted to the AVTA website. The battery baseline test results are included in the reports listed under Task 2.15.

http://avt.inel.gov/pdf/hev/factCivic2006.pdf

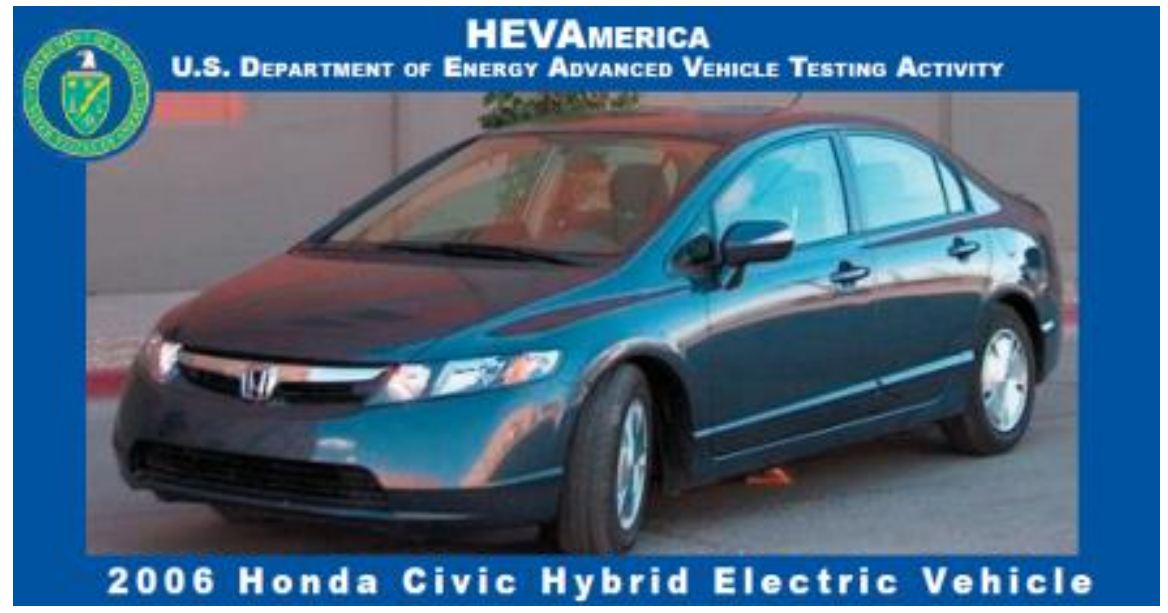


Task 2.15: 2 HEV Civic End-of-Life Baseline Testing (2 Battery Post Test)

Conduct Battery Baseline Post Testing of two Hybrid Civic vehicles.

Deliverable: Electronic copy of end-of-life battery test results.

Status: This task has been completed. The Test Results and Summary Data Sheet have been posted to the AVTA website.

http://avt.inel.gov/pdf/hev/batterycivic8725.pdf

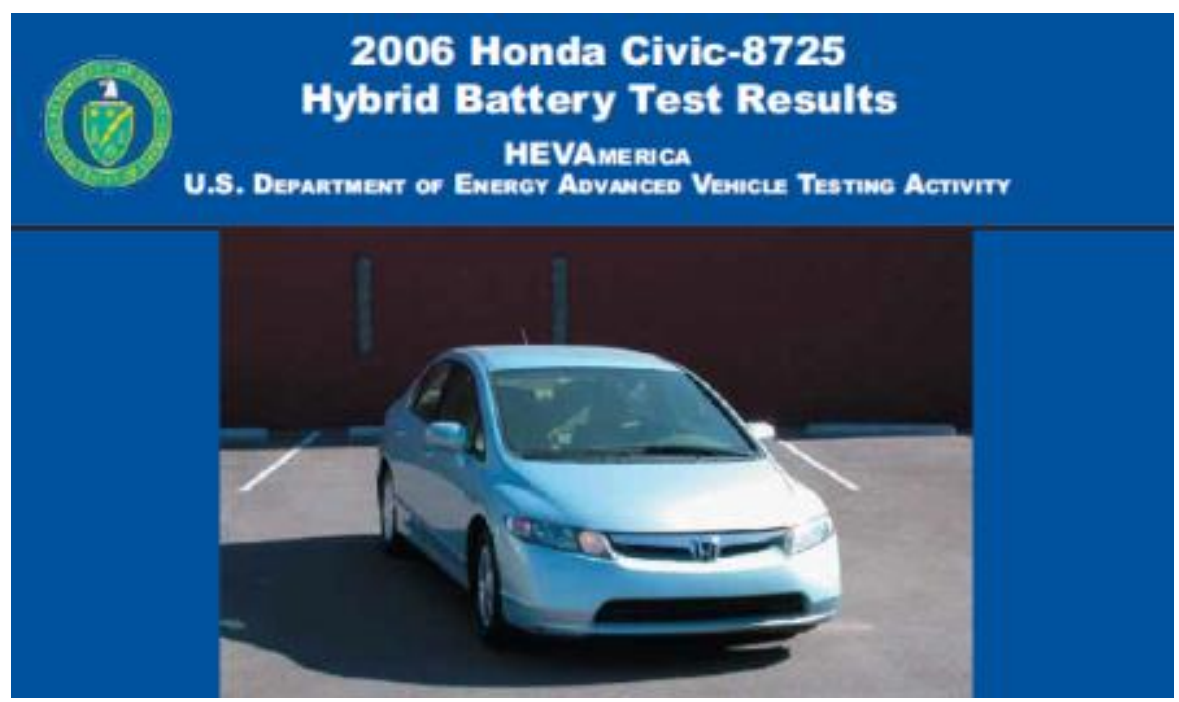

http://avt.inel.gov/pdf/hev/batterycivic9329.pdf

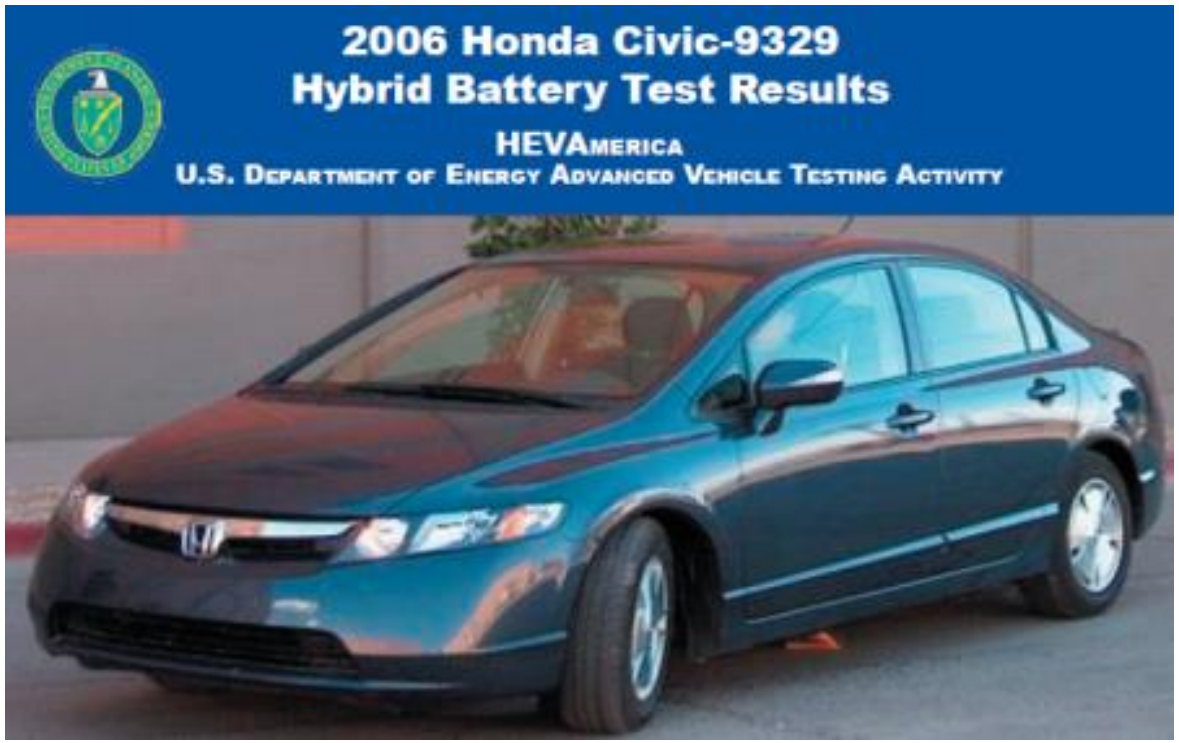


Task 2.16: Toyota Camry Baseline Testing (1 Baseline Test w/ANL Dyno and 2 Battery Pre-Tests)

Conduct Baseline Performance Testing of one future HEV using previously prepared HEVAmerica test procedures. Dynamometer testing shall be conducted by Argonne National Laboratory. Conduct Battery Baseline Pre-Testing of two future HEVs.

Deliverable: Electronic copy of HEVAmerica Summary Data Sheet.

Status: This task has been completed. The Summary Data Sheet has been posted to the AVTA website. The battery baseline test results are included in the reports listed under Task 2.17.

http://avt.inel.gov/pdf/hev/fact7129Camry07.pdf

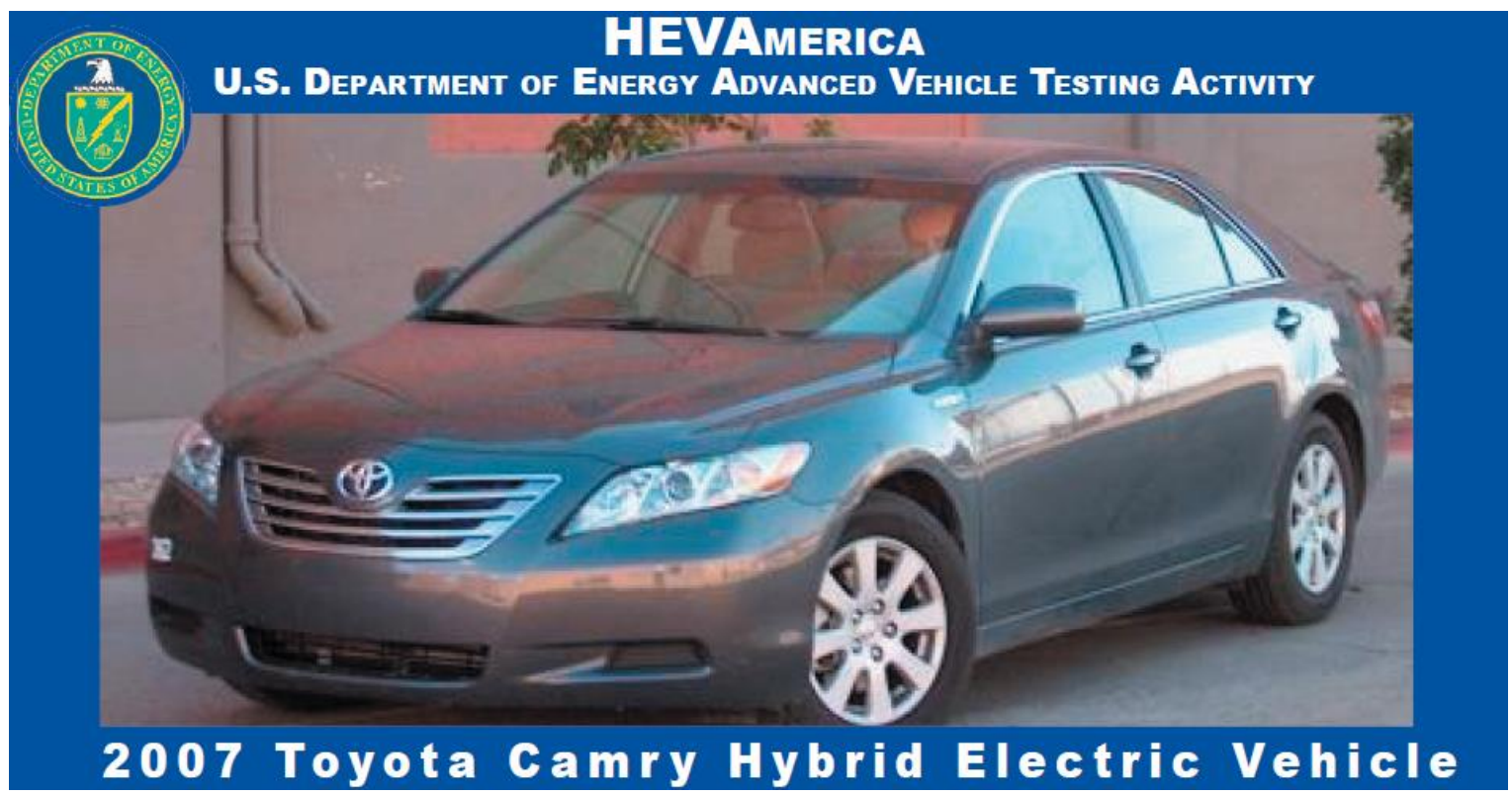


Task 2.17: 2 HEV Camry End-of-Life Baseline Testing (2 Battery Post Test) Conduct Battery Baseline Post Testing of two Hybrid Camry vehicles. Deliverable: Electronic copy of end-of-life battery test results.

Status: This task has been completed. The Test Results and Summary Data Sheets have been posted to the AVTA website.

http://avt.inel.gov/pdf/hev/batterycamry6330.pdf

\section{Toyota Camry-6330 Hybrid Electric Vehicle Battery Test Results}

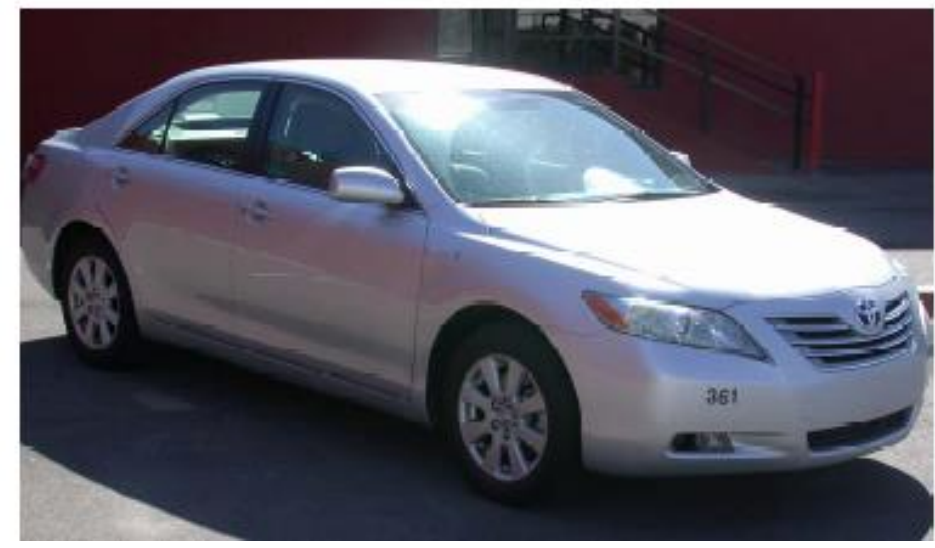

http://avt.inel.gov/pdf/hev/batterycamry7129.pdf

\section{Toyota Camry-7129 Hybrid Electric Vehicle Battery Test Results}

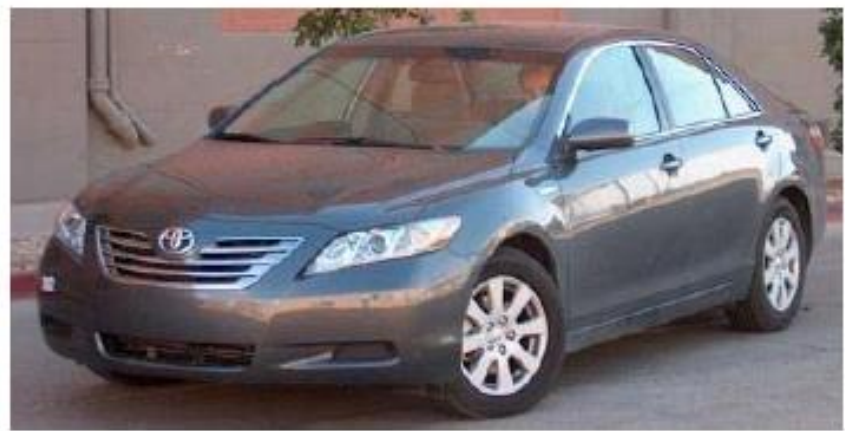


Task 2.20: NYSERDA PHEV Battery Baseline Pre-Tests (2 Battery Pre-Tests)

Conduct Battery Baseline Pre-Testing of two PHEVs.

Deliverable: Electronic copy of battery test results.

Status: This task was cancelled due to inability to establish NYSERDA fleet.

Task 2.21: NYSERDA PHEV Battery Baseline Post-Tests (2 Battery Post-Tests)

Conduct Battery Baseline Pre-Testing of two PHEVs.

Deliverable: Electronic copy of battery test results.

Status: This task was cancelled due to inability to establish NYSERDA fleet.

Task 2.22: Saturn VUE Baseline Testing (1 Baseline Test w/ANL Dyno and 2 Battery Pre-Tests)

Conduct Baseline Performance Testing of one Saturn VUE HEV using previously prepared HEVAmerica test procedures. Dynamometer testing shall be conducted by Argonne National Laboratory. Conduct Battery Baseline Pre-Testing of two future HEVs.

Deliverable: Printed and electronic copy of HEVAmerica Summary Data Sheet and battery test results.

Status: This task has been completed. The Summary Data Sheet has been posted to the AVTA website.

\section{http://avt.inel.gov/pdf/hev/factSaturnVue.pdf}

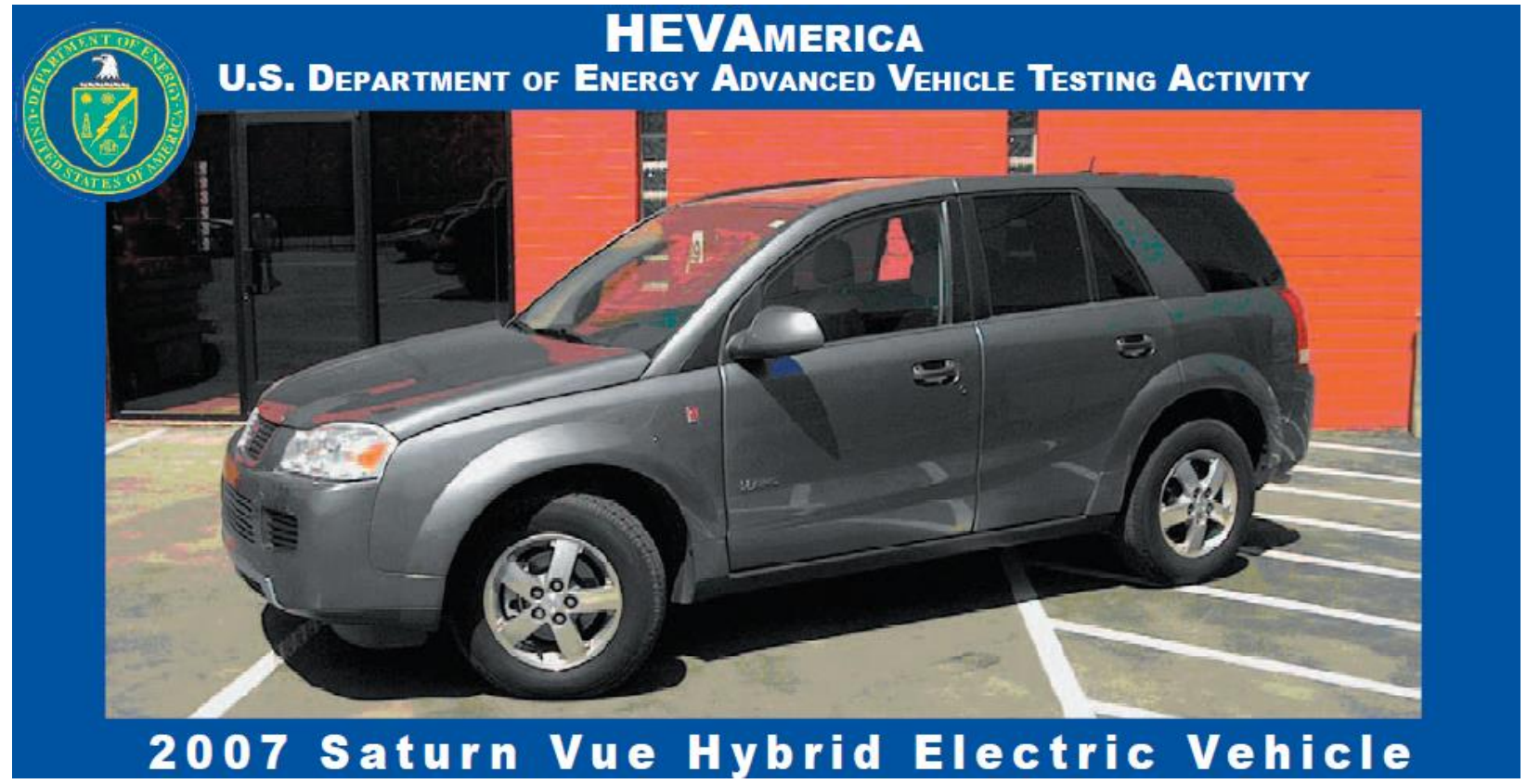




\section{Task 2.23: Saturn VUE End-of-Life Baseline Testing (2 Battery Post Test)}

Conduct Battery Baseline Post Testing of two Saturn VUE vehicles.

Deliverable: Electronic copy of end-of-life battery test results.

Status: This task has been completed. One vehicle was in a collision and the battery damaged. No testing was conducted for this vehicle. The other vehicle finished accumulating miles for fleet testing. There was no end-of-life testing, as the battery was replaced during testing.

\section{Task 2.24: Nissan Altima Baseline Testing (1Baseline w/ANL Dyno} and 2 Battery Pre-test)

Conduct Baseline Performance Testing of one Nissan Altima HEV, using previously prepared HEVAmerica test procedures. Dynamometer testing shall be conducted by Argonne National Laboratory. Conduct Battery Baseline Pre-Testing of two Nissan Altima HEVs.

Deliverable: Printed and electronic copy of HEVAmerica Summary Data Sheet and battery test results.

Status: This task has been completed. The Summary Data Sheet has been posted to the AVTA website. The battery baseline test results are included in the reports listed under Task 2.25.

\section{http://avt.inel.gov/pdf/hev/fact sheet7982.pdf}

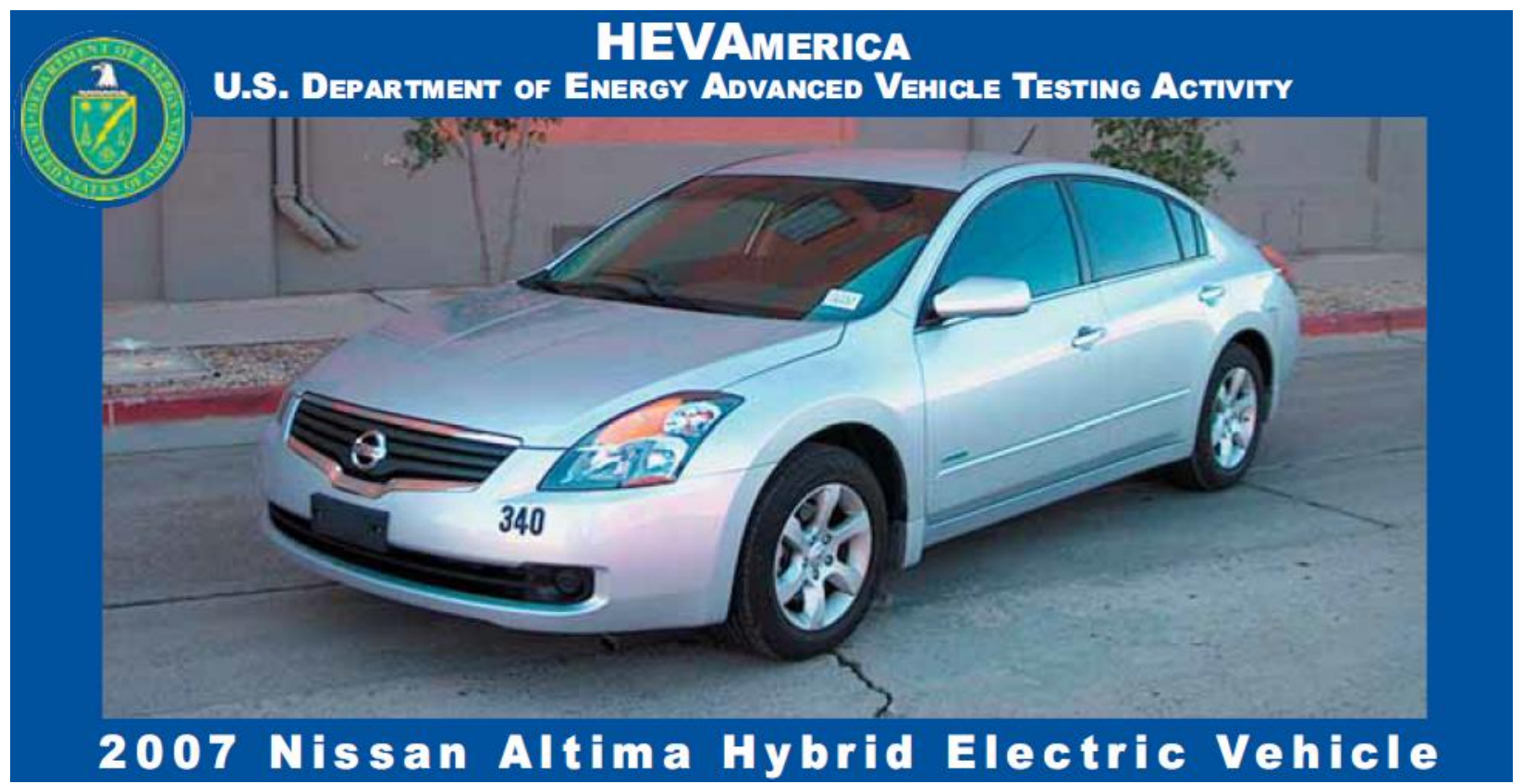


Task 2.25: Nissan Altima End-of-Life Baseline Testing (2 Battery Post Test) Conduct Battery Baseline Post Testing of two Nissan Altima vehicles. Deliverable: Electronic copy of end-of-life battery test results.

Status: This task has been completed. The Test Results and Summary Data Sheet have been posted to the AVTA website.

http://avt.inel.gov/pdf/hev/batteryaltima2351.pdf

\section{Nissan Altima-2351 Hybrid Electric Vehicle Battery Test Results}

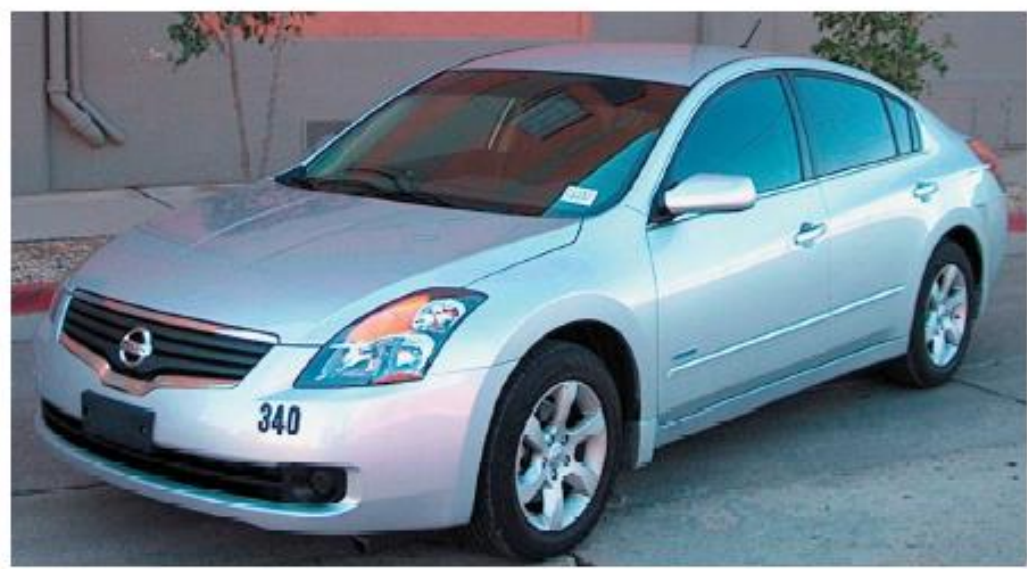

http://avt.inel.gov/pdf/hev/batteryaltima7982.pdf

\section{Nissan Altima-7982 Hybrid Electric Vehicle Battery Test Results}

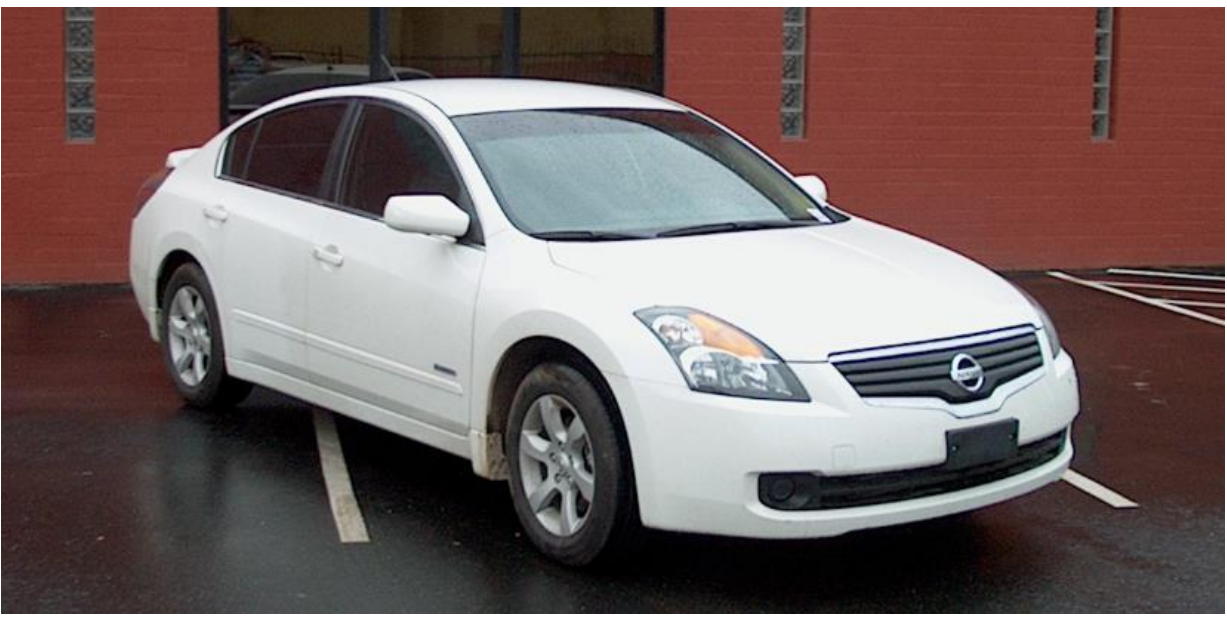


Task 2.28: HEV Chevy Tahoe Baseline Testing (1 Baseline w/ANL Dyno and 2 Battery Pre-test)

Conduct Baseline Performance Testing of a Chevy Tahoe using HEVAmerica test procedures. Dynamometer testing shall be conducted by Argonne National laboratory. Conduct Battery Baseline Pre-Testing.

Deliverable: Electronic copy of HEVAmerica Summary Data Sheet and battery test results.

Status: This task has been completed. The Summary Data Sheet and battery pre-test reports have been posted to the AVTA website.

http://avt.inel.gov/pdf/hev/fact sheet08Tahoe.pdf

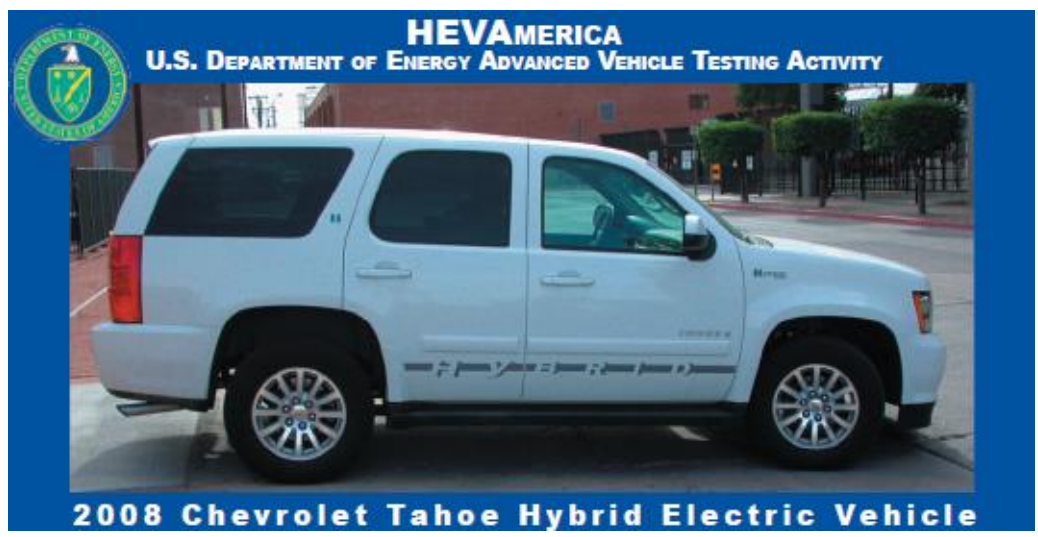

http://avt.inel.gov/pdf/hev/batterytahoe7400.pdf

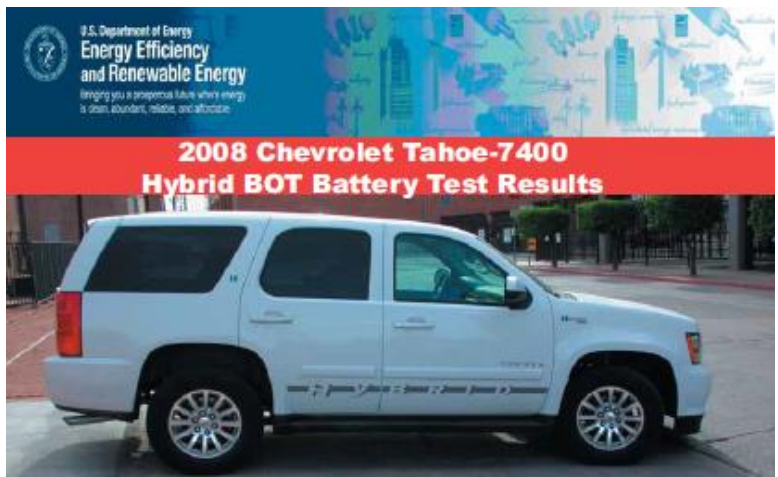

http://avt.inel.gov/pdf/hev/batterytahoe5170.pdf

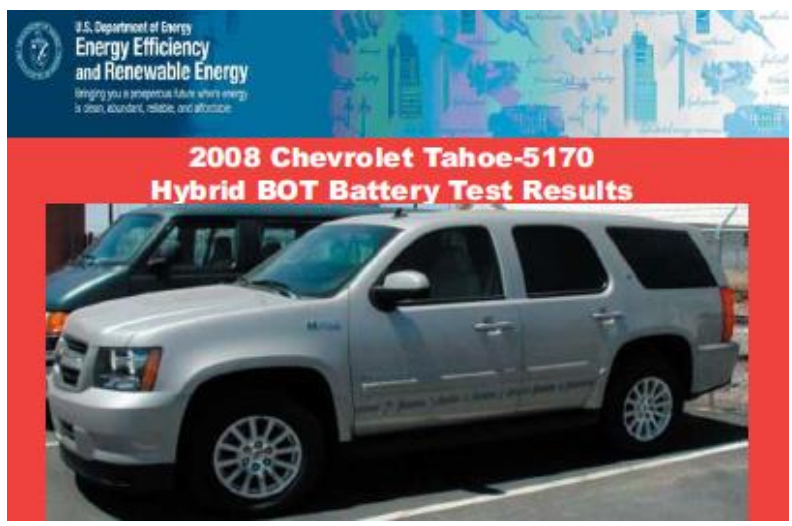


Task 2.29: HEV Chevy Tahoe End-of-Life Baseline Testing (2 Battery Post Test) Conduct Battery Baseline Post Testing of two Hybrid Chevy Tahoe vehicles. Deliverable: Electronic copy of end-of-life battery test results.

Status: This task has been completed. The Test Results and Summary Data Sheet have been posted to the AVTA website.

http://avt.inel.gov/pdf/hev/batterytahoeEOT7400.pdf

\section{Chevrolet Tahoe-7400 Hybrid} Electric Vehicle Battery Test Results

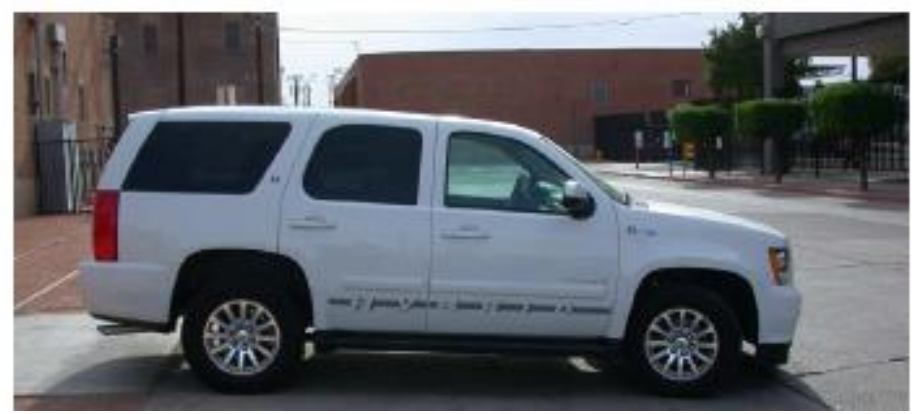

http://avt.inel.gov/pdf/hev/batterytahoeEOT5170.pdf

\section{Chevrolet Tahoe-5170 Hybrid Electric Vehicle Battery Test Results}

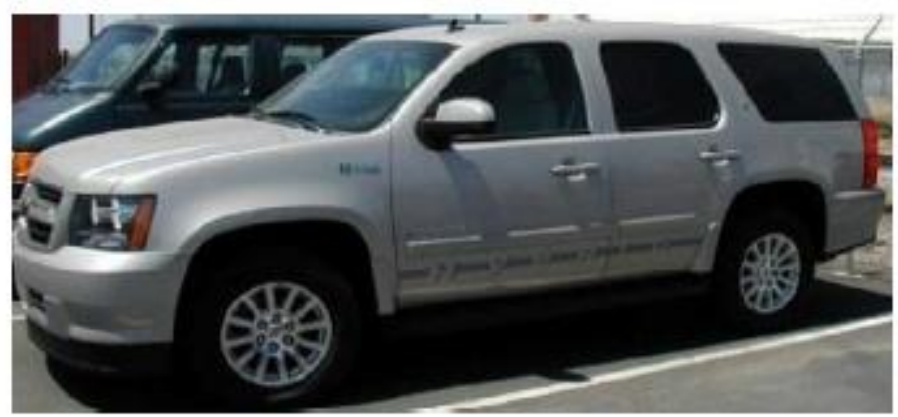


Task 2.30: GEM NEV (Neighborhood Electric Vehicle) Baseline Testing (2 Vehicles) Conduct Baseline testing of two GEM NEVs using previously prepared NEVAmerica test procedures.

Deliverable: Electronic copy of NEVAmerica Data Sheet.

Status: This task has been completed. The Summary Data Sheet has been posted to the AVTA website.

http://avt.inel.gov/pdf/nev/gem2007elXD.pdf

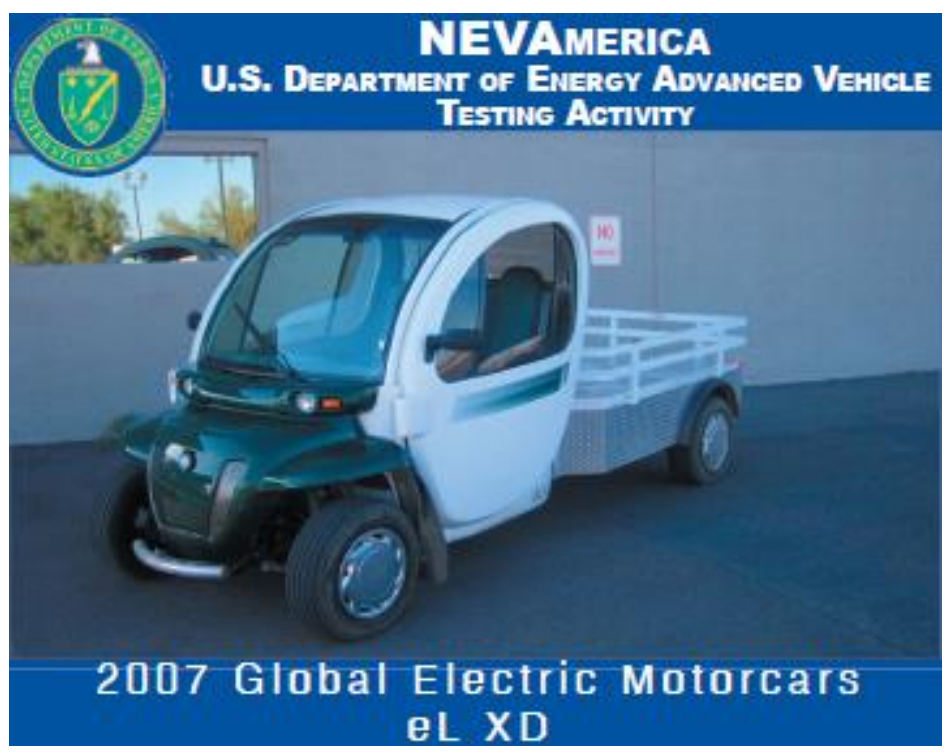

http://avt.inel.gov/pdf/nev/gem2007e6.pdf

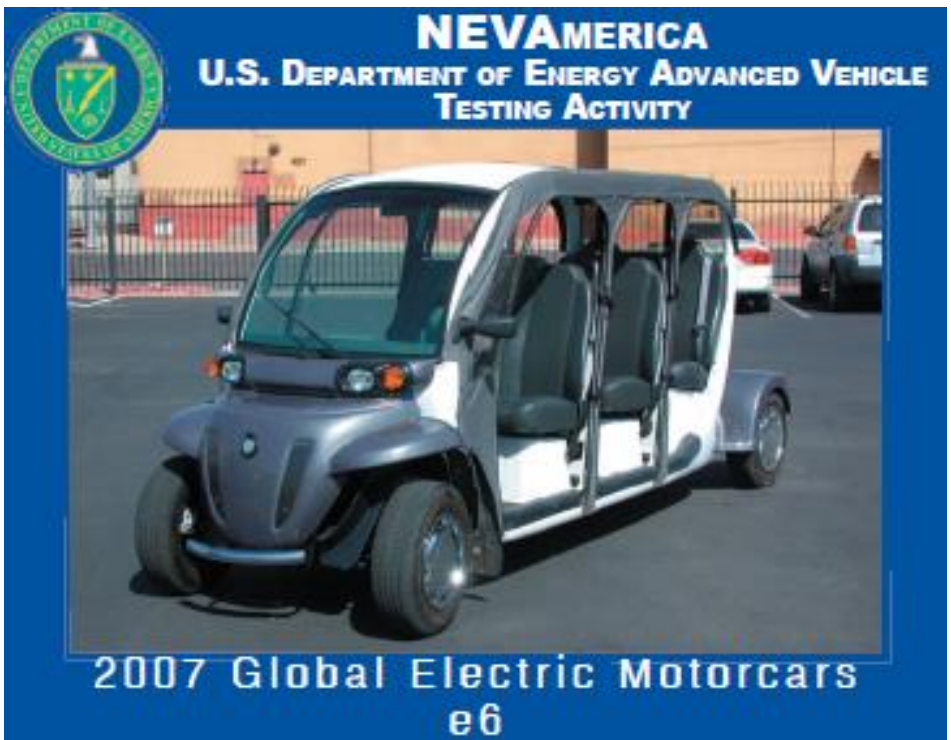


Task 2.31: Mercedes S400 HEV Baseline Testing (1 Baseline Test w/ANL Dyno and 2 Battery Pre-Tests)

Conduct Baseline Performance Testing of one Mercedes S400 HEV using previously prepared HEVAmerica test procedures. Dynamometer testing shall be conducted by Argonne National Laboratory. Conduct Battery Baseline Pre-Testing of two Mercedes S400 HEVs.

Deliverable: Electronic copy of HEVAmerica Summary Data Sheet and battery test results.

Status: This task has been completed. The Summary Data Sheet has been posted to the AVTA website. Two battery pre-tests were not performed due to the complexity of the battery.

\section{http://avt.inel.gov/pdf/hev/fact2010mercedesbenz.pdf}

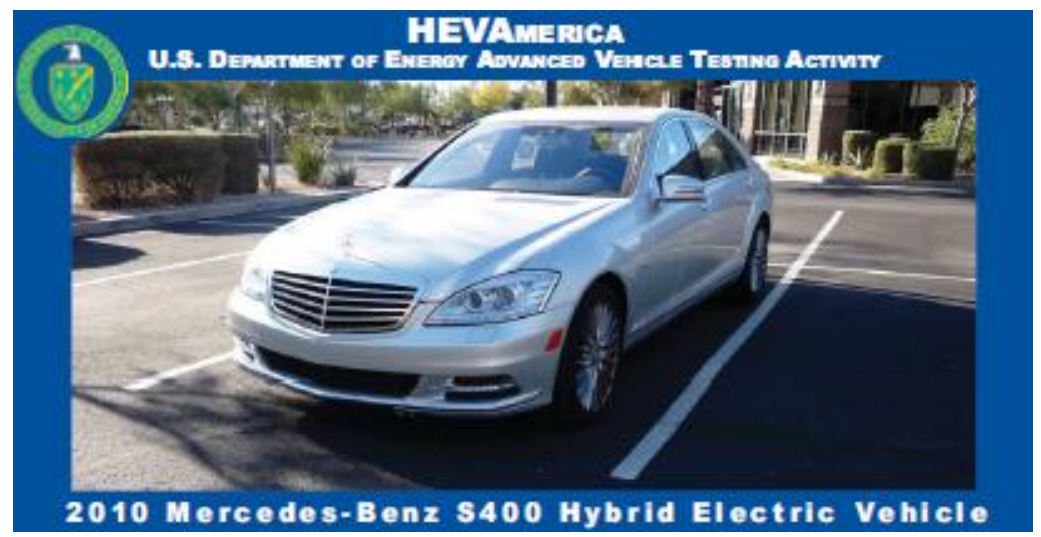

Task 2.32: Honda Insight Baseline Testing (1 Baseline w/ANL Dyno and 2 Battery Pre-Test)

Conduct Baseline Performance Testing of one Honda Insight, using previously prepared HEVAmerica test procedures. Dynamometer testing shall be conducted by Argonne National Laboratory. Conduct Battery Baseline Pre-Testing of two Honda Insights.

Deliverable: Electronic copy of HEVAmerica Summary Data Sheet.

Status: This task has been completed. The Summary Data Sheet has been posted to the AVTA website. The battery pre-test results are included with the end-of-life reports in Task 2.33.

http://avt.inel.gov/pdf/hev/fact2010hondainsight.pdf

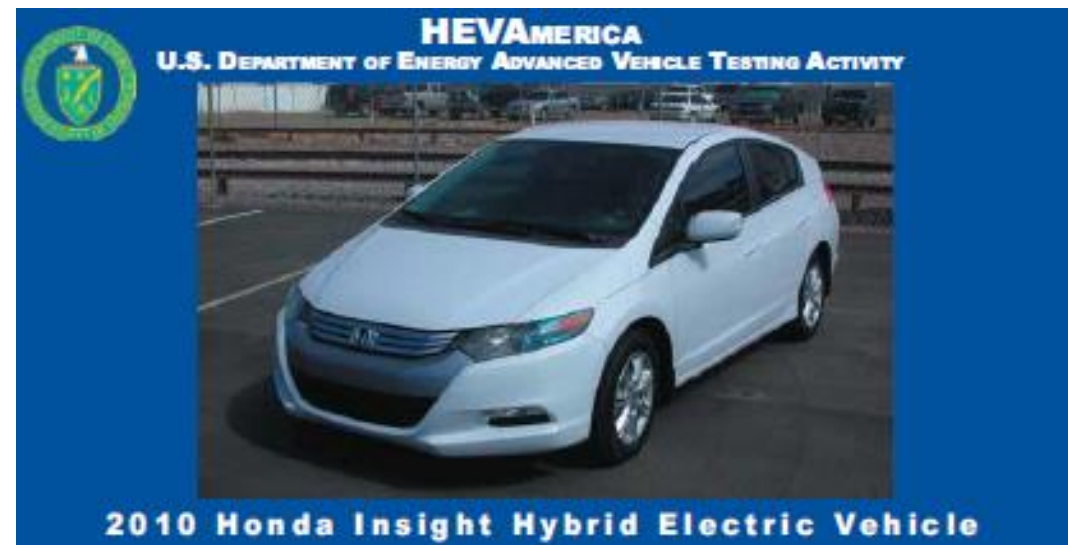


Task 2.33: Honda Insight HEV End-of-Life Baseline Testing (2 Battery Post Test) Conduct Battery Baseline Post Testing of two Honda Insight HEVs.

Deliverable: Electronic copy of end-of-life battery test results.

Status: This task has been completed. The Test Results and Summary Data Sheets have been posted to the AVTA website.

http://avt.inel.gov/pdf/hev/batteryinsight0141.pdf

\section{Honda Insight VIN 0141 Hybrid Electric Vehicle Battery Test Results}

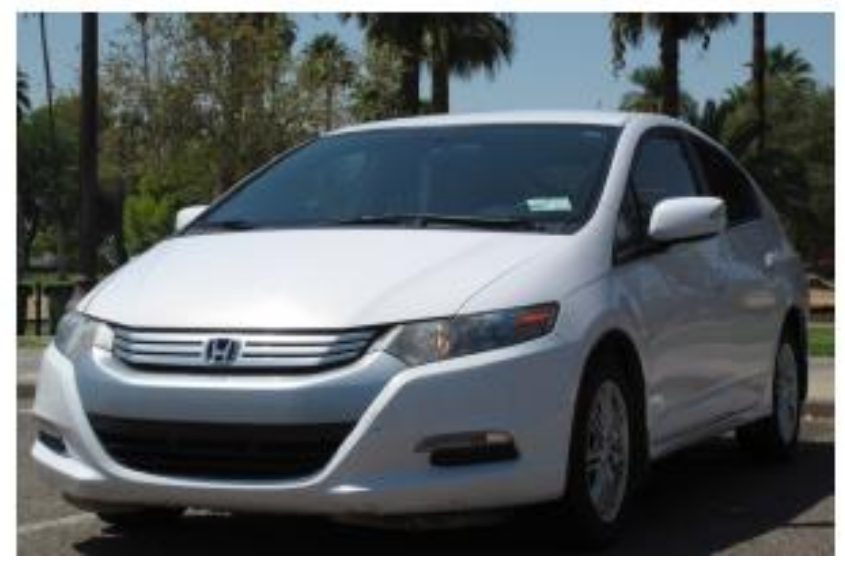

http://avt.inel.gov/pdf/hev/batteryinsight1748.pdf

\section{Honda Insight VIN 1748 Hybrid Electric Vehicle Battery Test Results}

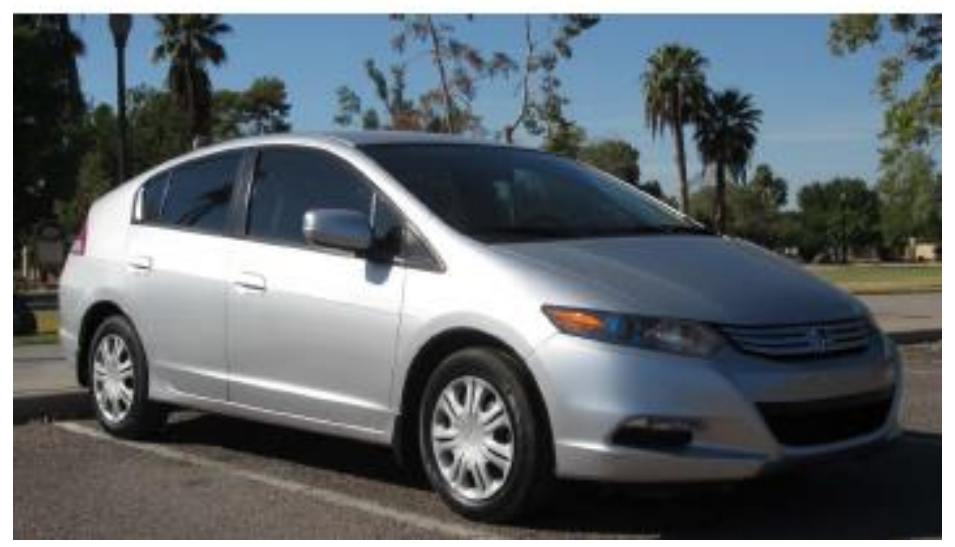


Task 2.34: (Added in A014) Mini E Baseline Testing (1 ANL Dyno and 1 Battery Pre-Test)

Conduct Baseline Performance Testing of one Mini E battery electric vehicle using EVAmerica test procedures. Dynamometer testing shall be conducted by Argonne National Laboratory. Conduct Battery Baseline Pre-Testing.

Deliverable: Electronic copy of EVAmerica Summary Data Sheet and battery test results.

Status: Vehicle is no longer available for testing. The Baseline and accelerated testing has been completed. The Baseline Performance report has been posted to the AVTA website. Accelerated durability testing partially completed when the task cancelled.

http://avt.inel.gov/pdf/uev/fact2009bmwmini.pdf

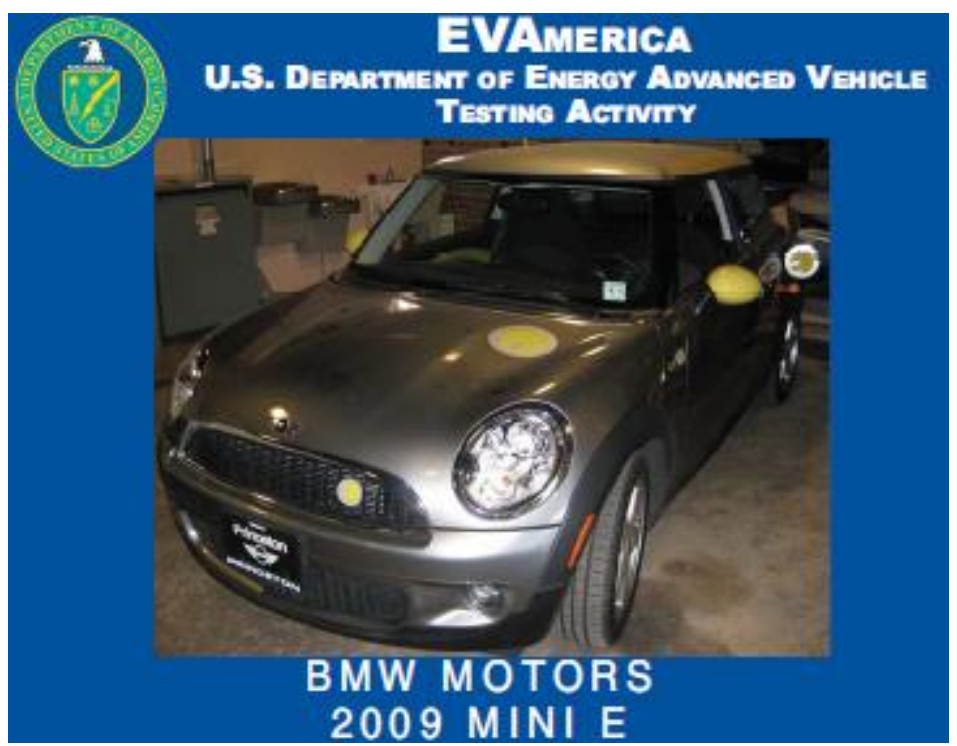

Task 2.35: RESERVED 


\section{Task 2.36: Ford Fusion HEV Baseline Testing (1 ANL Dyno and 2 Battery Pre-Test)} Conduct Baseline Performance Testing of one Ford Fusion HEV using HEVAmerica test procedures. Dynamometer testing shall be conducted by Argonne National Laboratory. Conduct Battery Baseline Pre-Testing on two vehicles.

Deliverable: Electronic copy of HEVAmerica Summary Data Sheet and battery test results.

Status: This task has been completed. The Summary Data Sheet and battery pre-test report for the vehicle that was in a collision have been posted to the AVTA website. The battery post-test report for the vehicle that completed the mileage accumulation is posted under Task 2.37.

\section{http://avt.inel.gov/pdf/hev/fact2010fordfusion.pdf}

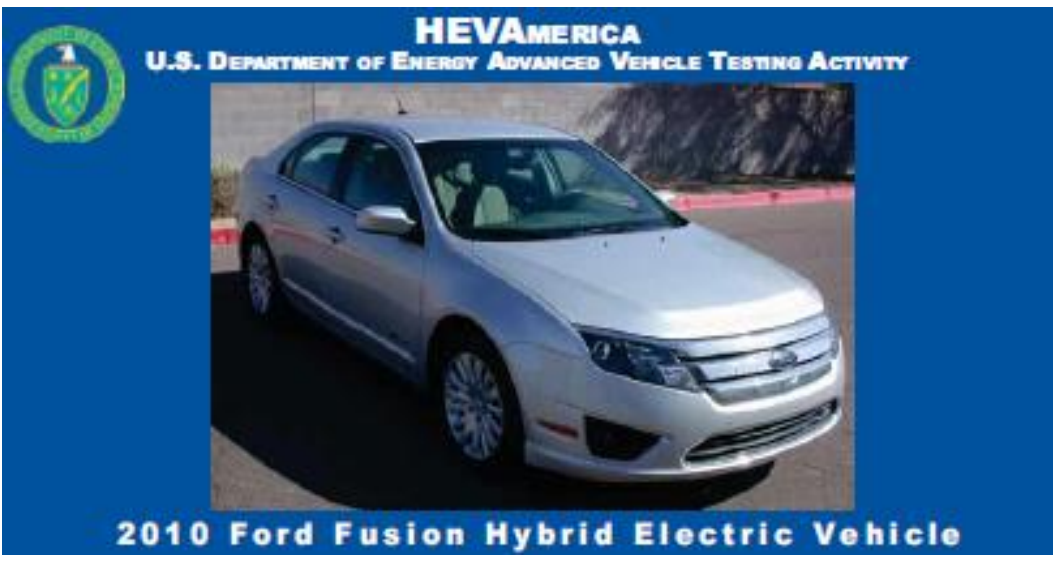

http://avt.inel.gov/pdf/hev/batteryfusion4699.pdf

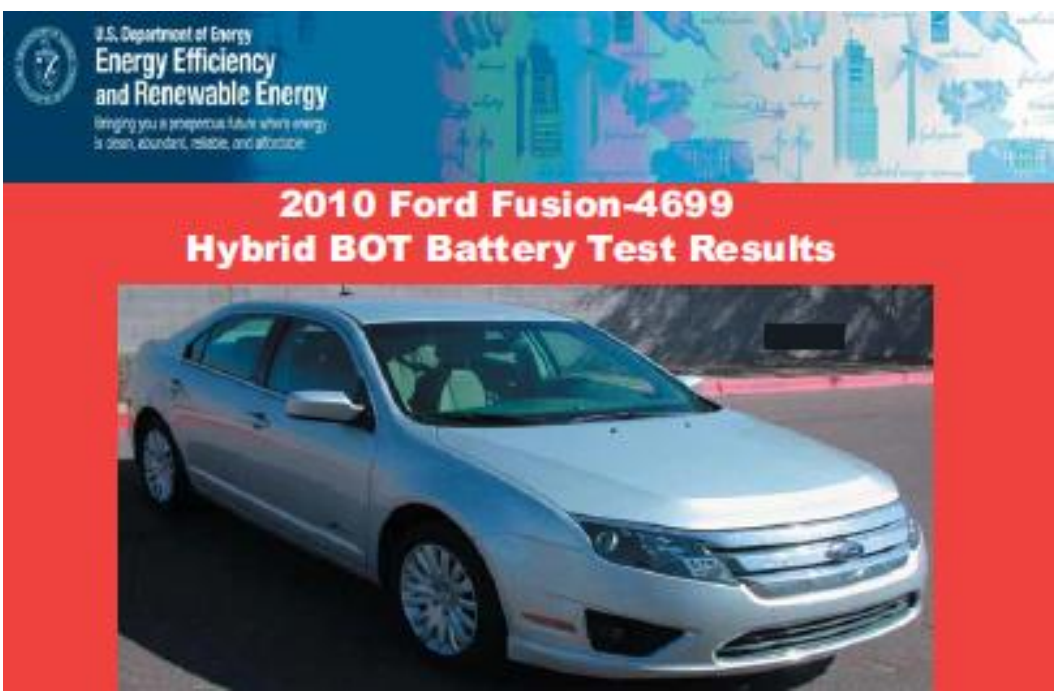




\section{Task 2.37: Ford Fusion HEV End-of-Life Baseline Testing (2 Battery Post Test)}

Conduct Battery Baseline Post Testing of two future hybrid electric vehicles.

Deliverable: Electronic copy of end-of-life battery test results.

Status: Fleet testing was completed on one vehicle; the other vehicle was in a collision and no longer operational. The battery pack from the vehicle in the collision was still operational, therefore End-of-Life testing was performed. Data from the battery pack was found to be marginalized by the collision at 74,964 miles and not valid for use in a report. The battery testing has been completed on the operable vehicle. The battery post-test report has been completed and posted on the AVTA website.

http://avt.inel.gov/pdf/hev/batteryfusion4757.pdf

\section{Ford Fusion VIN 4757 Hybrid Electric Vehicle Battery Test Results}

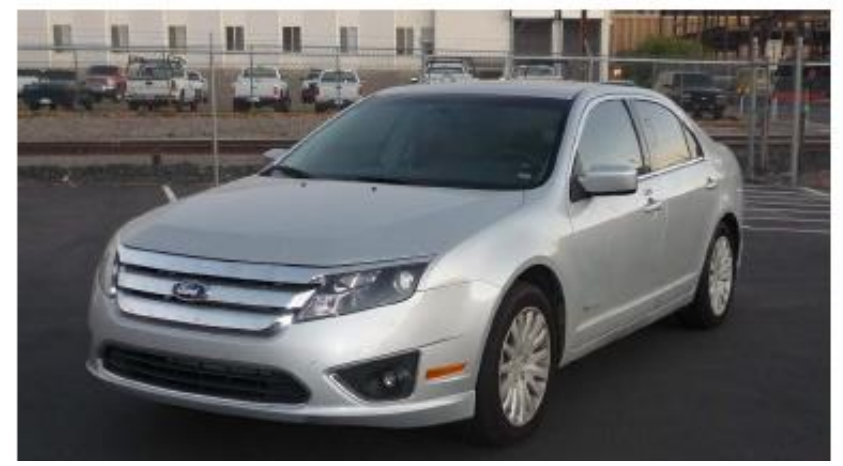

Task 2.38: (Added in A014) Gen 2 HyMotion Prius PHEV Baseline Testing (1 Baseline Test w/ANL Dyno)

Conduct Baseline Performance Testing of a HyMotion Gen 2 Prius PHEV using test procedures developed in Task 1.2. Dynamometer testing shall be conducted by Argonne National Laboratory.

Deliverable: Electronic copy of PHEVAmerica Summary Data Sheet.

Status: This task has been completed. The Summary Data Sheet has been posted to the AVTA website. The battery pre-test results are included with the end-of-life report in Task 2.39.

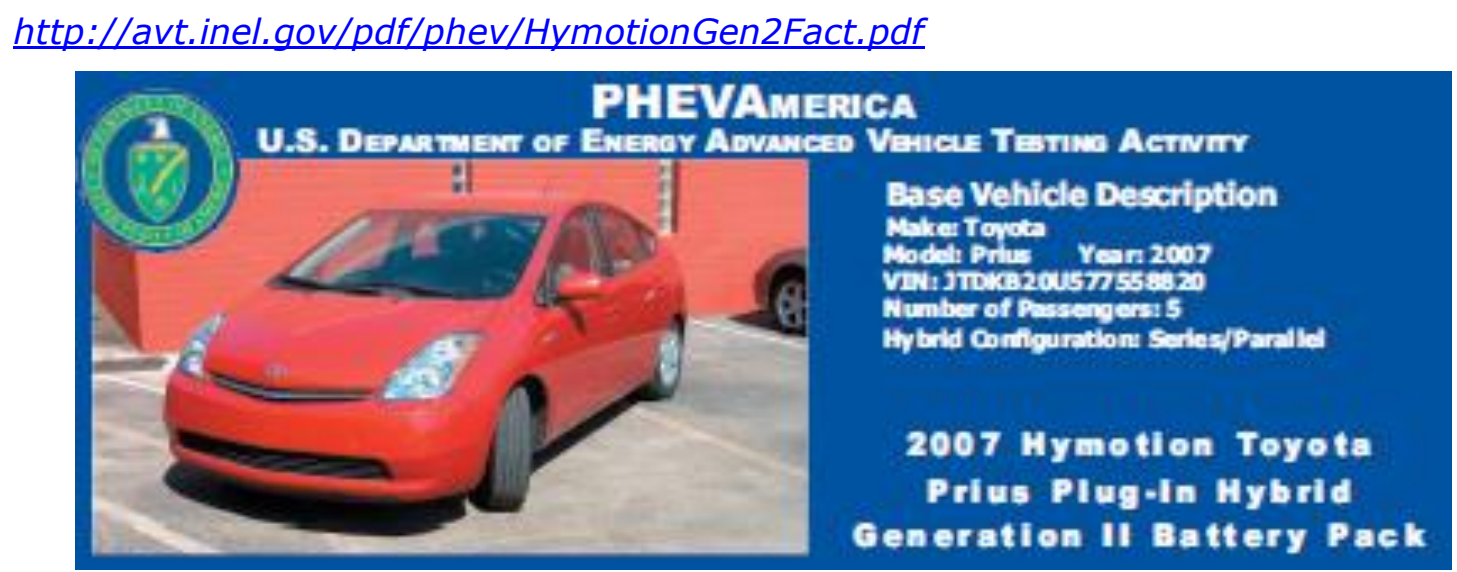


Task 2.39: (Added in A014) Gen 2 HyMotion Prius PHEV End-of-Life Testing (1 Battery Post Test/End of Life)

Conduct Battery Testing of future gasoline PHEV using test procedures developed in 1.2.

Deliverable: Electronic copy of PHEVAmerica Summary Data Sheet.

Status: This task has been completed. The battery post-test report has been completed, reviewed by INL, and posted to the AVTA website.

http://avt.inel.gov/pdf/phev/batterygenIIprius8820.pdf

\section{Toyota Prius 8820 with Gen II Hymotion Prius Conversion Plug-In Hybrid Battery Test Results}

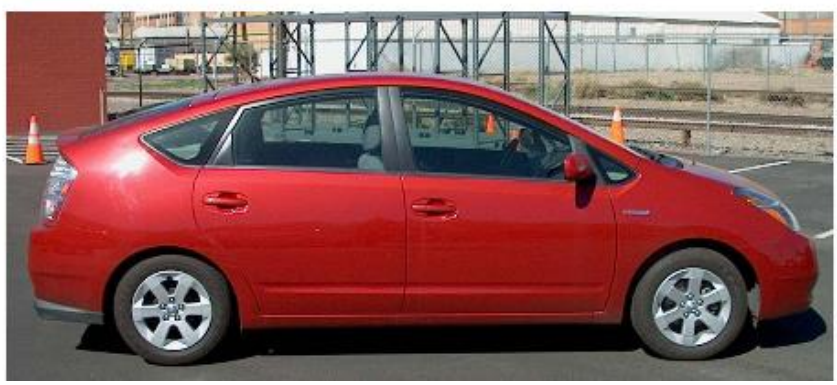

Task 2.40: (Added in A014) Ford Escape Gasoline PHEV Baseline Testing (1 Baseline Test)

Conduct Baseline Performance Testing of Ford Escape gasoline PHEV using test procedures developed in Task 1.2. Dynamometer testing shall be conducted by Argonne National Laboratory.

Deliverable: Electronic copy of PHEVAmerica Summary Data Sheet.

Status: This task has been completed. The Summary Data Sheet has been posted to the AVTA website.

\section{http://avt.inel.gov/pdf/phev/FordEscapePHEVfact.pdf}

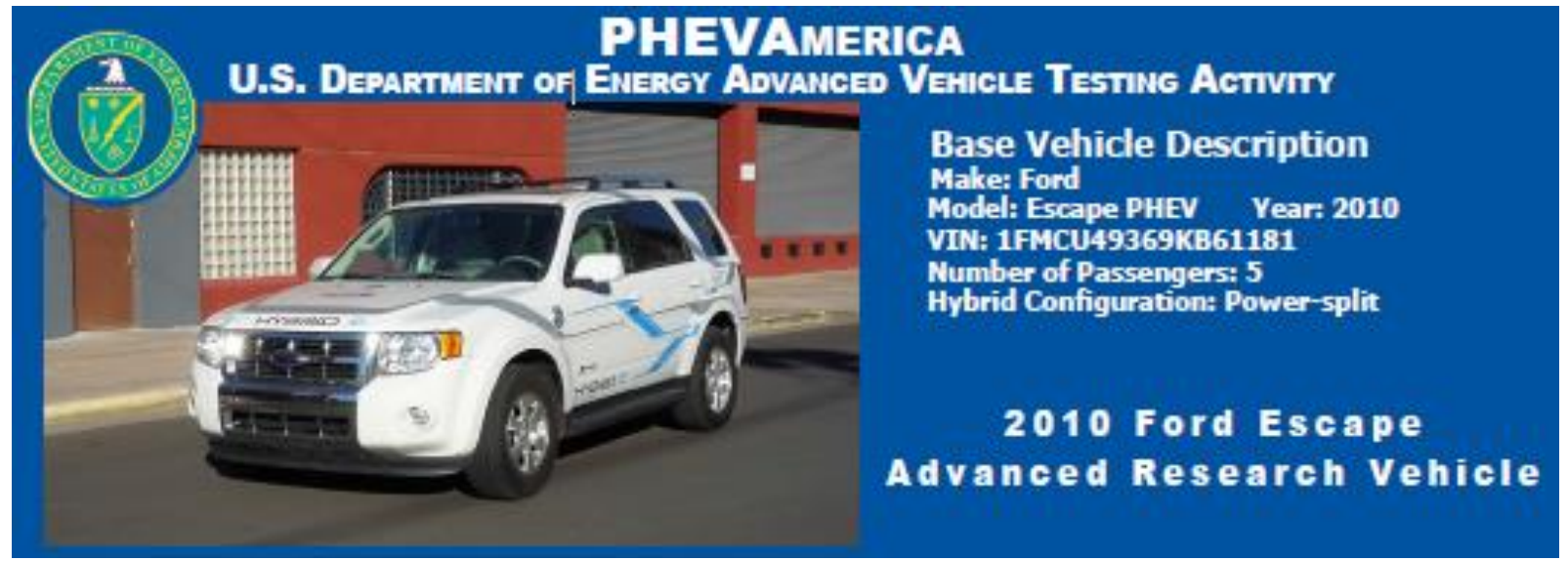


Task 2.41: (Added in A014) Ford Escape Gasoline PHEV End-of-Life Testing

(1 Battery Post Test/End of Life)

Conduct Battery Testing of Ford Escape gasoline PHEV using test procedures developed in 1.2 .

Deliverable: Electronic copy of PHEVAmerica Summary Data Sheet.

Status: This task was cancelled. The Battery test was not performed due to the vehicle is part of a Cooperative R\&D agreement with Ford and is a non-production prototype vehicle.

Task 2.42: (Added in A014) Gen 3 Prius HEV Baseline Testing (1 ANL Dyno and 1 Battery Pre-Test)

Conduct Baseline Performance Testing of one Gen 3 Prius HEV using HEVAmerica test procedures. Dynamometer testing shall be conducted by Argonne National Laboratory. Conduct Battery Baseline Pre-Testing on two vehicles.

Deliverable: Electronic copy of HEVAmerica Summary Data Sheet and battery test results.

Status: This task has been completed. The battery test results and Summary Data Sheet have been posted to the AVTA website. The battery pre-test results are included with the end-of-life reports in Task 2.43.

http://avt.inel.gov/pdf/hev/fact2010toyotaprius.pdf

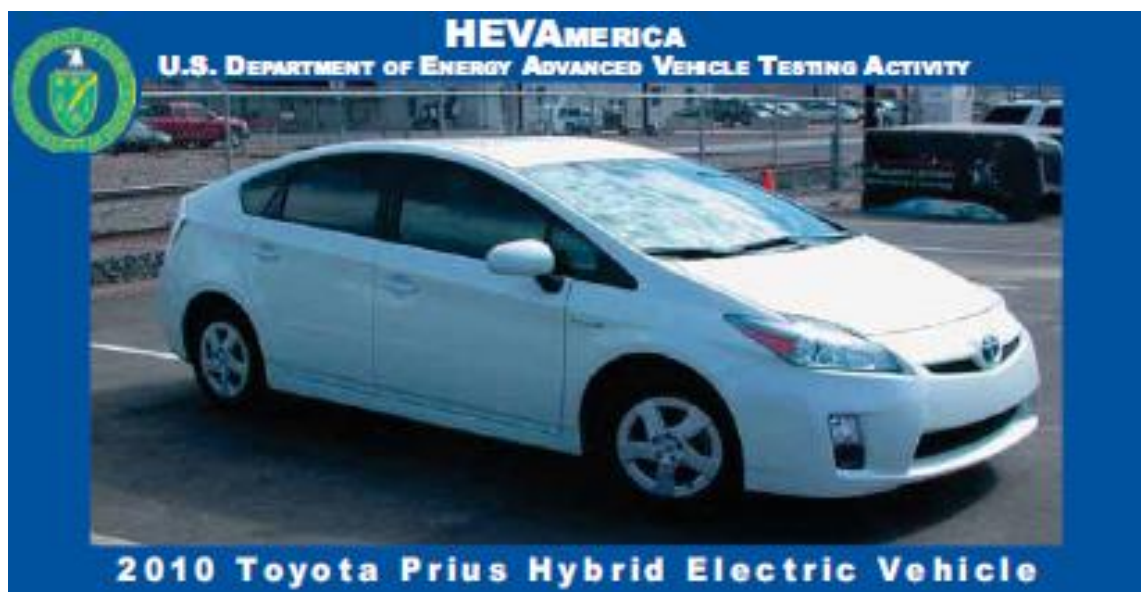


Task 2.43: Gen 3 Prius HEV End-of-Life Baseline Testing (2 Battery Post Test) Conduct Battery Baseline Post Testing of two future hybrid electric vehicles. Deliverable: Electronic copy of end-of-life battery test results.

Status: This task has been completed. The Test Results have been posted to the AVTA website.

http://avt.inel.gov/pdf/hev/batterygenIIIprius0462.pdf

\section{Toyota Prius VIN 0462 Hybrid Electric Vehicle Battery Test Results}

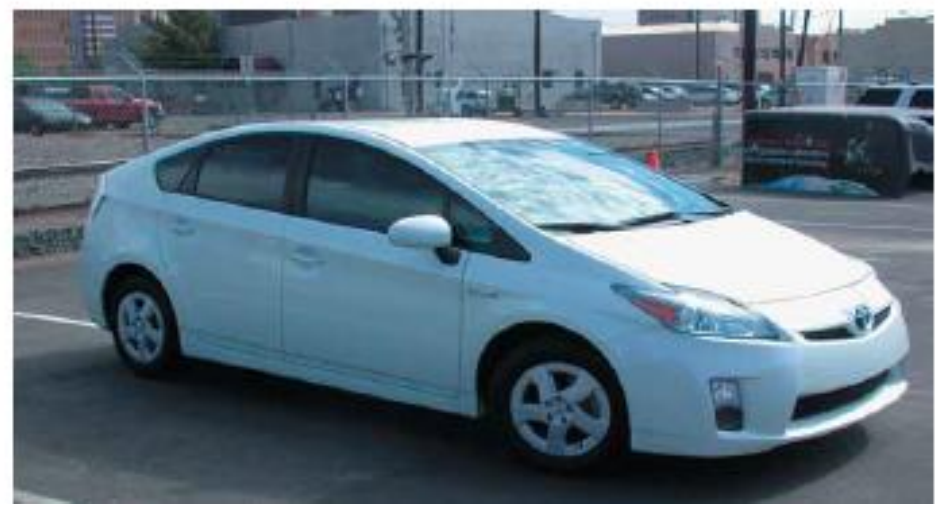

http://avt.inel.gov/pdf/hev/batterygenIIIprius6063.pdf

\section{Toyota Prius VIN 6063 Hybrid Electric Vehicle Battery Test Results}

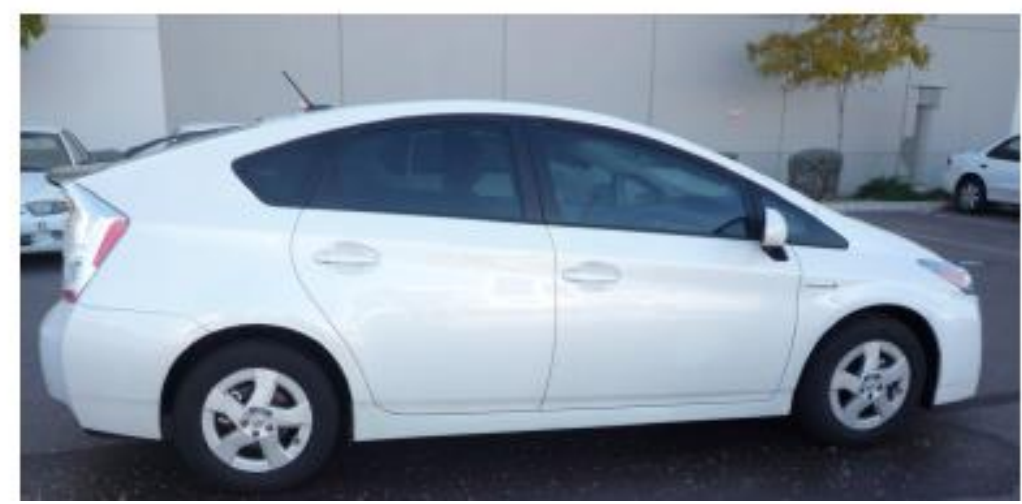

Task 2.44: Reserved

Task 2.45: Reserved 


\section{Task 2.46: Kangoo Baseline Testing (1 Baseline Test w/ANL Dyno)}

Conduct Baseline Performance Testing of Kangoo plug-in hybrid using test procedures developed in Task 1.2. Dynamometer testing shall be conducted by Argonne National Laboratory.

Deliverable: Electronic copy of PHEVAmerica Summary Data Sheet.

Status: This task has been completed. The Summary Data Sheet has been posted to the AVTA website.

\section{http://avt.inel.gov/pdf/phev/KangooFact.pdf}

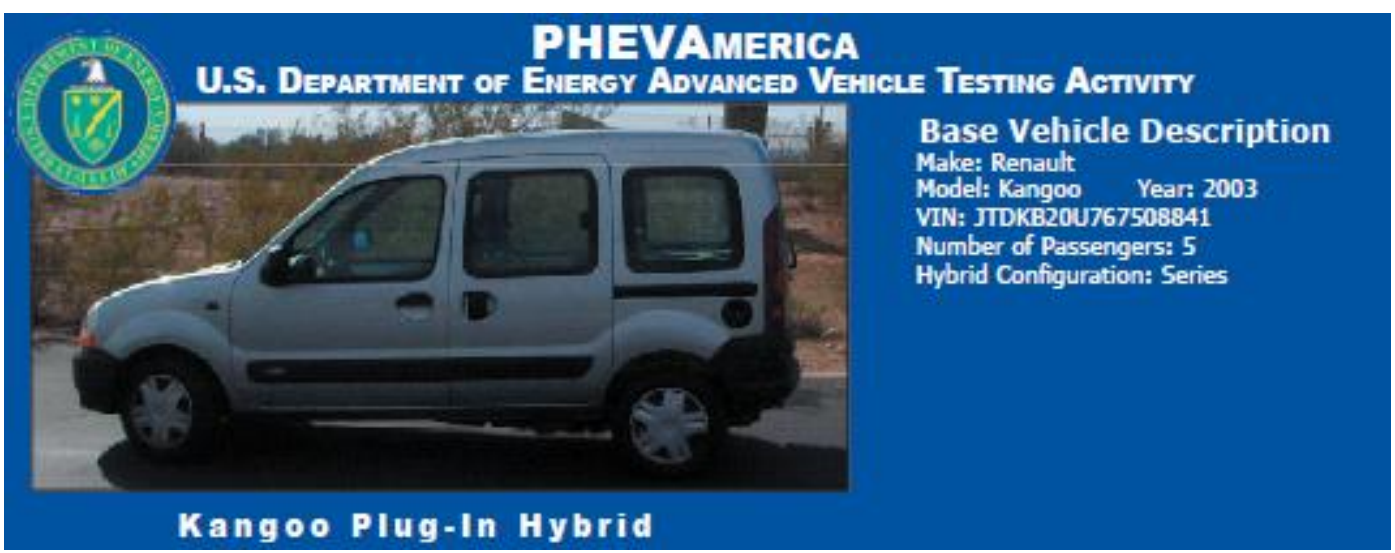

Task 2.47: Gen 1 HyMotion Prius PHEV Baseline Testing (1 Baseline Test w/ANL Dyno)

Conduct Baseline Performance Testing of HyMotion Prius hybrid using test procedures developed in Task 1.2. Dynamometer testing shall be conducted by Argonne National Laboratory.

Deliverable: Electronic copy of PHEVAmerica Summary Data Sheet and battery test results.

Status: This task has been completed. The Summary Data Sheet has been posted to the AVTA website.

http://avt.inel.gov/pdf/phev/toyotaPriusHymotionFact.pdf

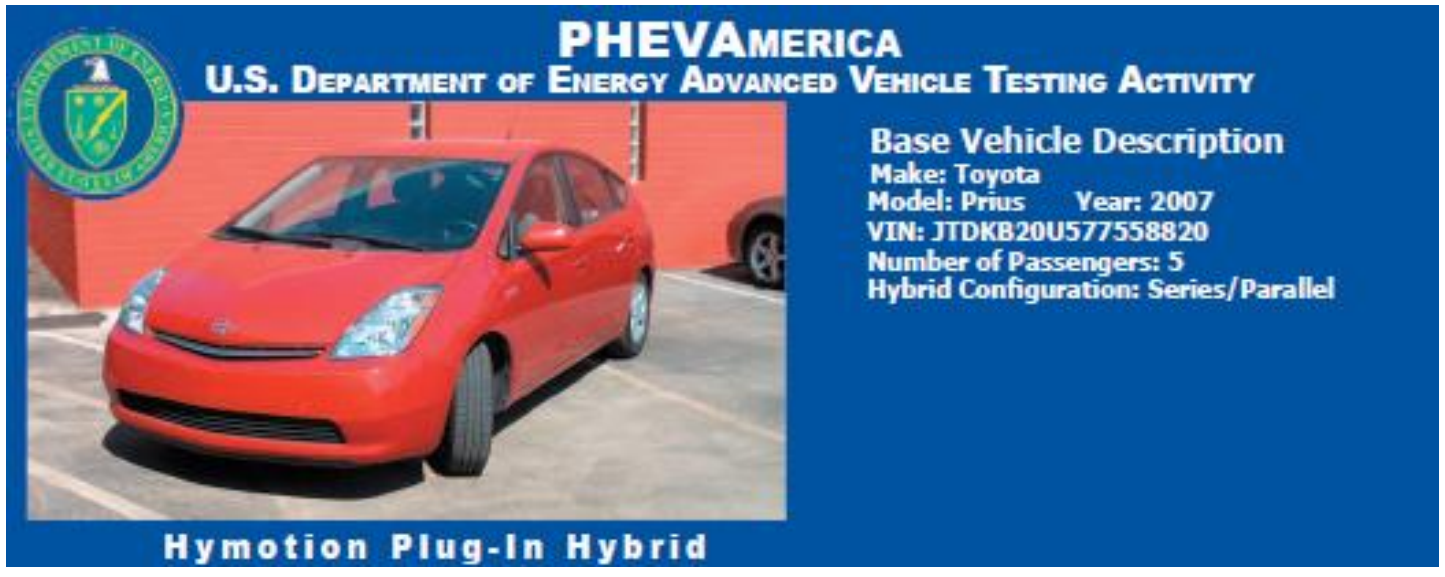




\section{Task 2.48: Baseline Testing of 4 NEVs}

Conduct Baseline Performance Testing of four future NEVs per year for two years using previously prepared NEVAmerica test procedures.

Deliverable: Electronic copy of NEVAmerica Summary Sheet.

Status: Seven NEVs have completed baseline testing: two Miles Automotive, two Vantages, one ZENN NEV, one EVI E-mega, and one BRP Commander Electric NEV. Seven Summary Data Sheets have been completed and posted to the AVTA website.

http://avt.inel.gov/pdf/nev/Zenn2008.pdf

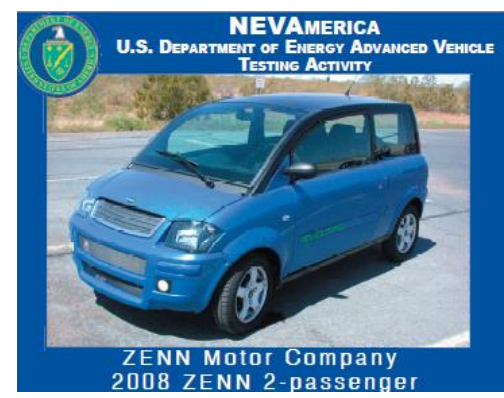

http://avt.inel.gov/pdf/nev/Miles2008ZX40ST.pdf

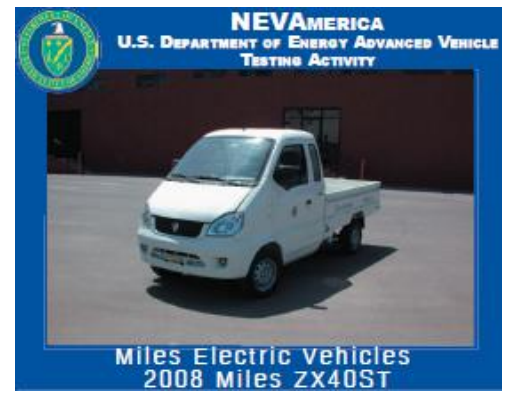

http://avt.inel.gov/pdf/nev/Miles2008ZX40S.pdf

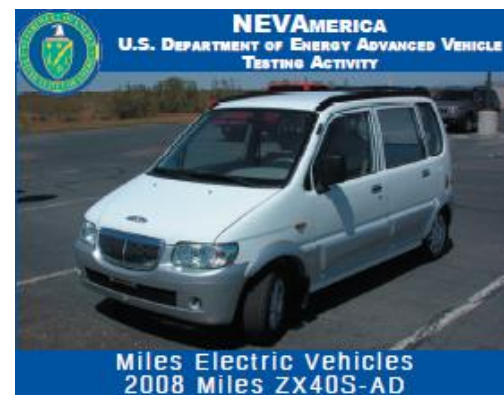

http://avt.inel.gov/pdf/nev/nev vantage pickup EVX1000.pdf

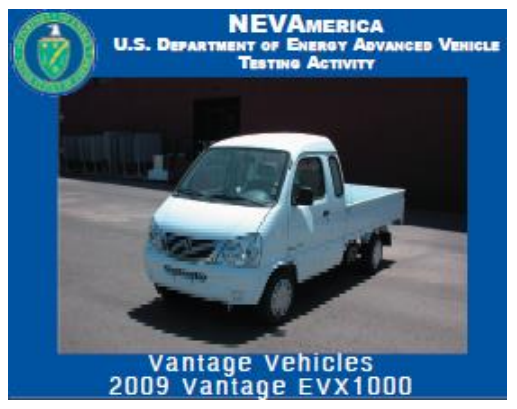




\section{http://avt.inel.gov/pdf/nev/nev vantage van EVC1000.pdf}

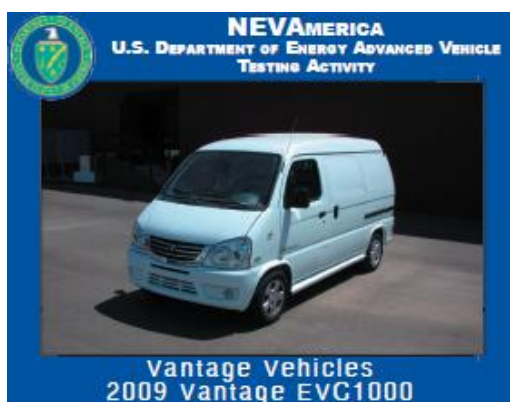

http://avt.inel.gov/pdf/nev/EVI2010.pdf

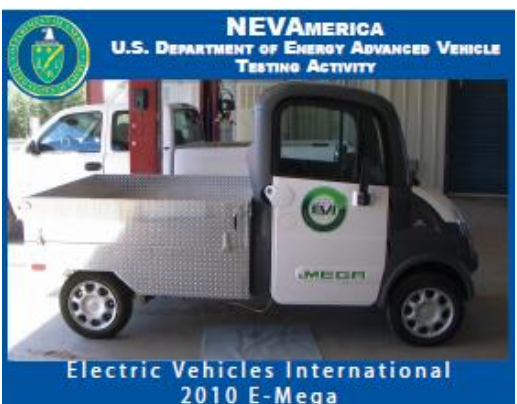

http://avt.inel.gov/pdf/nev/fact2013brpcommanderelectric.pdf

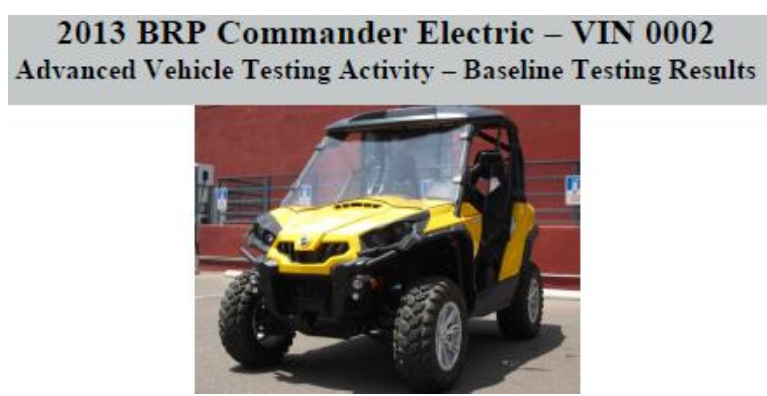

Task 2.49: Mercedes S400 HEV End-of-Life Baseline Testing (Battery Post Test) Conduct Battery Baseline Post Testing of plug-in gasoline hybrid.

Deliverable: Printed and electronic copy of battery test results.

Status: This task has been completed. Two battery post-tests were not performed due to the complexity of the batteries. 
Task 2.50: Gen 1 HyMotion Prius PHEV End-of-Life Testing

(1 Battery Post Test/End of Life)

End-of-life testing following the completion of 4,200 urban driving routes. Conduct Battery Testing of HyMotion Prius hybrid using test procedures developed in 1.2.

Deliverable: Results to be posted to electronic copy of PHEVAmerica Summary Data Sheet.

Status: This task has been completed. The battery post-test report has been completed, reviewed by INL, and posted to the AVTA website.

http://avt.inel.gov/pdf/phev/batterygenIprius8820.pdf

\section{Toyota Prius 8820 with Gen I Hymotion Prius Conversion Plug-In Hybrid Battery Test Results}

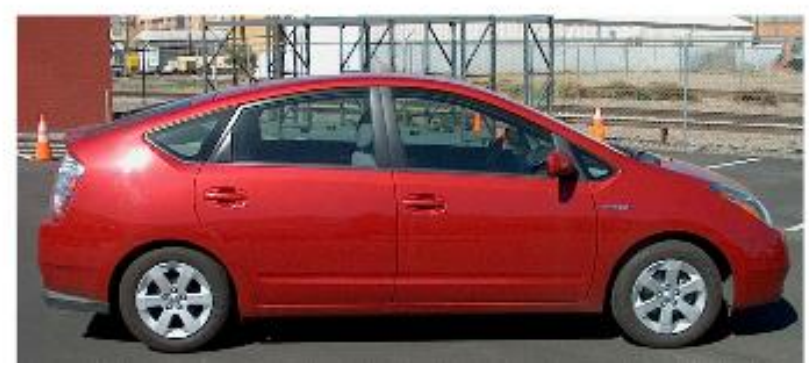

Task 2.51: (Added January 2010) Diesel Volkswagen Golf Idle-Stop Technology Vehicle Baseline Testing (1 Baseline Test w/ANL Dyno)

Conduct Baseline Performance Testing of one Idle-Stop Technology Volkswagen Golf 4-door with diesel engine using test procedures developed by AVTA. Dynamometer testing shall be conducted by Argonne National Laboratory (ANL).

Deliverable: Electronic copy of HEVAmerica Summary Data Sheet.

Status: Baseline performance and dynamometer testing have been completed. Battery performance testing was not conducted due to the conventional $12 \mathrm{~V}$ battery chemistry utilized on this vehicle.

http://avt.inel.gov/pdf/mhv/fact2010volkswagengolf.pdf

2010 Volkswagen Golf TDI Bluemotion - VIN 8111 Advanced Vehicle Testing - Baseline Testing Results

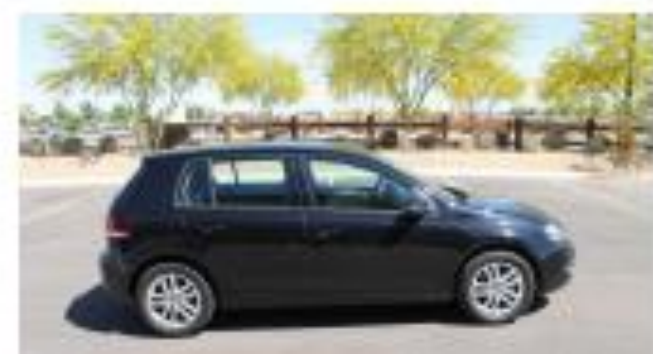


Task 2.52: (Added January 2010) Mazda3 I-stop Idle-Stop Technology Vehicle Baseline Testing (1 Baseline Test w/ANL Dyno)

Conduct Baseline Performance Testing of one Idle-Stop Technology Mazda3 I-stop using combustion restart using test procedures developed by AVTA. Dynamometer testing shall be conducted by Argonne National Laboratory.

Deliverable: Electronic copy of HEVAmerica Summary Data Sheet

Status: Baseline performance and dynamometer testing have been completed. Battery performance testing was not conducted due to the conventional $12 \mathrm{~V}$ system battery chemistry utilized on this vehicle.

http://avt.inel.gov/pdf/mhv/fact2010mazda3.pdf

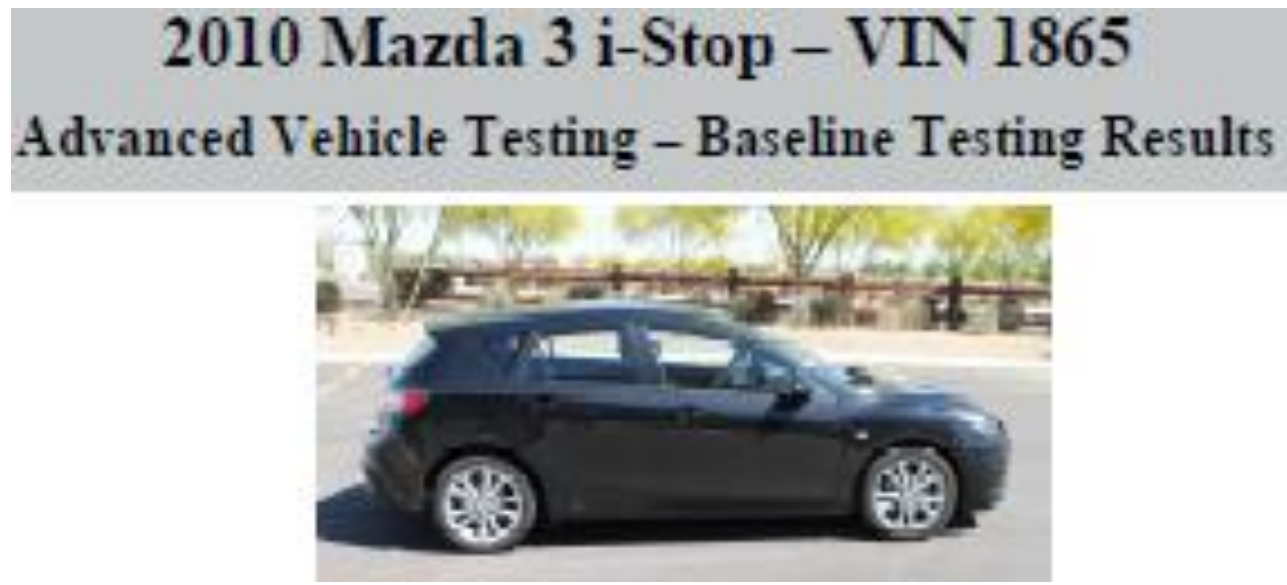

Task 2.53: (Added January 2010) Smart mhd fortwo Idle-Stop Technology Vehicle Baseline Testing (1 Baseline Test w/ANL Dyno and 2 Battery Pre-Test)

Conduct Baseline Performance Testing using test procedures developed by AVTA of one Idle-Stop Technology Smart mhd fortwo coupe with a conventional gas engine and electric restart. Dynamometer testing shall be conducted by Argonne National Laboratory.

Deliverable: Electronic copy of HEVAmerica Summary Data Sheet

Status: Baseline performance and dynamometer testing have been completed. Battery performance testing was not conducted due to the conventional $12 \mathrm{~V}$ system battery chemistry utilized on this vehicle.

http://avt.inel.gov/pdf/mhv/fact2010smartfortwo.pdf

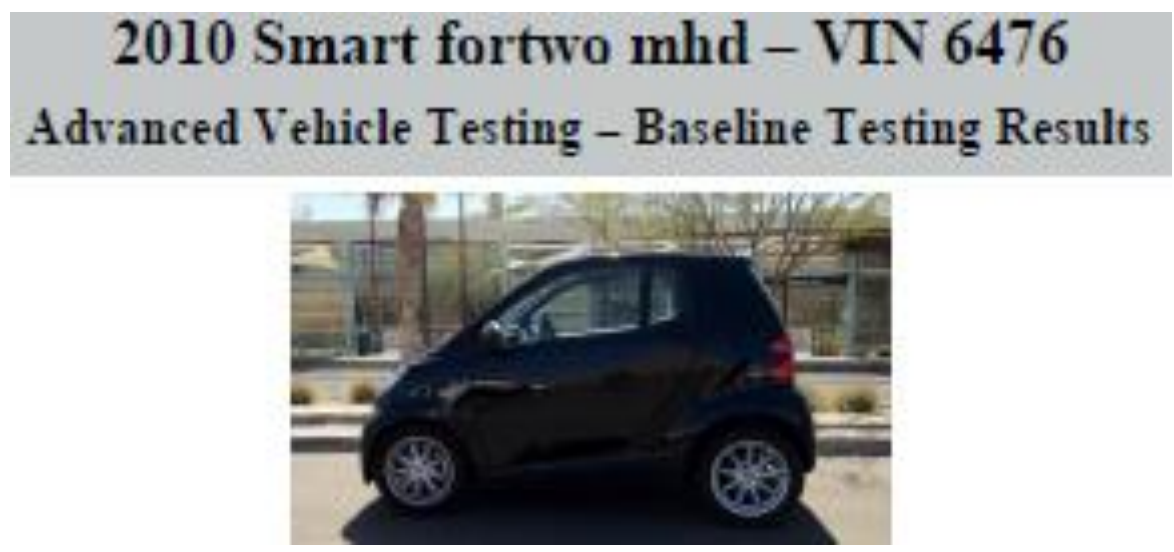


Task 2.54: (Added January 2010) Diesel Volkswagen Golf Idle-Stop Vehicle Technology End-of-Life Testing (2 Battery Post Test)

Conduct Battery Baseline Post Testing of two Idle-Stop Technology vehicles.

Deliverable: Electronic copy of end-of life battery test results.

Status: End-of-Life battery testing was not conducted due to the conventional $12 \mathrm{~V}$ batteries utilized on this vehicle.

Task 2.55: (Added January 2010) Mazda3 I-stop Idle-Stop Vehicle Technology End-of-Life Testing ( 2 Battery Post Test)

Conduct Battery Baseline Post Testing of two Idle-Stop Technology vehicles.

Deliverable: Electronic copy of end-of life battery test results.

Status: End-of-Life battery testing was not conducted due to the conventional $12 \mathrm{~V}$ batteries utilized on this vehicle.

Task 2.56: (Added January 2010) Smart mhd fortwo Idle-Stop Vehicle Technology End-of-Life Testing ( 2 Battery Post Test)

Conduct Battery Baseline Post Testing of two Idle-Stop technology vehicles.

Deliverable: Electronic copy of end-of life battery test results.

Status: End-of-Life battery testing will not be conducted due to the conventional $12 \mathrm{~V}$ batteries utilized on this vehicle. 
Task 2.57: (Added January 2010) Hyundai Sonata Hybrid (1 Baseline Test w/ANL Dynamometer and 2 Battery Pre-Tests)

Conduct Baseline Performance Testing of one Hyundai Sonata Hybrid using previously prepared HEVAmerica test procedures. Dynamometer testing shall be conducted by Argonne National Laboratory. Conduct Battery Baseline Pre-Testing of two Hyundai Sonata Hybrids.

Deliverable: Electronic copy of HEVAmerica Summary Data Sheet and Battery Test Results.

Status: This task has been completed. The Test Results and Summary Data Sheets have been posted to the AVTA website.

http://avt.inel.gov/pdf/hev/fact2011hyundaisonata.pdf

\section{Hyundai Sonata Hybrid - VIN 4932 \\ Advanced Vehicle Testing - Baseline Testing Results}

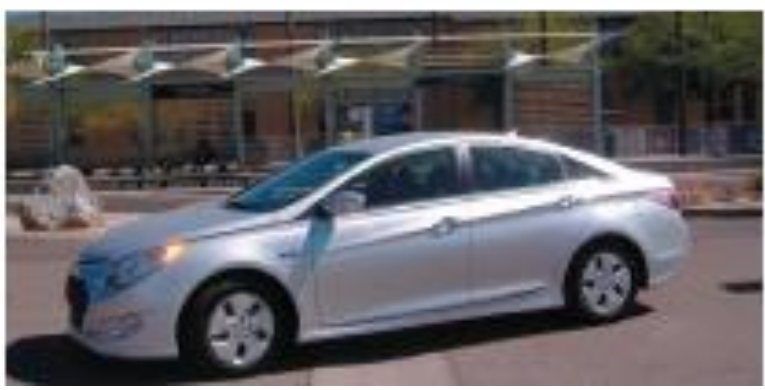

http://avt.inel.gov/pdf/hev/batterysonata3539.pdf

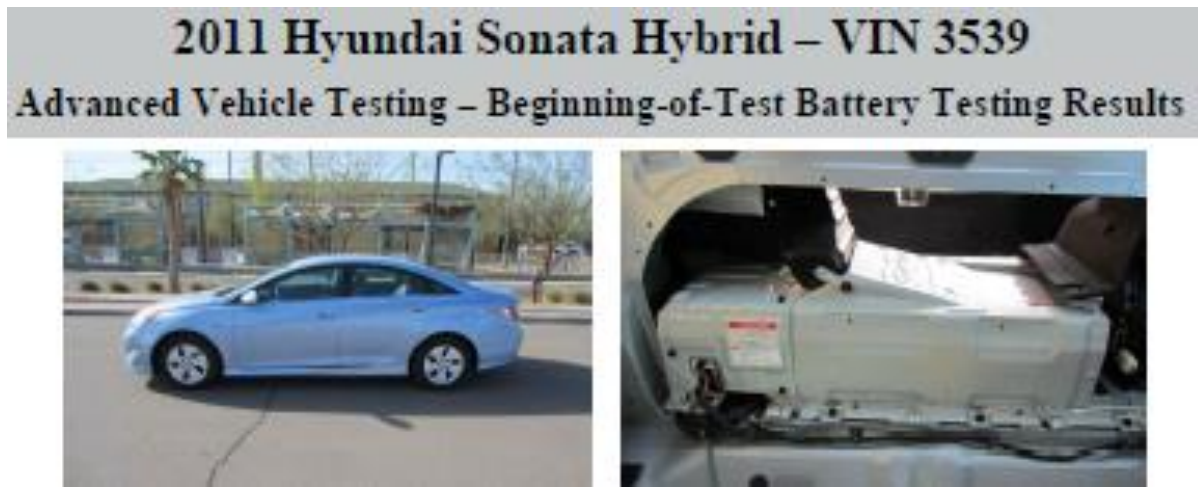

http://avt.inel.gov/pdf/hev/batterysonata4932.pdf

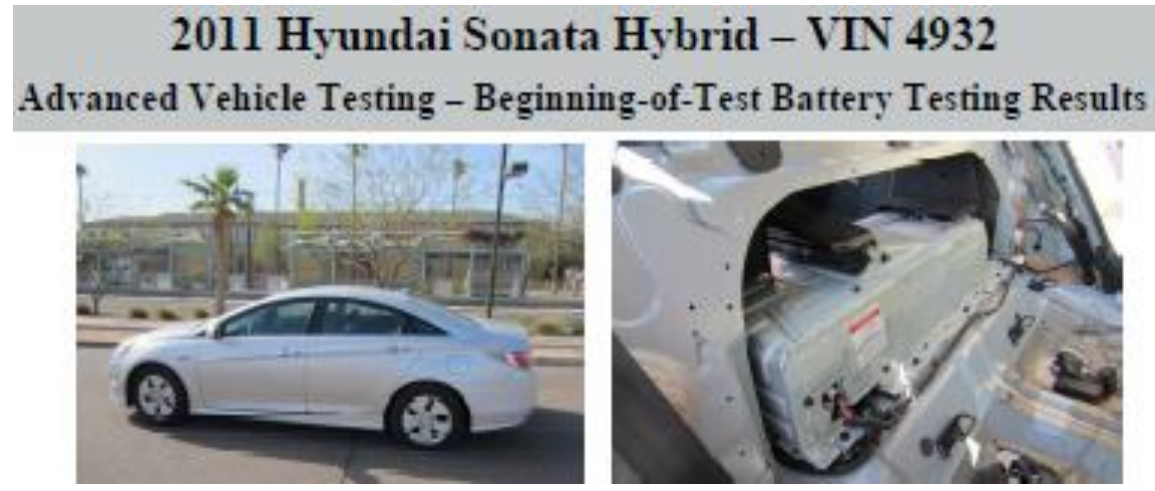


Task 2.58: (Added January 2010) Hyundai Sonata Hybrid End-of-Life Testing (2 Battery Post Test)

Conduct Battery Baseline Post Testing of two future HEVs.

Deliverable: Electronic copy of End-of-Life Battery Test Results.

Status: One vehicle experienced a drivetrain failure prior to completing $160 \mathrm{k}$ miles. The battery was removed and a end-of-life test was conducted on this vehicle. The second vehicle completed fleet testing under AVTA and has transitioned to cooperative agreement DE-EE0005501 to continue to $160 \mathrm{k}$ miles. Battery post test results will be available on the AVTA website at the conclusion of fleet testing under cooperative agreement DE-EE0005501.

Task 2.59: (Added January 2010) Nissan LEAF BEV Battery Baseline Testing

(1 Baseline w/ANL Dyno and Fast Charge and 1 Battery Pre-Test)

Conduct Baseline Performance Testing of one Nissan LEAF BEV using previously prepared EVAmerica test procedures. Dynamometer testing shall be conducted by Argonne National Laboratory. Conduct Battery Baseline Pre-Testing of one Nissan LEAF BEV.

Deliverable: Electronic copy of EVAmerica Summary Data Sheet and Battery Test Results.

Status: This task has been completed. The Test Results and Summary Data Sheet have been posted to the AVTA website.

http://avt.inel.gov/pdf/fsev/fact2011nissanleaf.pdf

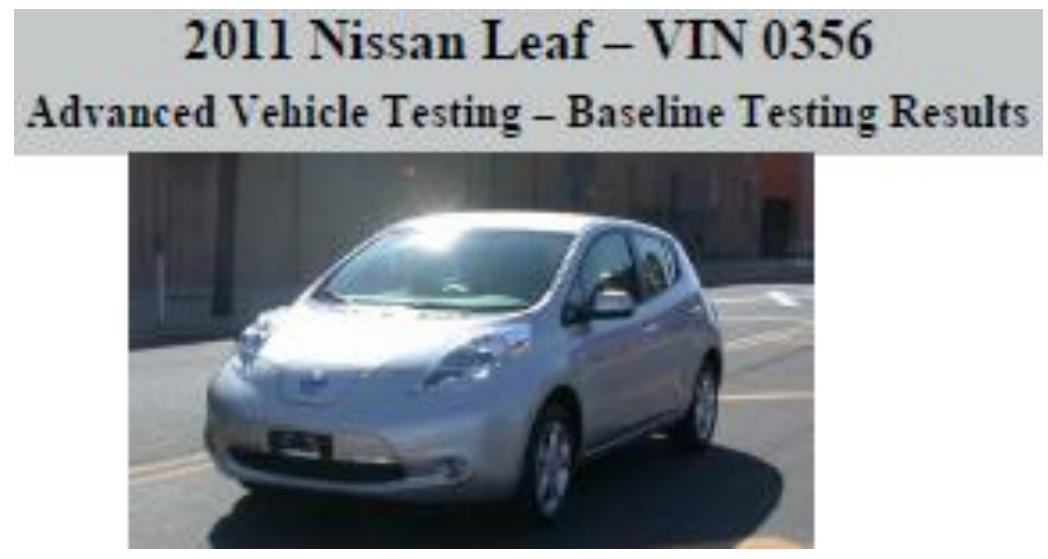

http://avt.inel.gov/pdf/fsev/batteryleaf0356.pdf

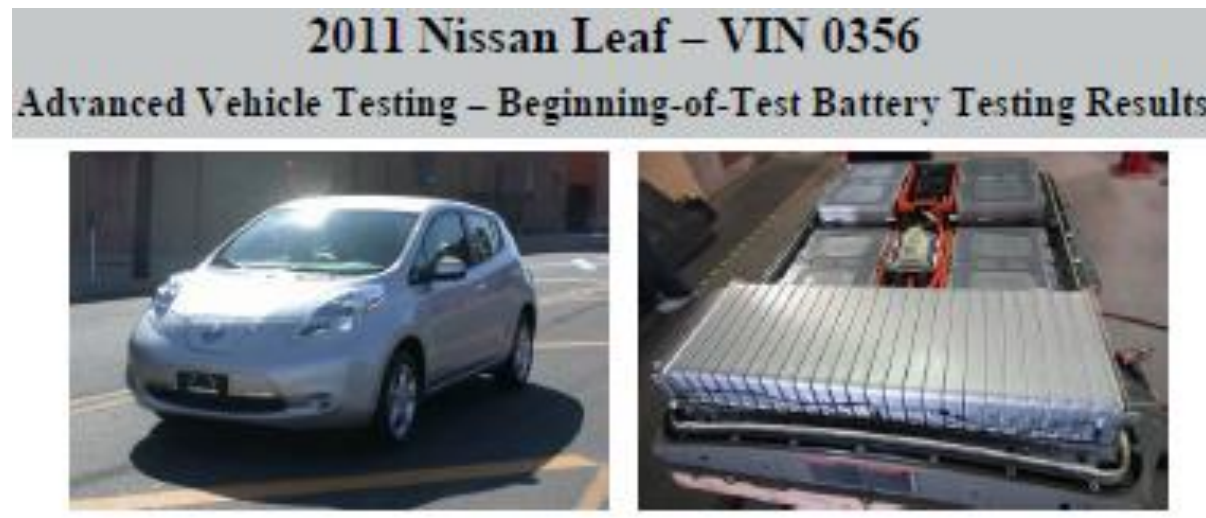


Task 2.60: (Added January 2010) Nissan LEAF BEV End-of-Life Baseline Testing (1 Battery Post Test)

Conduct Battery Baseline Post Testing of one Nissan LEAF BEV.

Deliverable: Electronic copy of Battery Test Results.

Status: The vehicle completed fleet testing under AVTA and transitioned to cooperative agreement DE-EE0005501 to continue to 60k miles. Battery post test results will be available on the AVTA website at the conclusion of fleet testing under cooperative agreement DE-EE0005501.

\section{Nissan Leaf VIN 0356 Electric Vehicle Battery Test Results}

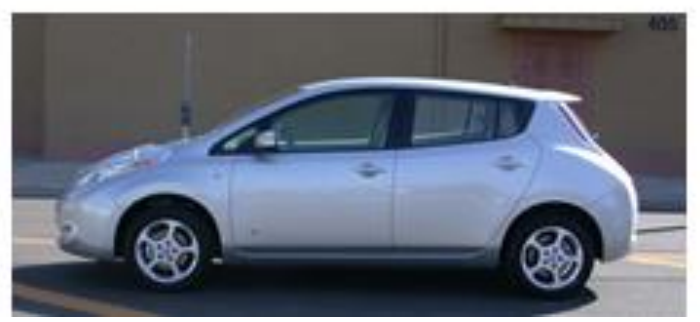

Task 2.61: (Added January 2010) BEV Battery Baseline Testing (1 Baseline w / ANL Dyno and Battery Pre-Test)

This task was cancelled due to lack of vehicle availability within project budget period.

Task 2.62: (Added January 2010) BEV End-of-Life Baseline Testing (1 Battery Post Test)

This task was cancelled due to lack of vehicle availability within project budget period.

Task 2.63: (Added January 2010) BEV Battery Baseline Testing (1 Baseline w/ANL Dyno \& Battery Pre-Test)

This task was cancelled due to lack of vehicle availability within project budget period.

Task 2.64: (Added January 2010) BEV End-of-Life Baseline Testing (1 Battery Post Test)

This task was cancelled due to lack of vehicle availability within project budget period.

Task 2.65: (Added January 2010) BEV Battery Baseline Testing (1 Baseline w/ANL Dyno and Battery Pre-Test)

This task was cancelled due to lack of vehicle availability within project budget period.

Task 2.66: (Added January 2010) BEV End-of-Life Baseline Testing (1 Battery Post Test)

This task was cancelled due to lack of vehicle availability within project budget period.

Task 2.67: (Added January 2010) BEV Battery Baseline Testing (1 Baseline w/ANL Dyno and Fast Charge and 1 Battery Pre-Test)

This task was cancelled due to lack of vehicle availability within project budget period. 
Task 2.68: (Added January 2010) BEV End-of-Life Baseline Testing (1 Battery Post Test)

This task was cancelled due to lack of vehicle availability within project budget period.

Task 2.69: (Added January 2010) BEV Battery Baseline Testing (1 Baseline w/ANL Dyno \& Battery Pre-Test)

This task was cancelled due to lack of vehicle availability within project budget period.

Task 2.70: (Added January 2010) BEV End-of-Life Baseline Testing (1 Battery Post Test)

This task was cancelled due to lack of vehicle availability within project budget period.

Task 2.71: (Added January 2010) BEV Battery Baseline Testing (ANL Dynamometer and Battery Pre-Test)

This task was cancelled due to lack of vehicle availability within project budget period.

Task 2.72: (Added January 2010) BEV End-of-Life Baseline Testing

(1 Battery Post Test)

This task was cancelled due to lack of vehicle availability within project budget period. 
Task 2.73: Honda Civic Ultra-Battery HEV Baseline Testing

(1 Baseline Test and Battery Pre-Test)

Conduct Baseline Performance Testing of one Ultra-Battery HEV using previously prepared HEVAmerica test procedures. Dynamometer testing shall be conducted by Argonne National Laboratory. Conduct Battery Baseline Pre-Testing of one future HEV.

Deliverable: Electronic copy of HEVAmerica Summary Data Sheet and Battery Test Results.

Status: This task has been completed. The Test Results and the Summay Data Sheet have been posted to the AVTA website.

http://avt.inel.gov/pdf/hev/fact2010ultrabatteryhondacivic.pdf
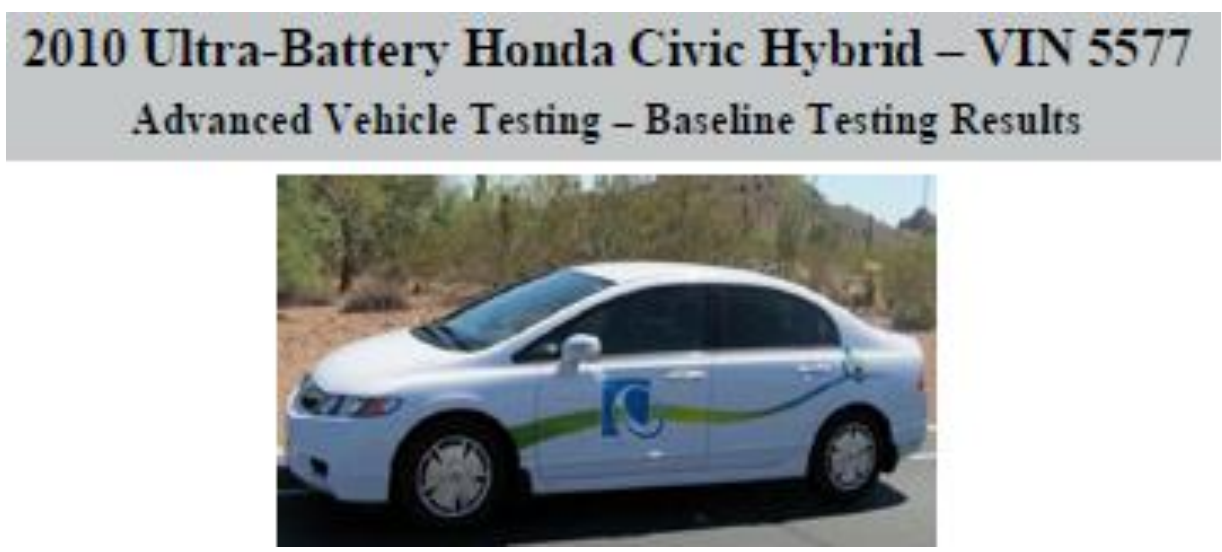

http://avt.inel.gov/pdf/hev/batterycivic5577.pdf

2010 Honda Civic Hybrid UltraBattery Conversion - VIN 5577

Advanced Vehicle Testing - Beginning-of-Test Battery Testing Results
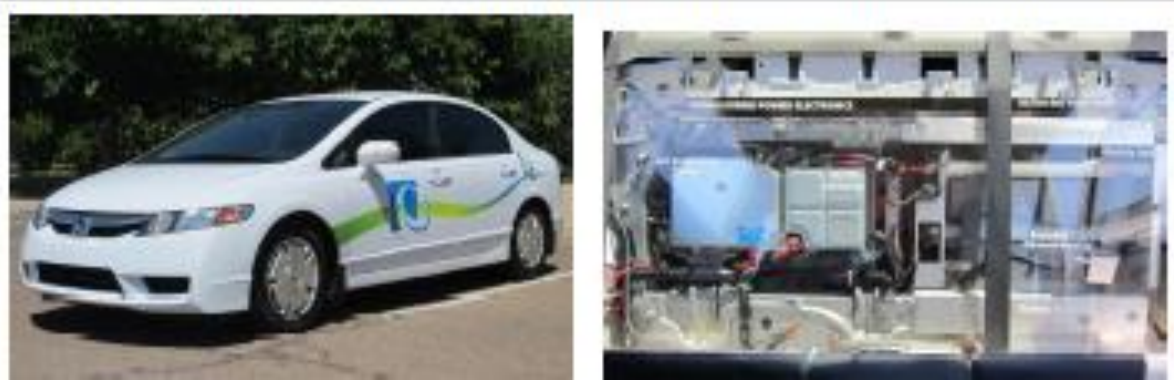
Task 2.74: Honda Civic Ultra-Battery HEV End-of-Life Baseline Testing (Battery Post Test)

Conduct Battery Baseline Post Testing of Honda Civic Ultra-Battery HEV.

Deliverable: Electronic copy of End-of-Life Battery Test Results.

Status: The vehicle completed fleet testing under AVTA and has transitioned to a separate contract to continue accumulating mileage. Battery post test results from reaching a fleet mileage of $100 \mathrm{~K}$ miles will be posted to the AVTA website.

\section{Honda Civic Hybrid UltraBattery Conversion 5577 - Hybrid Electric Vehicle Battery Test Results}

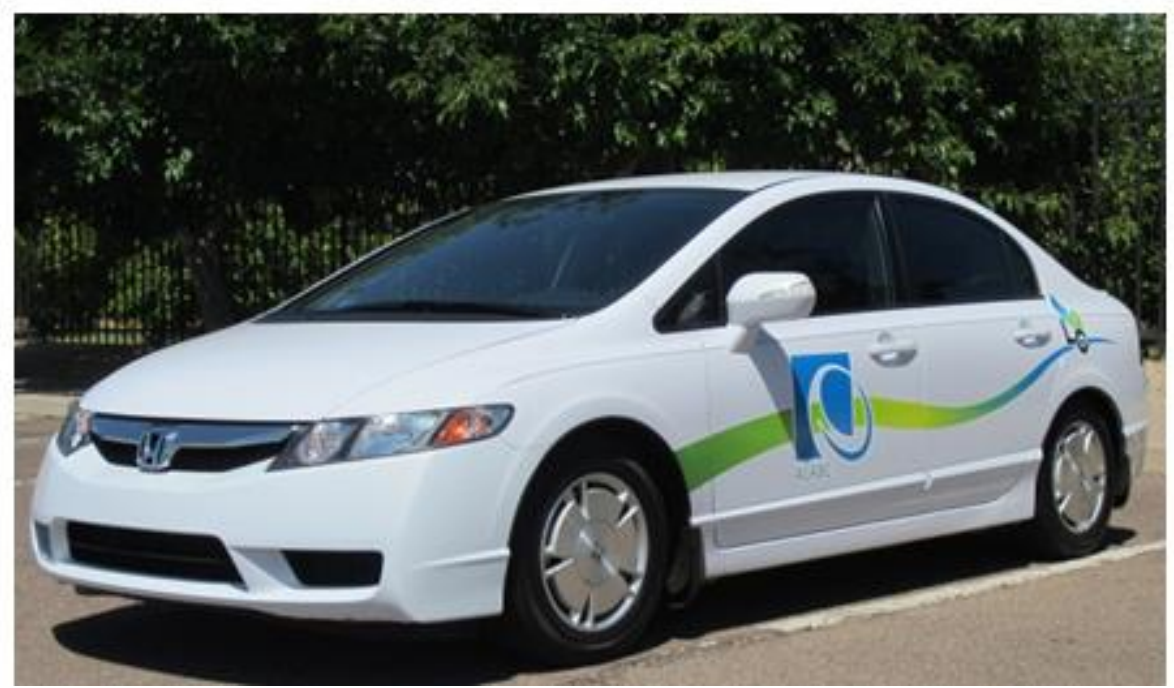


Task 2.75 (Added January 2010) Chevrolet Volt PHEV Baseline Testing (1 Baseline Test w/ANL Dyno and Battery Pre-Test)

Conduct Baseline Performance Testing of one Chevrolet Volt PHEV using test procedures developed by AVTA. Dynamometer testing shall be conducted by Argonne National Laboratory. Conduct Battery Baseline Pre-Testing of one future HEV.

Deliverable: Electronic copy of PHEVAmerica Summary Data Sheet.

Status: This task has been completed. The Test Results and Summary Data Sheets have been been posted to the AVTA website.

http://avt.inel.gov/pdf/EREV/fact2011chevroletvolt.pdf

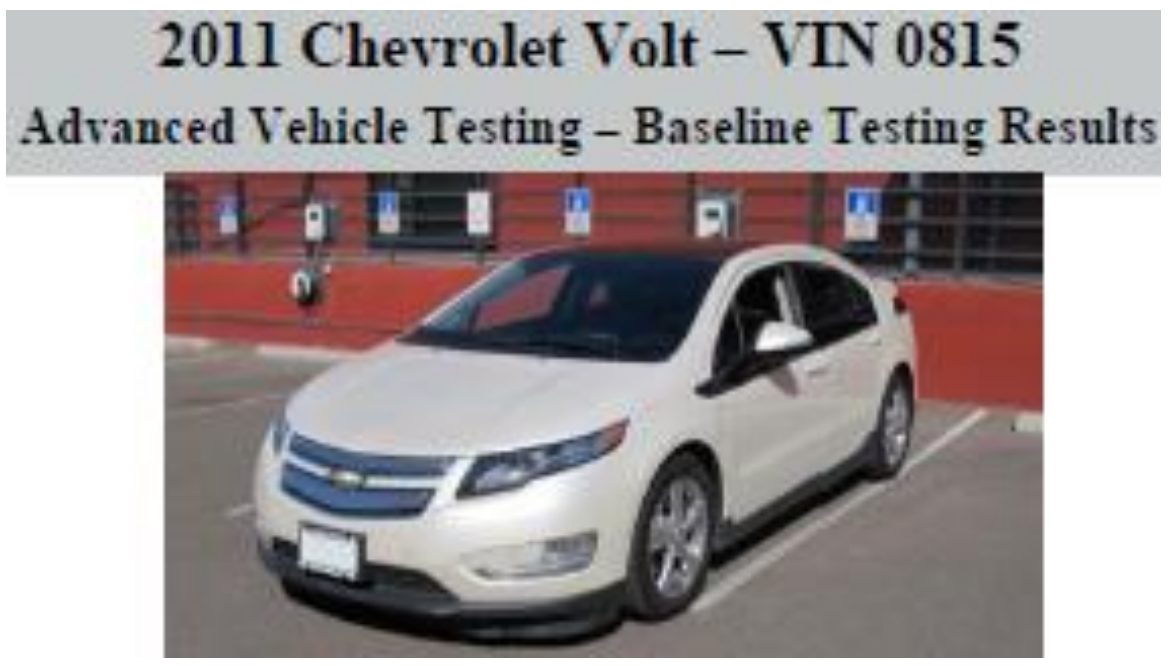

http://avt.inel.gov/pdf/EREV/batteryvolt0815.pdf
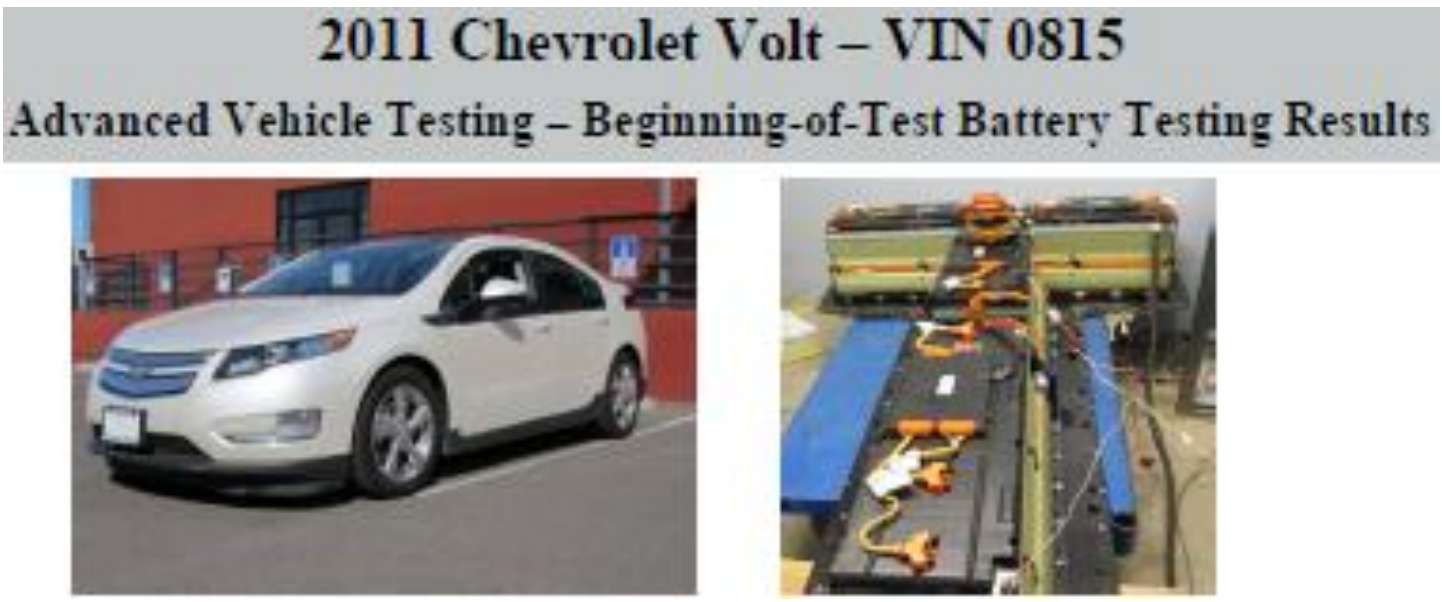
Task 2.76: (Added January 2010) Chevrolet Volt PHEV End-of-Life Testing

(1 Battery Post Test)

Conduct Battery Baseline Post Testing of one Chevrolet Volt PHEV.

Deliverable: Electronic copy of End-of-Life Battery Test Results.

Status: The vehicle has completed fleet testing under AVTA and has transitioned to cooperative agreement DE-EE0005501 to continue to $195 \mathrm{k}$ miles. Battery post test results will be available on the AVTA website at the conclusion of fleet testing under cooperative agreement DE-EE0005501.

\section{Chevrolet Volt VIN 0815 Plug-In Hybrid Electric Vehicle Battery Test Results}

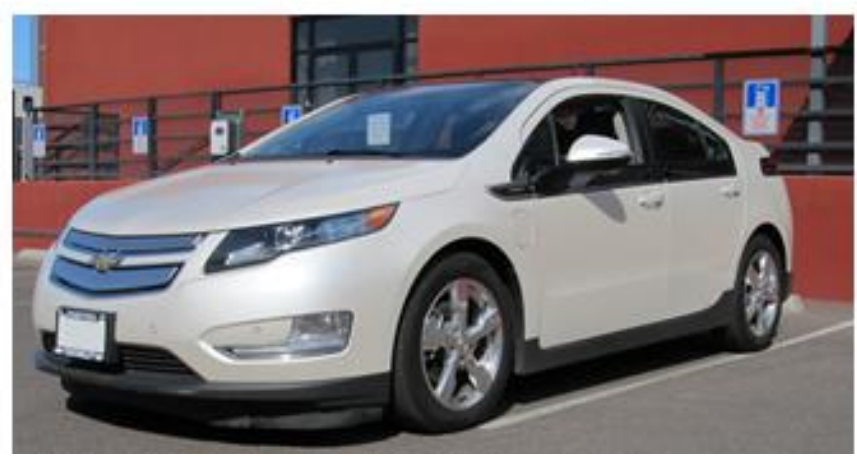

Task 2.77 (Added January 2010) PHEV Baseline Testing (1 Baseline Test w/ANL Dyno)

This task was cancelled. The vehicle was not available in time to support AVTA contract period.

Task 2.78: (Added January 2010) PHEV End-of-Life Testing (1 Battery Post Test)

This task was cancelled. The vehicle was not available in time to support AVTA contract period.

Task 2.79: (Added January 2010) HEV Baseline Testing (1 Baseline Test w/ANL Dyno \& 2 Battery Pre-Tests)

This task was cancelled. The vehicle was not available in time to support AVTA contract period.

Task 2.80: (Added January 2010) HEV End-of-Life Testing (2 Battery Post Test)

This task was cancelled. The vehicle was not available in time to support AVTA contract period. 
Task 2.81: (Added January 2010) Honda CR-Z HEV Baseline Testing (1 Baseline Test w/ANL Dynamometer and 2 Battery Pre-Tests)

Conduct Baseline Performance Testing of one Honda CR-Z HEV using test procedures developed by AVTA. Dynamometer testing shall be conducted by Argonne National Laboratory.

Deliverable: Electronic copy of HEVAmerica Summary Data Sheet.

Status: This task has been completed. The Summary Data Sheets have been posted to the AVTA website.

http://avt.inel.gov/pdf/hev/fact2011hondacrz.pdf

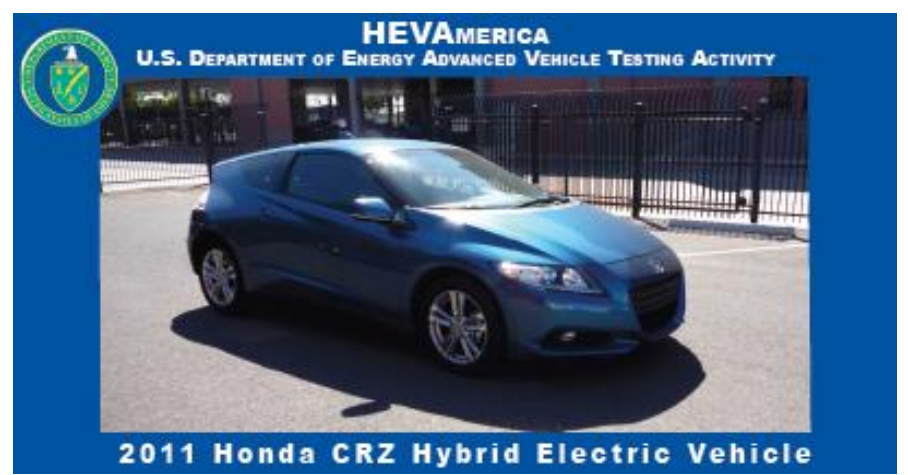

http://avt.inel.gov/pdf/hev/batterycrz2982.pdf

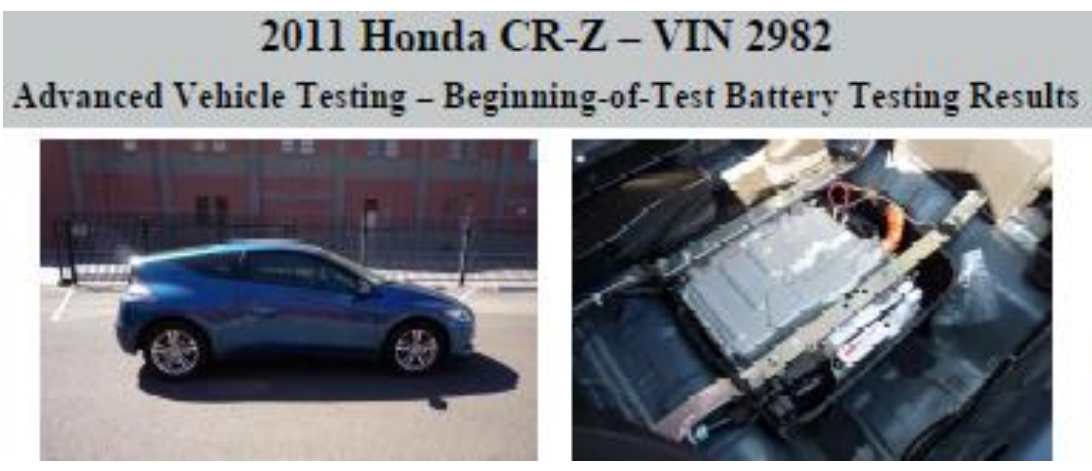

http://avt.inel.gov/pdf/hev/batterycrz4466.pdf

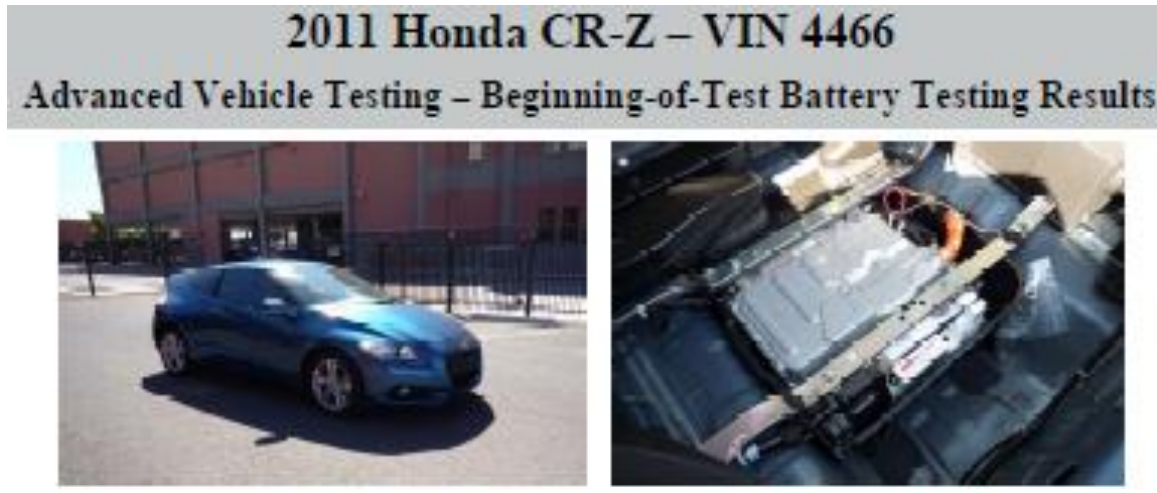


Task 2.82: (Added January 2010) Honda CR-Z HEV End-of-Life Testing

(2 Battery Post Test)

Conduct Battery Baseline Post Testing of two HEVs.

Deliverable: Electronic copy of End-of-Life Battery Test Results.

Status: The vehicles have completed fleet testing under AVTA and have transitioned to cooperative agreement DE-EE0005501 to continue to $160 \mathrm{k}$ miles. Battery post test results will be available on the AVTA website at the conclusion of fleet testing under cooperative agreement DE-EE0005501.

\section{Task 2.83: Reserved}

Task 2.84: Reserved

Task 2.85: (Added 2010) BEV Battery Baseline Testing

This task was cancelled. The vehicle was not available in time to support the AVTA contract period. 


\section{Task 3 - Accelerated Reliability Testing}

Task 3.a: HICE Ford F-150 2V Accelerated Reliability Test (6mo/6K mi)

Complete 6-month/6000 mile Accelerated Reliability testing of a Ford F-150 pick-up truck equipped with a 2-valve HICE engine (3 months and 3,000 miles completed under agreement DE-FC07-00ID13859.

Deliverable: Electronic reliability test data on a monthly basis.

Status: This task was cancelled due to the vehicle not being operational.

Task 3.b: 2 HEV Prius Accelerated Reliability (100K mi)

Complete 100,000 mile Accelerated Reliability testing of 2 Gen II Toyota Prius $(40,000$ miles/vehicle completed under agreement DE-FC07-00ID13859.

Deliverable: Electronic reliability test data on a monthly basis and Fleet Data Sheet upon test completion.

Status: This task has been completed. Further mileage is reported under task 4.23.

http://avt.inel.gov/pdf/hev/1052 04prius factsheet.pdf

http://avt.inel.gov/pdf/hev/1052 04prius maintain.pdf

http://avt.inel.gov/pdf/hev/2721ToyotaPrius04factsheet.pdf

http://avt.inel.gov/pdf/hev/2721 04prius maintain.pdf

Task 3.C: HICE F-150 4V Accelerated Reliability Testing (6 mo/6K mi)

(6mo/6K miles)

Complete 6-month/6,000 mile Accelerated Reliability testing of a Ford F-150 pick-up truck equipped with a 4-valve HICE engine completed under agreement DE-FC0700ID13859.

Deliverable: Electronic reliability test data on a monthly basis and Fleet Data Sheet upon test completion.

Status: The task has been completed. The Summary Data Sheet has been posted to the AVTA website.

http://avt.inel.gov/pdf/hydrogen/FactSheetFord32VHydrogenICE.pdf

Task 3.01: (Added in A014) Grid-Connected Vehicle Data Collection and Charging Hardware

Fabricate and provide Level II charger "wall boxes" to support fleet data collection by the Idaho National Laboratory.

Deliverable: Level II fleet vehicle EVSE units.

Status: All fleet locations have been identified for equipment installation. 


\section{Task 3.02: (Added in A014) Smart Grid Communication Interface}

Develop, test and validate communication protocol interfacing grid-connected vehicle chargers with the smart grid. Coordinate this protocol with the SAE and DOE to codify the protocol in an SAE standard.

Deliverable: Draft SAE standard defining smart grid communication protocol, a prototype charger "wall box" incorporating smart grid communications and test reports validating communication protocol electromagnetic compatibility and sub-metering accuracy.

Status: SAE has not determined protocols for Smart Grid interaction. Clarity Group, Inc. produced an EVSE that can interface to a utility and accept demand response commands (on/off) via a connection to the Clarity Group, Inc. back office systems in preparation for future Smart Grid capability.

\section{Task 3.03: Monitor H2 Station Performance}

Monitor Arizona Public Services Hydrogen Fueling Station operation using the monitoring system installed under cooperative agreement. Prepare reports on a semi-annual basis.

Deliverable: Ten (10) semi-annual reports in electronic format.

Status: This task has been completed. Work on this task ended in 2008.

\section{Task 3.04: PHEV Accelerated Reliability Testing (4 NYSERDA vehicles)} $(6 \mathrm{mo} / 4,200 \mathrm{mi})$

Complete 4,200 miles Accelerated Reliability Testing of four (4) PHEV NYSERDA vehicles (to be on loan for duration of testing).

Deliverable: Electronic reliability test data on a monthly basis and Fleet Data Sheet upon test completion.

Status: This task was cancelled.

Task 3.05: HICE Fleet Testing (8 Integrated Waste Hydrogen Utilization Project Vehicles $24 \mathrm{mo} / 24 \mathrm{~K} \mathrm{mi}$ )

\section{Complete 24 month/24,000 mile Accelerated Reliability testing of 8 HICE} vehicles in one or more fleets.

Deliverable: Electronic reliability test data on a monthly basis and Fleet Data Sheet upon test completion.

Status: Mileage has been completed for the current program. The Summary Data Sheet has been posted to the AVTA website.

\section{http://avt.inl.gov/pdf/hydrogen/FactSheetChevy1500HDHydrogenICE.pdf}

\section{Task 3.06: Energy CS Prius Accelerated Reliability Testing (4,200 miles)}

Conduct Accelerated Reliability testing of a plug-in gasoline hybrid electric vehicle to 4,200 miles using dedicated drivers.

Deliverable: Electronic reliability test data on a monthly basis and Fleet Data Sheet upon test completion.

Status: This task has been completed. All 4,200 miles of tests have been completed. 
Task 3.07: Future HICE Fleet Testing (3 Vehicles $16 \mathrm{mo} / 8 \mathrm{~K} \mathrm{mi}$ )

Complete 12-month/8,000 mile Accelerated Reliability testing of three HICE vehicles in one or more fleets.

Deliverable: Electronic reliability test data on a monthly basis and Fleet Data Sheet upon test completion.

Status: This task has been completed. The Summary Data Sheet has been posted to the AVTA website.

\section{http://avt.inl.gov/pdf/hydrogen/FactSheetChevy1500HDHydrogenICE.pdf}

Task 3.08: (Added in A003) Kangoo HEV Accelerated Reliability Testing (4,200 miles)

Accelerated Reliability testing of a plug-in gasoline hybrid electric vehicle to 4,200 miles using dedicated drivers.

Deliverable: Electronic reliability test data on a monthly basis and Fleet Data Sheet upon test completion.

Status: This task has been completed. Results are presented in Table 2, below.

Table 2 - Kangoo HEV Accelerated Reliability Testing Results

\begin{tabular}{|c|c|c|c|c|c|}
\hline $\begin{array}{c}\text { Cycle } \\
\text { (mi) }\end{array}$ & $\begin{array}{c}\text { Urban } \\
(\mathbf{1 0} \\
\mathbf{m i}\end{array}$ & $\begin{array}{c}\text { Highway } \mathbf{( 1 0} \\
\mathbf{m i})\end{array}$ & $\begin{array}{c}\text { Charge } \\
\text { (hr) }\end{array}$ & Repetitions (N) & $\begin{array}{c}\text { Status } \\
\text { Kangoo }\end{array}$ \\
\hline 10 & 1 & 0 & 4 & 60 & Complete 5/18/07 \\
\hline 20 & 1 & 1 & 8 & 30 & Complete 11/13/07 \\
\hline 40 & 4 & 0 & 12 & 5 & Complete 12/3/07 \\
\hline 40 & 2 & 2 & 12 & 5 & Complete 12/11/07 \\
\hline 40 & 0 & 4 & 12 & 5 & Complete 12/19/07 \\
\hline 60 & 2 & 4 & 12 & 10 & Complete 1/25/08 \\
\hline 80 & 2 & 6 & 12 & 8 & Complete 3/14/08 \\
\hline
\end{tabular}


Task 3.09: (Added per A003) Gen 1 HyMotion Prius PHEV Accelerated Reliability Testing

Accelerated Reliability testing of a plug-in gasoline hybrid electric vehicle to 4,200 miles of testing using dedicated drivers at billed rate of $\$ 40 / \mathrm{hr}$.

Deliverable: Electronic reliability test data on a monthly basis and Fleet Data Sheet upon test completion.

Status: This task has been complete. Results are presented in Table 3, below.

Table 3 - Gen 1 HyMotion Prius PHEV Accelerated Reliability Testing Results

\begin{tabular}{|c|c|c|c|c|c|c|c|c|c|c|c|c|}
\hline Cycle (mi) & $\begin{array}{c}\text { Urban (10 } \\
\text { mi) }\end{array}$ & $\begin{array}{c}\text { Highway } \\
(10 \mathrm{mi})\end{array}$ & Charge $(\mathrm{Hr})$ & $\begin{array}{c}\text { Repetitions } \\
\text { (N) }\end{array}$ & Total (mi) & $\begin{array}{c}\text { Repetitions } \\
(\%)\end{array}$ & Miles (\%) & $\underset{(\mathrm{mi})}{\text { Cumulative }}$ & $\begin{array}{l}\text { Electricity } \\
\text { (kwh) }\end{array}$ & Gasoline & $\begin{array}{c}\text { MPG } \\
\text { Summary }\end{array}$ & Status \\
\hline 10 & 1 & 0 & 4 & 60 & 600 & $37 \%$ & $11 \%$ & 600 & 136.33 & 4.814 & 127.2 & Complete 4/21/08 \\
\hline 20 & 1 & 1 & 8 & 30 & 600 & $19 \%$ & $11 \%$ & 1200 & 122.09 & 5.371 & 115.9 & Complete 9/20/2007 \\
\hline 40 & 4 & 0 & 12 & 5 & 200 & $3 \%$ & $4 \%$ & 1400 & 29.84 & 1.870 & 108.9 & Complete 9/28/07 \\
\hline 40 & 4 & 0 & 12 & 10 & 400 & $6 \%$ & $7 \%$ & 1800 & 54.26 & 4.180 & 97.6 & Complete 5-6-08 \\
\hline 40 & 2 & 2 & 12 & 15 & 600 & $9 \%$ & $11 \%$ & 2400 & 87.22 & 5.784 & 106.8 & Complete $12 / 10 / 07$ \\
\hline 40 & 0 & 4 & 12 & 15 & 600 & $9 \%$ & $11 \%$ & 3000 & 79.82 & 8.540 & 73.1 & Complete 1/10/08 \\
\hline 60 & 2 & 4 & 12 & 10 & 600 & $6 \%$ & $11 \%$ & 3600 & 55.33 & 8.984 & 68.9 & Complete $3 / 6 / 08$ \\
\hline 80 & 2 & 6 & 12 & 8 & 640 & $5 \%$ & $12 \%$ & 4240 & 43.99 & 11.355 & 58.3 & Complete 2/13/08 \\
\hline 100 & 2 & 8 & 12 & 6 & 600 & $4 \%$ & $11 \%$ & 4840 & 34.98 & 8.428 & 73.2 & Complete $8 / 2 / 07$ \\
\hline 200 & 2 & 18 & 12 & 3 & 600 & $2 \%$ & $11 \%$ & 5440 & 15.00 & 11.017 & 54.8 & Complete $1 / 24 / 08$ \\
\hline "Total & 20 & 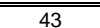 & (108 & 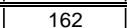 & 5440 & & & 5440 & & & & \\
\hline
\end{tabular}

Task 3.10: RESERVED

Task 3.11: BEV Accelerated Reliability Testing (1 Vehicle 12 months / 12,000 miles)

Complete 12-month/ 12,000 mile Fleet testing of one (1) BEV.

Deliverable: Electronic reliability test data on a monthly basis and Fleet Data Sheet upon test completion.

Status: This task was cancelled. The vehicle was not available in time to support AVTA contract period.

Task 3.12: (Added in A014) Mini E Accelerated Reliability Testing (1 Vehicle 12 months / 12,000 miles)

Complete 12-month/ 12,000 mile Fleet testing of one (1) BEV.

Deliverable: Electronic reliability test data on a monthly basis and Fleet Data Sheet upon test completion.

Status: Accelerated testing began, but the vehicle was removed from service by the dealer. Further testing was cancelled. Refer to Table 4, below.

Table 4 - Mini E Accelerated Reliability Testing Results

\begin{tabular}{|c|c|c|c|c|c|c|c|c|c|}
\hline \multicolumn{2}{|c|}{ BEV Drive Schedule } & \multicolumn{3}{|c|}{ Vehicle: Mini E - VIN\# 5670} & \multicolumn{4}{|c|}{ Charge \#: CO02678 } & \multirow{3}{*}{$\frac{\text { A83.12 }}{\text { MPGe }^{*}}$} \\
\hline \begin{tabular}{|l} 
Test Date \\
\end{tabular} & Cycle & Urban & Highway & Repetitions & Total & Actual & Total & $\mathrm{KWh}$ & \\
\hline (Start/End) & (Mi.) & (10 Mi.) & (10Mi.) & $(\mathrm{N})$ & (Mi.) & (Mi.) & (KWh) & (per mile) & \\
\hline $11 / 3 / 09-11 / 10 / 09$ & 10 & 1 & 0 & 10 & 100 & 100.2 & 40 & 0.399202 & 84.43103 \\
\hline $11 / 12 / 09-11 / 17 / 09$ & 10 & 0 & 1 & 10 & 100 & 103.0 & 38 & 0.368932 & 91.35829 \\
\hline $11 / 18 / 09-11 / 24 / 09$ & 20 & 1 & 1 & 10 & 200 & 203.1 & 72 & 0.354505 & 95.07619 \\
\hline 11/25/09-12/11/09 & 40 & 2 & 2 & 10 & 400 & 448.4 & 155 & 0.345674 & 97.5053 \\
\hline $12 / 14 / 09-12 / 29 / 09$ & 40 & 4 & 0 & 10 & 400 & 402.3 & 134 & 0.333085 & 101.1905 \\
\hline & 40 & 0 & 4 & 10 & 400 & & & & \\
\hline & 60 & 2 & 4 & 10 & 600 & & & & \\
\hline & 80 & 2 & 6 & 10 & 800 & & & & \\
\hline & Total & 1200 & 1800 & 80 & 3000 & & & & \\
\hline & Average & $40 \%$ & $60 \%$ & & & & & & \\
\hline
\end{tabular}


Task 3.13: (Added January 2010) Smart mhd fortwo Idle-Stop Technology Fuel Economy Study

Complete field and dynamometer evaluation of the fuel economy benefit of idle-stop technology, including creation of dynamometer drive cycle tests and field experience.

Deliverable: Draft and final reports presenting findings of the dynamometer and field testing of idle-stop technology.

Status: This task has been completed. The fuel economy study final report has been posted to the AVTA website.

http://avt.inel.gov/pdf/mhv/Idle-StopLightDutyPassengerVehicles.pdf

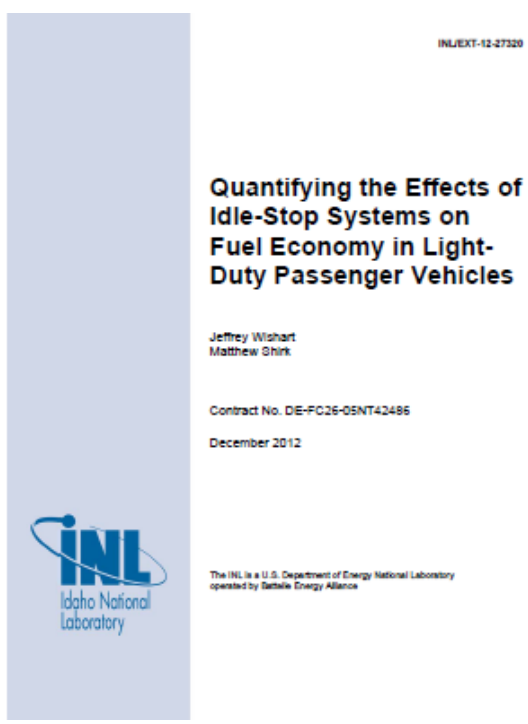




\section{Task 3.14: (Added January 2010) Test Procedure Development for Fast Chargers Utilizing Energy Storage}

Fast chargers for on-road EVs will soon appear that utilize energy storage. No procedural methods currently exist to evaluate the performance of these chargers as used with onroad EVs. This task will conduct modeling of a fast charger utilizing energy storage and will conduct cycling of batteries to develop procedures for evaluation of energy storage devices associated with on-road EV fast chargers. A typical on-road EV fast charger will be modeled to establish performance targets for capacity, voltage range, maximum power output, cost, and availability, based on system loads up to $100 \%$ of the total fast charging load. Based on this modeling, a battery test cycle will be developed for testing batteries in the laboratory, simulating likely daily use. Excess time when the battery is not operating during the cycle will be eliminated to accelerate the actual time needed to perform life cycle testing on the battery. The cycle will be derived based on maximum power and energy values a complete battery pack will need to support fast charging. The laboratory test cycle will then be trialed using three different battery chemistries. A string of three battery cells from each chemistry will be cycled for a period of three months to validate the test cycle. This testing will yield information on how each battery's chemistry reacts on the proposed test cycle and the ability of the test cycle to quantify battery performance in on-road EV fast charger energy storage duty.

Deliverable: On-Road EV Battery Fast Charger Energy Storage Device Test Procedure, including a Laboratory Test Cycle and a report describing the validation of such procedure.

Status: This task has been completed. The Test Procedures and validation report have been posted to the AVTA website.

\section{http://avt.inel.gov/pdf/energystorage/EnergyStorageForDCFC.pdf}

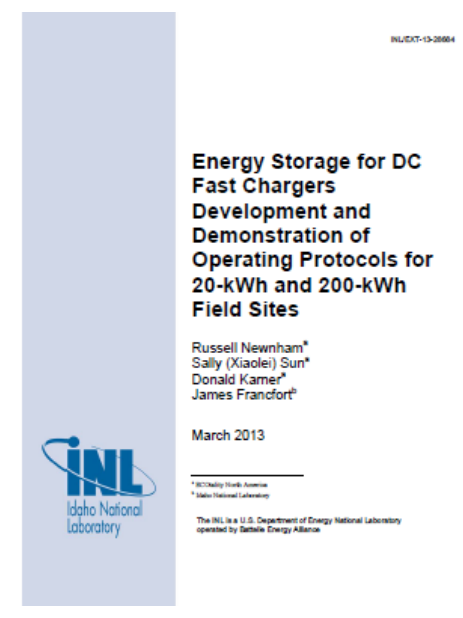




\section{Task 3.15: (Added January 2010) DCFC Battery Test Procedure Development}

In consultation with INL battery test team, evaluate various alternative test procedures for evaluating on-road vehicle batteries under DCFC charging conditions. Conduct laboratory testing, as required.

Deliverable: Draft and final reports summarizing testing conducted in support of Level 3 battery test procedures.

Status: This task has been completed. The test specification (procedure) for on-road vehicle battery testing with DCFC has been submitted to INL for review and will be finalized once a vehicle is tested under cooperative agreement DE-EE0005501.

\section{Task 3.16: (Added January 2010) Support SAE Level 3 Communication Standard} Development

Attend and support national meetings associated with Level 3 charge port standard development, and performing programmable logic controller testing.

Deliverable: Draft SAE standard defining Level 3 communication protocol and connector.

Status: Clarity Group, Inc. participated and continues to participate in the SAE committee. It appears that the committee has elected to invent a new physical and digital interface rather than accept the CHAdeMO protocol. Clarity Group, Inc. implemented the CHAdeMO protocol for use with the DC fast charger. 


\section{Task 3.17: (added January 2010) Advanced Material Handling Electrification Evaluation}

Advanced batteries will soon be available for use in electric ground support equipment (eGSE). Additionally, smart charging is currently available to improve the interface between eGSE and the electric grid supplying charge energy. Adoption and use of eGSE is currently limited by issues with adequate battery capacity in cold weather operations, short battery life in high-temperature climates, capacity challenges when operating in a partial state of charge operation (PSOC), the cost of electricity, and impacts to the local electrical grid with high charger power demands. Advanced batteries are capable of resolving the problems of battery capacity. These batteries, coupled with smart charging concepts adapted from current state-of-the-art on-road charge infrastructure, have the potential to solve each issue identified and significantly enhance the adoption of eGSE. This task will test the performance of eGSE using advanced lead-carbon and lithium batteries in conjunction with smart charging in diverse climatic regions, with particular attention to this configuration's ability to resolve barriers to eGSE deployment. Results of this testing will be made available to the industry in a report and in a presentation at a major industry conference.

Under this task, two battery chemistries will be evaluated, lead-carbon batteries developed by East Penn Manufacturing and lithium-based batteries from a supplier currently funded by a DOE battery manufacturing contract. Electric bag tractors operating with these batteries will be instrumented to allow evaluation of vehicle performance. Chargers supplying energy to these vehicles will be updated with Internet communications and data transmittal capability to allow real-time monitoring of status and power consumption. Data will be collected from the vehicles and from the charge stations to monitor the performance of the advanced batteries in the varying climates and operations. Strategies to utilize the communications and control-enabled charge infrastructure to maintain battery state-of-charge while avoiding any impacts to the electrical grid and minimizing electricity costs will be evaluated.

\section{Deliverables:}

1. Two electric baggage tractors converted to utilize East Penn Manufacturing leadcarbon battery. Tractors shall conform to specifications issued by the AVTA.

2. Two electric baggage tractors converted to utilize a lithium-based battery. Tractors shall conform to specifications issued by the AVTA.

3. Four $15 \mathrm{~kW}$ chargers (or two $30 \mathrm{~kW}$ dual port chargers) using a power manager to facilitate installation and with Internet conductivity and data collection capability, installed at an operational airport and ready to support charging of tractors converted in Tasks 1 and 2.

4. Data from operational batteries and chargers reported informally on a monthly basis and six months of operational data reported in a formal report suitable for publication.

Status: Four baggage tractors consisting of two lead-acid and two lithium-ion battery packs have completed their six month demonstration period at an operational airport. A report was reviewed by INL and posted to the AVTA website.

http://avt.inel.gov/pdf/airport/in/-ext-13-29680 ro eGSE.pdf 


\section{Task 3.18: Conduct USPS Factory Tests ( 5 vehicles)}

Conduct factory testing (inspection and measurement) of five United States Postal Service (USPS) prototype electric vehicles using test procedures developed from USPS vehicle specifications.

Deliverable: Test reports for each vehicle consistent with AVTA report format.

Status: This task has been completed. Test results were sent to INL for delivery to USPS.

\section{Task 3.19: Develop USPS Baseline Test Procedures}

Develop Baseline Test procedures (dynamic testing) for USPS prototype electric vehicles using USPS vehicle specifications.

Deliverable: Baseline Test procedures consistent with AVTA test format.

Status: This task has been completed. Test procedures have been developed and approved by INL.

\section{Task 3.20: Conduct USPS Baseline Testing (5 vehicles)}

Conduct Baseline Testing of five USPS prototype electric vehicles.

Deliverable: Baseline Test reports consistent with AVTA report format.

Status: This task has been completed. All data has been delivered to INL.

\section{Task 3.21: Develop USPS Accelerated Reliability Test Procedures}

Develop Accelerated Reliability Test procedures for field testing of USPS prototype electric vehicles.

Deliverable: Accelerated reliability Test procedures consistent with AVTA test format.

Status: Accelerated reliability test procedures were conducted via field evaluation by USPS. All test procedures have been delivered to INL.

\section{Task 3.22: Conduct USPS Accelerated Reliability Testing ( 5 vehicles)}

Conduct Accelerated Reliability Testing of five USPS prototype electric vehicles.

Deliverable: Accelerated Reliability Test reports consistent with AVTA report format.

Status: This task was cancelled. Testing is to be completed by USPS.

\section{Task 3.23: (Added January 2011) PEV Fleet Testing}

Place one battery electric vehicle and one extended range electric vehicle with associated wall mounted EVSE charger in fleet service at DOE headquarters. Monitor vehicle usage in this fleet environment for six months and evaluate any issues that arise with their use in this fleet mission.

Deliverable: Electronic copy of charger and vehicle data sent to INL and final report on vehicle use.

Status: One Chevrolet Volt and one Nissan LEAF were returned from DOE headquarters and placed into fleet testing at Clarity Group, Inc. in Phoenix, AZ. The Chevrolet Volt and Nissan Leaf have completed fleet testing under AVTA and have transitioned to cooperative agreement DE-EE0005501. The Chevrolet Volt will continue to $195 \mathrm{~K}$ miles, while the Nissan LEAF will continue to $60 \mathrm{~K}$ miles under cooperative agreement DE-

EE0005501. See Table 1 for the final status under AVTA. 


\section{Task 4 - Fleet Testing}

Task 4.a: Fleet Test 8 HCNG Vehicles

Collect fleet data (mileage and fuel-related repair costs) for at least eight vehicles operated over a total of 40,000 miles utilizing a blended fuel of $15 \%$ hydrogen in compressed natural gas (initiated under agreement DE-FC07-00ID13859).

Deliverable: Electronic reliability test data on a monthly basis and Fleet Data Sheet upon test completion.

Status: This task has been completed. The report has been posted to the AVTA website. http://avt.inel.gov/pdf/hydrogen/2006 h2 summary report.pdf

Task 4.b: Extended HEV Fleet Testing (2-Silverado, 2-Escape \& 2 Lexus 400h) Complete fleet testing of 2 Silverado trucks to 72,000 miles, 2 Ford Escape SUVs to 100,000 miles (will now be reported under Task 4.03) and 2 Lexus 400h SUVs to 100,000 miles (initiated under agreement DE-FC07-00ID13859).

Deliverable: Electronic reliability test data on a monthly basis and Fleet Data Sheet upon test completion.

Status: This task has been complete. The data has been posted to the AVTA website.

Silverado: http://avt.inel.gov/pdf/hev/04chevroletsilverado ar.pdf

Escape: http://avt.inel.gov/pdf/hev/fordescape ar.pdf

Lexus: http://avt.inel.gov/pdf/hev/fact sheet4807.pdf

Task 4.c: 2 Accord Fleet Testing (100K mi)

Complete fleet testing of 2 Honda Accord sedans to 100,000 miles (initiated under agreement DE-FC07-00ID13859).

Deliverable: Electronic reliability test data on a monthly basis and Fleet Data Sheet upon test completion.

Status: This task has been completed. The data has been posted to the AVTA website. Further accumulated miles is reported under Task 4.5.

http://avt.inel.gov/pdf/hev/hondaaccord ar.pdf

http://avt.inel.gov/pdf/hev/fact sheet0657.pdf

http://avt.inel.gov/pdf/hev/ms 065705 Honda Accord.pdf

http://avt.inel.gov/pdf/hev/fact sheet1096.pdf

http://avt.inel.gov/pdf/hev/ms 109605 Honda Accord.pdf 
Task 4.d: Roush HICE Silverado Fleet Testing (12 mo/12K mi)

Complete 12-month/12,000 mile Fleet testing of a Chevrolet Silverado pick-up truck equipped with an HICE engine (initiated under agreement DE-FC07-00ID13859).

Deliverable: Electronic reliability test data on a monthly basis and Fleet Data Sheet upon test completion.

Status: This task has been complete. The Summary Data Sheet has been posted to the AVTA website.

http://avt.inel.gov/pdf/hydrogen/FactSheetChevy1500HDHydrogenICE.pdf

Task 4.e: NEV Roush Electric Vehicle Fleet Testing (6K mi)

Complete 6-month/6,000 mile Fleet testing of an NEV Roush Electric Vehicle (initiated under agreement DE-FC07-00ID13859).

Deliverable: Electronic reliability test data on a monthly basis and Fleet Data Sheet upon test completion.

Status: This task has been completed. The battery test results after 6,000 miles have been posted to the AVTA website.

http://avt.inel.gov/pdf/nev/batteryroushrev1505.pdf

Task 4.f: GSE Life Cycle Cost Study

Develop a life cycle cost estimate for electric bag tractors operating in ground support duty (initiated under agreement DE-FC07-00ID13859). Benchmark this estimate using data from at least two airports. Summarize results in a report for distribution via the INL website.

Deliverable: Electronic copy of GSE Life Cycle Cost Report and Modeling software program.

Status: This task has been completed. A cost estimating model has been completed and posted to the AVTA website.

http://avt.inel.gov/pdf/airport/GSECostBenefitHigh.pdf

http://avt.inel.gov/pdf/airport/GSEModel111.zip

Task 4.01: HEV Highlander Fleet Testing (2 New Vehicles 36mo/160K mi)

Complete 36-month/160,000 mile Fleet testing of 2 Toyota Highlander HEVs.

Deliverable: Electronic reliability test data on a monthly basis and Fleet Data Sheet upon test completion.

Status: This task has been completed. The Fleet Data Sheets have been posted to the AVTA website.

http://avt.inel.gov/pdf/hev/fact sheet5681.pdf

http://avt.inel.gov/pdf/hev/ms toyota highlander 5681.pdf

http://avt.inel.gov/pdf/hev/fact sheet6395.pdf

http://avt.inel.gov/pdf/hev/ms toyota highlander 6395.pdf 
Task 4.02: Extend 2 HEV Silverado Fleet Test (72K mi to $160 \mathrm{~K} \mathrm{mi}$ )

Extend Fleet testing of 2 Silverado HEVs from 72,000 to 160,000 miles.

Deliverable: Electronic reliability test data on a monthly basis and Fleet Data Sheet upon test completion. See Task $4 \mathrm{~b}$ for posted data sheets to $100 \mathrm{k}$ miles.

Status: This task has been completed. The Fleet Data Sheets have been posted to the AVTA website.

http://avt.inel.gov/pdf/hev/9284 2wd silverado factsheet.pdf

http://avt.inel.gov/pdf/hev/9664silverado factsheet.pdf

http://avt.inel.gov/pdf/hev/ms $928404 \quad 2 W D$ Silverado.pdf

http://avt.inel.gov/pdf/hev/ms 966404 4WD Silverado.pdf

Task 4.03: Extend 2 HEV Escape Fleet Test (100K $\mathrm{mi}$ to $160 \mathrm{~K} \mathrm{mi}$ )

Extend Fleet testing of 2 Ford Escape HEVs from 100,000 to 160,000 miles.

Deliverable: Electronic reliability test data on a monthly basis and Fleet Data Sheet upon test completion. See Task 4b for posted data sheets to $100 \mathrm{k}$ miles.

Status: This task has been completed. The Fleet Data Sheets have been posted to the AVTA website.

http://avt.inel.gov/pdf/hev/fact sheet5881.pdf

http://avt.inel.gov/pdf/hev/ms 588105 Escape 2WD.pdf

http://avt.inel.gov/pdf/hev/fact sheet8237.pdf

http://avt.inel.gov/pdf/hev/ms 823705 Escape 4WD.pdf

Task 4.04: Extend 2 Lexus 400h Fleet Test (100K mi to $160 \mathrm{~K} \mathrm{mi}$ )

Extend Fleet testing of 2 Lexus 400h HEVs from 100,000 to 160,000 miles.

Deliverable: Electronic reliability test data on a monthly basis and Fleet Data Sheet upon test completion. See Task 4b for posted data sheets to $100 \mathrm{k}$ miles.

Status: This task has been completed. The Fleet Data Sheets have been posted to the AVTA website.

http://avt.inel.gov/pdf/hev/4807LexusRX400h06factsheet.pdf

http://avt.inel.gov/pdf/hev/ms lexus 4807.pdf

http://avt.inel.gov/pdf/hev/2575LexusRX400h06factsheet.pdf

http://avt.inel.gov/pdf/hev/ms lexus 2575.pdf 
Task 4.05: Extend 2 HEV Accord Fleet Test (100K mi to $160 \mathrm{~K} \mathrm{mi}$ )

Extend Fleet testing of 2 Honda Accord HEVs from 100,000 to 160,000 miles.

Deliverable: Electronic reliability test data on a monthly basis and Fleet Data Sheet upon test completion. See Task 4c for posted data sheets to $100 \mathrm{k}$ miles.

Status: This task has been completed. The Fleet Data Sheets have been posted to the AVTA website.

http://avt.inel.gov/pdf/hev/fact sheet0657.pdf

http://avt.inel.gov/pdf/hev/ms 065705 Honda Accord.pdf

http://avt.inel.gov/pdf/hev/fact sheet1096.pdf

http://avt.inel.gov/pdf/hev/ms 109605 Honda Accord.pdf

Task 4.06: Monitor HICE National Fleet Status

Monitor deployment of HICE vehicles in United States fleets. Develop and maintain a database containing the fleet location, number of vehicles, and general description of vehicle missions.

Deliverable: Electronic copy of 10 semi-annual HICE Fleet Status Reports.

Status: This task has been completed. Work on this task ended in 2008.

Task 4.07: Gen II Civic Fleet Testing ( 2 Vehicles $36 \mathrm{mo} / 160 \mathrm{~K} \mathrm{mi}$ )

Complete 36-month/160,000 mile Fleet testing of 2 Gen II Civics Hybrid

Deliverable: Electronic reliability test data on a monthly basis and Fleet Data Sheet upon test completion.

Status: This task has been completed. The Fleet Data Sheets have been posted to the AVTA website.

http://avt.inel.gov/pdf/hev/ms 872506 Honda Civic.pdf

http://avt.inel.gov/pdf/hev/ms 932906 Honda Civic.pdf

http://avt.inel.gov/pdf/hev/hondacivicII ar.pdf

Task 4.08: Toyota Camry HEV Fleet Testing (2 Vehicles 36mo/160K mi)

Complete 36-month/160,000 mile Fleet testing of Toyota Camry Hybrid

Deliverable: Electronic reliability test data on a monthly basis and Fleet Data Sheet upon test completion.

Status: This task has been completed. The Fleet Data Sheets have been posted to the AVTA website.

http://avt.inel.gov/pdf/hev/ms 712907 Toyota Camry.pdf

http://avt.inel.gov/pdf/hev/ms 633007 Toyota Camry.pdf

http://avt.inel.gov/pdf/hev/toyotacamry ar.pdf 
Task 4.09: Lexus 400H 2WD HEV Fleet Testing ( 1 Vehicles $36 \mathrm{mo} / 36 \mathrm{~K} \mathrm{mi}$ )

Complete 36-month/60,000 mile Urban Fleet testing

Deliverable: Electronic reliability test data on a monthly basis and Fleet Data Sheet upon test completion.

Status: This task has been complete. The Fleet Data Sheets have been posted to the AVTA website.

http://avt.inel.gov/pdf/hev/4807LexusRX400h06factsheet.pdf

http://avt.inel.gov/pdf/hev/2575LexusRX400h06factsheet.pdf

http://avt.inel.gov/pdf/hev/lexus ar.pdf

Task 4.10: Future PHEV Fleet Testing (20 NYSERDA Vehicles)

Complete $12 \mathrm{mo} / 12,000$ mile fleet testing for each of 20 NYSERDA vehicles.

Deliverable: Electronic reliability test data on a monthly basis and Fleet Data Sheet upon test completion.

Status: This task was cancelled.

Task 4.11: Saturn VUE HEV Fleet Testing (2 Vehicles $36 \mathrm{mo} / 160 \mathrm{~K} \mathrm{mi}$ )

Complete 36-month/160,000 mile Fleet testing of 2 future HEVs

Deliverable: Electronic reliability test data on a monthly basis and Fleet Data Sheet upon test completion.

Status: This task has been completed. The Fleet Data Sheets have been posted to the AVTA website. One vehicle was destroyed in a collision at 102,934 miles. See Table 1 for status.

http://avt.inel.gov/pdf/hev/factSaturnVue.pdf

http://avt.inel.gov/pdf/hev/saturnvue ar.pdf

http://avt.inel.gov/pdf/hev/3344SaturnVue07factsheet.pdf

http://avt.inel.gov/pdf/hev/8122SaturnVue07factsheet.pdf

Task 4.12: Nissan Altima HEV Fleet Testing (2 Vehicles 36mo/160K mi)

Complete 36-month/160,000 mile Fleet testing of 2 Nissan Altima HEVs

Deliverable: Electronic reliability test data on a monthly basis and Fleet Data Sheet upon test completion.

Status: This task has been completed. The Fleet Data Sheets have been posted to the AVTA website.

http://avt.inel.gov/pdf/hev/ms 798207 Altima.pdf

http://avt.inel.gov/pdf/hev/ms altima 2351.pdf

http://avt.inel.gov/pdf/hev/altima ar.pdf 
Task 4.14: Chevy Tahoe HEV Fleet Testing (2 Vehicles $36 \mathrm{mo} / 160 \mathrm{~K} \mathrm{mi}$ )

Complete 36-month/160K mile fleet testing of 2 Chevy Tahoe Hybrids.

Deliverable: Electronic reliability test data on a monthly basis and Fleet Data Sheet upon test completion.

Status: This task has been completed. The Fleet Data Sheets have been posted to the AVTA website.

http://avt.inel.gov/pdf/hev/fact sheet08Tahoe.pdf

http://avt.inel.gov/pdf/hev/chevrolettahoe ar.pdf

http://avt.inel.gov/pdf/hev/5170ChevyTahoe08factsheet.pdf

http://avt.inel.gov/pdf/hev/ms 517008 Chevrolet Tahoe.pdf

http://avt.inel.gov/pdf/hev/7400ChevyTahoe08factsheet.pdf

http://avt.inel.gov/pdf/hev/ms 740008 Chevrolet Tahoe.pdf

Task 4.16: Honda Insight Fleet Testing (2 Vehicles $36 \mathrm{mo} / 160 \mathrm{~K} \mathrm{mi}$ )

Complete 36-month/160,000 mile fleet testing of 2 Honda Insight HEVs.

Deliverable: Electronic reliability test data on a monthly basis and Fleet Data Sheet upon test completion.

Status: This task has been completed. The Fleet Data Sheets have been posted to the AVTA website.

http://avt.inel.gov/pdf/hev/hondainsightII ar.pdf

http://avt.inel.gov/pdf/hev/fs2010insight0141.pdf

http://avt.inel.gov/pdf/hev/ms2010insight0141.pdf

http://avt.inel.gov/pdf/hev/fs2010insight1748.pdf

http://avt.inel.gov/pdf/hev/ms2010insight1748.pdf

\section{Task 4.17: PHEV Fleet Testing ( 6 vehicles 12 months)}

Monitor six (6) PHEVs converted by Energy CS. Collect data using the EnergyCS onboard data collection system. Transfer data to the Idaho National Laboratory for processing.

Deliverable: Electronic reliability test data on a monthly basis.

Status: This task has been completed. A report has been posted to the AVTA website. http://avt.inel.gov/pdf/phev/EnergyCSPriusAccelTestingResultsReport.pdf 
Task 4.18: Ford Fusion HEV Fleet Testing ( 2 Vehicles $36 \mathrm{mo} / 160 \mathrm{~K} \mathrm{mi}$ )

Complete 36-month/160K mile fleet testing of 2 Ford Fusion HEVs.

Deliverable: Electronic reliability test data on a monthly basis and Fleet Data Sheet upon test completion.

Status: This task has been completed. The Fleet Data Sheets have been posted to the AVTA website for one vehicle. The second vehicle was made inoperable due to a collision at 74,964 miles. See Table 1 for status.

http://avt.inel.gov/pdf/hev/fordfusion ar.pdf

http://avt.inel.gov/pdf/hev/4699FordFusion10factsheet.pdf

http://avt.inel.gov/pdf/hev/ms 46992010 ford fusion.pdf

http://avt.inel.gov/pdf/hev/fs2010fusion4757.pdf

http://avt.inel.gov/pdf/hev/ms2010fusion4757.pdf

Task 4.19: (Added in A014) HyMotion Gen II PHEV Accelerated Reliability Testing (6 months / 5,400 miles)

Complete 6-month/ 5,400 mile Accelerated Reliability testing of a plug-in gasoline hybrid electric vehicle.

Deliverable: Electronic reliability test data on a monthly basis and Fleet Data Sheet upon test completion.

Status: This task has been completed. The Fleet Data Sheet has been posted to the AVTA website.

http://avt.inel.gov/pdf/phev/HymotionPriusV2GreenApr08-Sept11.pdf

Task 4.20: (Added in A014) Ford Escape Gasoline PHEV Accelerated Reliability Testing ( 6 months / 5,400 miles)

Complete 6-month/ 5,400 mile Accelerated Reliability testing of a plug-in gasoline hybrid electric vehicle.

Deliverable: Electronic reliability test data on a monthly basis and Fleet Data Sheet upon test completion.

Status: This task has been completed. Test results are shown in Table 5, presented below.

Table 5 - PHEV Ford Escape Accelerated Reliability Testing Results

PHEV-15 2009 Ford Escape VIN\# 1181

\begin{tabular}{|c|c|c|c|c|c|c|c|c|c|c|c|c|c|}
\hline Test Date & $\begin{array}{c}\text { Cycle } \\
\text { (mi) }\end{array}$ & $\begin{array}{l}\text { Urban } \\
(10 \mathrm{mi})\end{array}$ & $\begin{array}{c}\text { Highway } \\
(10 \mathrm{mi})\end{array}$ & $\begin{array}{c}\text { Charge } \\
(\mathrm{Hr})\end{array}$ & $\begin{array}{c}\text { Repetitions } \\
\text { (N) }\end{array}$ & $\begin{array}{c}\text { Total } \\
(\mathrm{mi})\end{array}$ & $\begin{array}{c}\text { Repetitions } \\
(\%)\end{array}$ & $\begin{array}{c}\text { Miles } \\
(\%)\end{array}$ & $\begin{array}{c}\text { Cumulative } \\
\text { (mi) }\end{array}$ & $\begin{array}{c}\text { Electricity } \\
\text { (kwh) }\end{array}$ & $\begin{array}{l}\text { Fuel } \\
\text { (E-85) }\end{array}$ & MPG & Status \\
\hline $4 / 5-5 / 20 / 11$ & 10 & 1 & 0 & 4 & 60 & 610 & $37 \%$ & $11 \%$ & 610 & 238.26 & 2.000 & 305.0 & \\
\hline $2 / 15 / 11-4 / 4 / 11$ & 20 & 1 & 1 & 8 & 30 & 621.6 & $19 \%$ & $11 \%$ & 1231.6 & 224.57 & 6.900 & 90.1 & \\
\hline $1 / 24 /-2 / 14 / 11$ & 40 & 4 & 0 & 12 & 15 & 612.8 & $9 \%$ & $11 \%$ & 1844.4 & 186.12 & 3.200 & 191.5 & \\
\hline $8 / 24-9 / 15 / 10$ & 40 & 2 & 2 & 12 & 15 & 620 & $9 \%$ & $11 \%$ & 2464.4 & 171.74 & 7.300 & 84.9 & \\
\hline $12 / 3 / 10-1 / 7 / 11$ & 40 & 0 & 4 & 12 & 15 & 632.6 & $9 \%$ & $11 \%$ & 3097 & 200.02 & 9.700 & 65.2 & \\
\hline $11 / 17-12 / 2 / 10$ & 60 & 2 & 4 & 12 & 10 & 624.2 & $6 \%$ & $11 \%$ & 3721.2 & 124.16 & 11.800 & 52.9 & \\
\hline 9/16-9/27/10 & 80 & 2 & 6 & 12 & 8 & 664.1 & $5 \%$ & $12 \%$ & 4385.3 & 89.50 & 13.600 & 48.8 & \\
\hline $8 / 16-8 / 23 / 10$ & 100 & 2 & 8 & 12 & 6 & 603 & $4 \%$ & $11 \%$ & 4988.3 & 64.01 & 13.700 & 44.0 & shortened last day of route due to low fuel \\
\hline \multirow[t]{2}{*}{$8 / 1-8 / 3 / 10$} & 200 & 2 & 18 & 12 & 3 & 557.2 & $2 \%$ & $10 \%$ & 5545.5 & 31.53 & $15.28 \mathrm{gal}$ & 36.5 & shortened last day of route due to low fuel \\
\hline & Total & 16 & 43 & 96 & 162 & 5546 & & & & & & & \\
\hline
\end{tabular}


Task 4.21: Mercedes Benz HEV Fleet Testing (2 Vehicles / 36 months / 160K mi) Complete 36-month/ 160,000 mile Fleet testing of 2 Future HEVs.

Deliverable: Electronic reliability test data on a monthly basis and Fleet Data Sheet upon test completion.

Status: This task has been completed. The Fleet Data Sheet have been posted to the AVTA website. The second vehicle had a high voltage battery failure during fleet testing and was considered inoperable.

http://avt.inel.gov/pdf/hev/ftr2010benz5883.pdf

http://avt.inel.gov/pdf/hev/ftr2010benz6231.pdf

Task 4.22: (Added in A014) Gen 3 Prius HEV Fleet Testing (2 Vehicles / $36 \mathrm{mo} / 160 \mathrm{~K} \mathrm{mi}$ )

Complete 36-month/160K mile fleet testing of 2 Gen 3 Prius HEVs.

Deliverable: Electronic reliability test data on a monthly basis and Fleet Data Sheet upon test completion.

Status: This task has been completed. The Fleet Data Sheets have been posted to the AVTA website.

http://avt.inel.gov/pdf/hev/toyotapriusIII ar.pdf

http://avt.inel.gov/pdf/hev/fs2010prius0462.pdf

http://avt.inel.gov/pdf/hev/ms2010prius0462.pdf

http://avt.inel.gov/pdf/hev/fs2010prius6063.pdf

http://avt.inel.gov/pdf/hev/ms2010prius6063.pdf

Task 4.23 (Added in A003): Extend 2 HEV GEN II Prius Fleet Test (100K mi to $160 \mathrm{~K} \mathrm{mi}$ )

Extend fleet testing of 2 Gen II Toyota Priuses HEVs from 100,000 to 160,000 miles.

Deliverable: Electronic reliability test data on a monthly basis and Fleet Data Sheet upon test completion.

Status: This task has been completed. The Fleet Data Sheets have been posted to the AVTA website.

http://avt.inel.gov/pdf/hev/04toyotaprius ar.pdf

http://avt.inel.gov/pdf/hev/1052 04prius factsheet.pdf

http://avt.inel.gov/pdf/hev/1052 04prius maintain.pdf

http://avt.inel.gov/pdf/hev/2721 04prius factsheet.pdf

http://avt.inel.gov/pdf/hev/2721 04prius maintain.pdf 
Task 4.24: (Added January 2010) Diesel Volkswagen Golf Idle-Stop Technology Fleet Testing ( 2 Vehicles $36 \mathrm{mo} / 160 \mathrm{~K} \mathrm{mi}$ )

Complete 36-month/160,000 mile Fleet testing of two Idle-Stop Technology Volkswagen Golfs equipped with diesel engines.

Deliverable: Electronic Reliability test data on a monthly basis and Fleet Data Sheet upon test completion.

Status: This task has been completed. The Fleet Data Sheets have been posted to the AVTA website.

http://avt.inel.gov/pdf/mhv/volkswagengolf_ar.pdf

http://avt.inel.gov/pdf/mhv/fs2010golf5777.pdf

http://avt.inel.gov/pdf/mhv/ms2010golf5777.pdf

http://avt.inel.gov/pdf/mhv/fs2010golf8111.pdf

http://avt.inel.gov/pdf/mhv/ms2010golf8111.pdf

Task 4.25: (Added January 2010) Mazda3 I-stop Idle-Stop Technology Fleet Testing (2 Vehicles $36 \mathrm{mo} / 160 \mathrm{~K} \mathrm{mi}$ )

Complete 36-month/160,000 mile Fleet testing of two Idle-Stop Technology Mazda3 I-stops equipped with combustion re-start technology.

Deliverable: Electronic Reliability test data on a monthly basis and Fleet Data Sheet upon test completion.

Status: This task has been completed. The Fleet Data Sheets have been posted to the AVTA website.

http://avt.inel.gov/pdf/mhv/mazda3 ar.pdf

http://avt.inel.gov/pdf/mhv/fs2010mazda31865.pdf

http://avt.inel.gov/pdf/mhv/ms2010mazda31865.pdf

http://avt.inel.gov/pdf/mhv/fs2010mazda32736.pdf

http://avt.inel.gov/pdf/mhv/ms2010mazda32736.pdf 
Task 4.26: (Added January 2010) Smart mhd fortwo Idle-Stop Technology Fleet Testing (2 Vehicles $36 \mathrm{mo} / 160 \mathrm{~K} \mathrm{mi}$ )

Complete 36-month/160,000 mile Fleet testing of two Idle-Stop Technology Smart mhd fortwos equipped with conventional gasoline engine and electric re-start.

Deliverable: Electronic Reliability test data on a monthly basis and Fleet Data Sheet upon test completion.

Status: This task has been completed. Both vehicles experienced a mechanical failure and were removed from the fleet. The fuel economy study Smart mhd fortwo was substituted for fleet testing and completed fleet testing. Refer to Table 1 for results. The Fleet Data Sheets have been posted to the AVTA website.

http://avt.inel.gov/pdf/mhv/smartfortwo ar.pdf

http://avt.inel.gov/pdf/mhv/fs2010smart6476.pdf

http://avt.inel.gov/pdf/mhv/ms2010smart6476.pdf

http://avt.inel.gov/pdf/mhv/fs2010smart6644.pdf

http://avt.inel.gov/pdf/mhv/ms2010smart6644.pdf

http://avt.inel.gov/pdf/mhv/fs2010smart6659.pdf

http://avt.inel.gov/pdf/mhv/ms2010smart6659.pdf

Task 4.27: (Added January 2010) Hyundai Sonata Hybrid HEV Fleet Testing (2 Vehicles $36 \mathrm{mo} / 160 \mathrm{~K} \mathrm{mi}$ )

Complete 36-month/160,000 mile Fleet testing of two Hyundai Sonata Hybrids

Deliverable: Electronic Reliability test data on a monthly basis and Fleet Data Sheet upon test completion.

Status: This task has been completed. One vehicle has experienced a drivetrain failure prior to completing $160 \mathrm{k}$ miles. The second vehicle completed fleet testing under AVTA and transitioned to cooperative agreement DE-EE0005501 to continue to $160 \mathrm{k}$ miles. See Table 1 for the final status under AVTA. The Fleet Data Sheets have been posted to the AVTA website.

http://avt.inel.gov/pdf/hev/hyundaisonata ar.pdf

http://avt.inel.gov/pdf/hev/fs2011sonata3539.pdf

http://avt.inel.gov/pdf/hev/ms2011sonata3539.pdf

http://avt.inel.gov/pdf/hev/fs2011sonata4932.pdf

http://avt.inel.gov/pdf/hev/ms2011sonata4932.pdf

Task 4.28: (Added January 2010) Future HEV Fleet Testing (2 Vehicles 36 $\mathrm{mo} / 160 \mathrm{~K} \mathrm{mi}$ )

This task has been cancelled. The vehicle was not available in time to support AVTA contract period. 
Task 4.29: (Added January 2010) Honda CR-Z HEV Fleet Testing (2 Vehicles 36 $\mathrm{mo} / 160 \mathrm{~K} \mathrm{mi})$

Complete 36-month/160,000 mile Fleet testing of two Honda CR-Z HEVs

Deliverable: Electronic Reliability test data on a monthly basis and Fleet Data Sheet upon test completion.

Status: The vehicles have completed fleet testing under AVTA and have transitioned to cooperative agreement DE-EE0005501 to continue to $160 \mathrm{k}$ miles. See Table 1 for the final status under AVTA. The Fleet Data Sheets have been posted to the AVTA website.

http://avt.inel.gov/pdf/hev/hondacrz ar.pdf

http://avt.inel.gov/pdf/hev/fs2011crz2982.pdf

http://avt.inel.gov/pdf/hev/ms2011crz2982.pdf

http://avt.inel.gov/pdf/hev/fs2011crz4466.pdf

http://avt.inel.gov/pdf/hev/ms2011crz4466.pdf

Task 4.30: Reserved

Task 4.31: (Added January 2010) Nissan LEAF BEV Fleet Testing (1 Vehicle, $12 \mathrm{mo} / 12 \mathrm{k} \mathrm{mi}$ )

Complete 12-month/ 12,000 mile Fleet testing of one (1) Nissan LEAF BEV.

Deliverable: Electronic Reliability test data on a monthly basis and Fleet Data Sheet upon test completion.

Status: This task has been completed. The vehicle completed fleet testing under AVTA and transitioned to cooperative agreement DE-EE0005501 to continue to 60k miles. See Table 1 for the final status under AVTA.

Task 4.32: (Added January 2010) BEV Accelerated Reliability Testing (1 Vehicle, $12 \mathrm{mo} / 12 \mathrm{k} \mathrm{mi}$ )

This task has been cancelled due to lack of vehicle availability within the project period.

Task 4.33: (Added January 2010) BEV Accelerated Reliability Testing (1 Vehicle, $12 \mathrm{mo} / 12 \mathrm{k} \mathrm{mi}$ )

This task has been cancelled due to lack of vehicle availability within the project period.

Task 4.34: (Added January 2010) BEV Accelerated Reliability Testing (1 Vehicle, $12 \mathrm{mo} / 12 \mathrm{k} \mathrm{mi}$ )

This task has been cancelled due to lack of vehicle availability within the project period.

Task 4.35: (Added January 2010) BEV Accelerated Reliability Testing (1 Vehicle, $12 \mathrm{mo} / 12 \mathrm{k} \mathrm{mi}$ )

This task has been cancelled due to lack of vehicle availability within the project period.

Task 4.36: (Added January 2010) BEV Accelerated Reliability Testing (1 Vehicle, $12 \mathrm{mo} / 12 \mathrm{k} \mathrm{mi}$ )

This task has been cancelled due to lack of vehicle availability within the project period. 
Task 4.37: (Added January 2010) BEV Accelerated Reliability Testing (1 Vehicle, $12 \mathrm{mo} / \mathbf{1 2} \mathrm{k} \mathrm{mi}$ )

This task has been cancelled due to lack of vehicle availability within the project period.

Task 4.38: (Added January 2010) Honda Civic Ultra-Battery HEV Fleet Testing (1 Vehicle, 24 mo / 100k mi)

Complete 24-month/100,000 mile Fleet Testing of Honda Civic Ultra-Battery HEV.

Deliverable: Electronic Reliability test data on a monthly basis and Fleet Data Sheet upon test completion.

Status: This task has been completed. The battery report, which includes the fleet data results, has been uploaded to the AVTA website.

http://avt.inel.gov/pdf/hev/batteryultrabatterycivic5577.pdf

Task 4.39: (Added January 2010) Chevrolet Volt PHEV Fleet Testing

(12 mo / 12k mi )

Complete 12-month/ 12,000 mile Fleet testing of a Chevrolet Volt plug-in gasoline PHEV.

Deliverable: Electronic Reliability test data on a monthly basis and Fleet Data Sheet upon test completion.

Status: This task has been completed. The vehicle completed fleet testing under AVTA and transitioned to cooperative agreement DE-EE0005501 to continue to $60 \mathrm{k}$ miles. See Table 1 for the final status under AVTA.

Task 4.40: (Added January 2010) Plug-In Gasoline HEV Accelerated Reliability Testing ( $6 \mathrm{mo} / 5,400 \mathrm{mi})$

This task has been cancelled due to lack of vehicle availability within the project period.

Task 4.41: (Added January 2011) Evaluation of Federal Fleets

Coordinate through FEMP to install data loggers on up to 40 federal fleet vehicles. Gather vehicle use data from these vehicles for approximately 60 days, and then move the loggers to new vehicles in additional fleets until data has been collected for a total of up to 200 vehicles.

Deliverable: Electronic copy of vehicle data sent to INL and a final report characterizing vehicle missions.

Status: Clarity Group, Inc. partnered with five agencies and 13 site locations in support of the AVTA Federal Fleet Data Logging and Characterization Study. Located in 11 states and the District of Columbia, Clarity Group, Inc. completed data collection on 142 fleet vehicles (60 vehicles in 2011-2012 and 82 vehicles 2012-2013) and collected nearly 200,000 miles of vehicle data. Data was analyzed for each agency/site and reports were prepared and provided to agencies for their use. A separate contract with Battelle Energy Alliance, LLC, (BEA) continued this initial work conducted under AVTA. A final FEMP report for all vehicle data collected for this task and the BEA contract was submitted to INL for review, then posted to the AVTA website. 


\section{Task 4.42: (Added January 2011) PHEV Fleet Testing}

Install vehicle monitoring instrumentation to 20 Ford Escape vehicles that have been converted to plug-in hybrids. Collect vehicle performance data and monitor the vehicle usage for up to 12 months or 12,000 miles.

Deliverable: Electronic copy of charger and vehicle data sent to INL and final report on vehicle use.

Status: This task has been completed. The Data collection has been completed for all 20 vehicles in the PHEV fleet. Reports have been published to the INL website for the 12 months of the study.

http://avt.inel.gov/pdf/phev/QuantumJanuary2012.pdf

http://avt.inel.gov/pdf/phev/QuantumFebruary2012.pdf

http://avt.inel.gov/pdf/phev/QuantumMarch2012.pdf

http://avt.inel.gov/pdf/phev/QuantumApril2012.pdf

http://avt.inel.gov/pdf/phev/QuantumMay2012.pdf

http://avt.inel.gov/pdf/phev/QuantumJune2012.pdf

http://avt.inel.gov/pdf/phev/QuantumJuly2012.pdf

http://avt.inel.gov/pdf/phev/QuantumAugust2012.pdf

http://avt.inel.gov/pdf/phev/QuantumSeptember2012.pdf

http://avt.inel.gov/pdf/phev/QuantumOctober2012.pdf

http://avt.inel.gov/pdf/phev/QuantumNovember2012.pdf

http://avt.inel.gov/pdf/phev/QuantumDecember2012.pdf 


\section{Task 5 - Communication and Outreach Support (2005-2013)}

Task 5.a (Added in A003): Model NEV Program

Incorporate NEV fleet data collected under previous AVTA Tasks into the Model NEV Report (prepared under agreement DE-FC07-00ID13859) to substantiate recommendations presented.

Deliverable: Electronic copy of a Model NEV Report incorporating NEV fleet data.

Status: This task has been completed. The Data has been posted to the AVTA website. http://avt.inel.gov/pdf/nev/nev deploy guidelines report.pdf

Task 5.01 (Added in A003): 2006 DOE Ad Hoc Requests for Data, Analysis, and Reports

Conduct work beneficial only to the Department of Energy (DOE) as requested by the DOE.

Deliverable: Electronic report summarizing results of work performed, filed quarterly and annually.

Status: This task has been completed. All activities that generated data, analysis, or reports in the period were included as tasks in above. No additional ad hoc requests were received.

Task 5.02 (Added in A003): 2007 DOE Ad Hoc Requests for Data, Analysis, and Reports

Conduct work beneficial only to the Department of Energy (DOE) as requested by the DOE.

Deliverable: Electronic report summarizing results of work performed.

Status: This task has been completed. All activities that generated data, analysis, or reports in the period were included as tasks in above. No additional ad hoc requests were received.

Task 5.03 (Added in A003): 2008 DOE Ad Hoc Requests for Data, Analysis, and Reports

Conduct work beneficial only to the Department of Energy (DOE) as requested by the DOE.

Deliverable: Electronic report summarizing results of work performed.

Status: This task has been completed. Data collection and analysis of project tasks were reported to DOE as requested monthly and posted per contract requirements.

The first task was to host a meeting at the Clarity Group facilities in Phoenix, AZ where George Blaisdell and Albert Nunez from the NSF were able to inspect the following NEV models;

- GEM 6 passenger

- GEM eL XD long bed

- Roush REV

- Miles ZX40ST truck 
- Miles ZX40S-AD sedan

- ZENN 2 passenger sedan (MY 2008)

- ZENN 2 passenger sedan (MY 2006)

The second task was to prepare a table of the capabilities, sizes, costs, etc. for available and claimed available NEVs for the NSF.

In addition to cold temperatures, Antarctica presents unique vehicle operations requirements, including the need for sufficient space in the cab for operations by personnel with large coats and heavy boots. NSF seemed to be most interested in a NEV pickup from Miles Automotive due to space in the cab and the pickup bed.

A question was raised regarding NEV petroleum displacement. Analysis indicated that the Miles Pickup would achieve an equivalent of approximately 65 miles per gallon of diesel fuel used to generate electricity in Antarctica. The Miles pickup uses 156 AC watt hours per mile, with a $50 \%$ penalty assumed for cold weather operations with heater use, resulting in $234 \mathrm{AC}$ watt hours per mile. The diesel-powered generator is assumed to be about $40 \%$ efficient, resulting in about $585 \mathrm{AC}$ watt hours per mile. Diesel fuel can generate about 38,000 watt hours per gallon. With 38,000 watt hours per gallon divided by 585 AC watt hours per mile, approximately 65 miles per gallon can be achieved. The type of internal combustion engine pickups the NEVs will replace would likely get between 15 and 20 miles per gallon in "normal" domestic operations, but these vehicles are idled for extended periods of time and are operated inefficiently in Antarctica, so a likely mpg would be in the 10 to $12 \mathrm{mpg}$ range at best. This provides the NEV with a 5 to 6 times improvement in petroleum use. In addition to significant savings in petroleum use, it is anticipated that savings of a similar magnitude can be achieved in vehicle maintenance.

As part of this Task 5.03, additional support was provided through the following activities.

ORNL requested the drive train from the 04 Prius VIN 1052, which had previously been sold. Clarity Group, Inc. reacquired the vehicle and removed the requested parts and shipped them to ORNL, at the request of DOE Project Management in support of the overall Vehicle Technologies development testing as part of Task 5 activities. The balance of the vehicle was scrapped.

A Ford Escape PHEV was tested using the 10 and 20-mile cycles of the PHEV accelerated reliability test. Results were transmitted to INL under a Non-Disclosure Agreement with Ford.

Task 5.04 (Added in A003): 2009 DOE Ad Hoc Requests for Data, Analysis, and Reports

Conduct work beneficial only to the Department of Energy (DOE) as requested by the DOE.

Deliverable: Electronic report summarizing results of work performed.

Status: This task has been completed. All activities that generated data, analysis, or reports in the period were included as tasks in above. No additional ad hoc requests were received. 
Task 5.05 (Added in A003): 2010-2013 DOE Ad Hoc Requests for Data, Analysis, and Reports

Conduct work beneficial only to the DOE as requested by the DOE.

Deliverable: Electronic report summarizing results of work performed.

Status: This task has been completed. All activities that generated data, analysis, or reports in the period were included as tasks in above. Ad hoc requests completed included providing PHEV vehicle used in AVTA fleet testing to INL for first-hand use and Winter performance analysis.

\section{Task 5.06 2006 DOE Administrative Tasks}

Administrative tasks conducted as required by DOE in support of award. Administrative work needed to comply with contract requirements.

Deliverable: Electronic reports required by contract.

Status: This task has been completed. Clarity Group, Inc. personnel participated in the Electric Drive Transportation Association Conference in Vancouver from December 6-8, 2005, and also the WestStart Clean Heavy Duty Vehicle Conference on February 22, 2006 to discuss HICE integration. Three displays were created for the HICE discussions, including one on the Hydrogen fueling station and fleet data, Hydrogen and blended fuel, and the third display on the Roush HICE truck. The Roush HICE truck and IWHUP project were presented at the National Hydrogen Association Meeting during the week of March 12, 2006. A paper was presented regarding baseline and end-of-life battery testing at the SAE Congress in Detroit, MI in April 2006. At the request of the DOE Project Manager, Clarity Group personnel participated in a DOE led Plug-In Hybrid Discussion meeting on May 4-5, 2006 at DOE headquarters in Washington, DC. Clarity personnel participated in breakout session discussions. Clarity Group, Inc. personnel also participated in the Phoenix Clean Cities Meeting on May 8-10, 2006. Data from the Drive AVTA Testing presented during the Advanced Automobile Battery Conference in Baltimore, Maryland in May 2006. The annual DOE summit was conducted at Clarity Group, Inc. in Phoenix on June 6, 2006 to discuss current and ongoing vehicle tasks.

\section{Task 5.07 2007 DOE Administrative Tasks}

Administrative tasks conducted as required by DOE in support of award. Administrative work needed to comply with contract requirements.

Deliverable: Electronic reports required by contract.

Status: This task has been completed. A DOE meeting to discuss current and future tasks was held on October 24, 2007. The annual DOE summit was conducted at Clarity Group, Inc. in Phoenix on January 18, 2007 to discuss 2007 and future vehicle tasks. Clarity Group, Inc. personnel participated in a Clean Cities Legislative presentation. Hydrogen, electric, and hybrid vehicles were displayed at the state capitol building as part of this presentation on February 28, 2007. A presentation was given on Alternative Fuel Vehicles at the Transportation and Environment Issue Day on August 17, 2007. No additional administrative tasks were required in 2007. 


\section{Task 5.08 2008 DOE Administrative tasks}

Administrative tasks conducted as required by DOE in support of award. Administrative work needed to comply with contract requirements.

Deliverable: Electronic reports required by contract.

Status: This task has been completed. The annual DOE summit was conducted at Clarity Group, Inc. in Phoenix in January 2008 to discuss 2008 and future vehicle tasks. No additional administrative tasks were required in 2008.

\section{Task 5.092009 DOE Administrative tasks}

Administrative tasks conducted as required by DOE in support of award. Administrative work needed to comply with contract requirements.

Deliverable: Electronic reports required by contract.

Status: This task has been completed and included the investigation of a battery failure in a plug-in hybrid electric vehicle. A Ford Escape Hybrid was converted to a Plug-In Hybrid Electric Vehicle configuration by Electrovaya and delivered to the New York State Energy Research and Development Authority in August, 2007. The vehicle was tested for both NYSERDA and the US Department of Energy for performance, emissions and reliability. At the conclusion of this test work, the vehicle was parked and plugged into a wall outlet. It was found several days later to have suffered a catastrophic failure of the battery pack, which destroyed portions of the cargo area of the vehicle. The vehicle was equipped with an add-on battery pack that increased battery capacity by $12 \mathrm{kWh}$. At least two repairs were made to the vehicle prior to the incident. The vehicle suffered a severe overheating of the battery, but no signs of sustained fire were found. All cells in the pack were found to be in place but destroyed. Components with low melting points were missing; aluminized pouch bag, solvents and polymer separators. The electrodes, graphite, carbon, and copper foil were all present. Aluminum containers were deformed and in many places found melted and/or disintegrated. All circuit boards were found delaminated. The cause of the incident appears to be continuous overcharge. Data recorded from an energy meter connected to the wall outlet shows an average power draw of $200 \mathrm{~W}$ for the 11 days during which the vehicle was parked and plugged into the wall. The exact cause of this overcharge is uncertain, but likely due to a failure in the onboard battery charger or the Battery Management System, which controls the onboard charger. In spite of the high heat created by this overcharge condition, the vehicle did not catch fire, or at least was not consumed by any fire. The battery cells remained in place and did not explode. There is no evidence of extreme electrical shorting, arcing or sparking. While the battery pack was completely destroyed, damage to the vehicle was limited.

In addition to the battery failure investigation, at the request of the DOE Project Manager, Clarity Group personnel participated in a DOE-led PHEV Market Introduction Study Workshop meeting on December 1-2, 2008 at DOE headquarters in Washington, DC. Clarity Group, Inc. personnel participated in breakout session discussions. The annual DOE summit was conducted at Clarity Group, Inc. in Phoenix in January 2009 to discuss 2009 and future vehicle tasks. 


\section{Task 5.10 2010-2013 DOE Administrative Tasks}

Administrative tasks conducted as required by DOE in support of award. Administrative work needed to comply with contract requirements.

Deliverable: Electronic reports required by contract.

Status: This task has been completed. The annual DOE summit was conducted annually in January at Clarity Group, Inc. in Phoenix to discuss 2010 through project close vehicle tasks. Any new requests will be through cooperative agreement DEEE0005501. No additional administrative tasks were required in 2010-2013.

\section{Task 5.11 Support Chinese Battery \& Vehicle Manufacturer Interface}

Develop a status report of Chinese battery and vehicle manufacturers and conduct interface work with these manufacturers as requested by DOE.

Deliverable: Status report of battery and vehicle manufacturers and ad hoc reports as required by DOE

Status: A Clarity Group, Inc. engineer visited battery suppliers and vehicle converters during Q1 of FY 2012. Initial discovery information was shared with INL. It was determined that no further interface was necessary at this time.

\section{Task 5.12 Support Chinese Sister Cities}

Conduct work required to support DOE Chinese Sister Cities Program.

Deliverable: Electronic reports as required by $\mathrm{DOE}$

Status: China travel by a Clarity Group, Inc. engineer included Sister City Shanghai. As in task 5.11, general information was shared with INL that was later utilized for a workgroup review that INL personnel participated in. No formal report will be issued. 


\section{Accomplishments}

Over the course of 90 months, a total of 113 vehicles have been tested during this cooperative agreement. These advanced technology vehicles evaluated included the following;

- 37 Hybrid Electric Vehicles

- 29 Plug-In Hybrid Electric Vehicles

- 9 Battery Electric Vehicles

- 10 Neighborhood Electric Vehicles

- 14 Hydrogen Internal Combustion Engine Vehicles

- 4 Natural Gas-fueled Vehicles

- 7 Stop-Start Vehicles (Micro-Hybrids)

- 3 eGSE Vehicles (Off-Road)

These vehicles accumulated over $6,600,000$ test miles.

The following observations and accomplishments were identified during the conduct of the AVTA vehicle testing activity:

- Highest average fuel economy for a hybrid: $44.2 \mathrm{mpg}$ average for the two 2010 Toyota Prius Hybrids and also for the two 2004 Toyota Prius Hybrids

- Highest average fuel economy for a mid-size hybrid sedan: $35.0 \mathrm{mpg}$ average for the two 2010 Ford Fusion Hybrids

- Highest average fuel economy for a hybrid SUV: $27.0 \mathrm{mpg}$ average for the two 2005 Ford Escape Hybrids

- Highest average fuel economy for a hybrid pickup truck: $17.9 \mathrm{mpg}$ average for the two 2004 Chevrolet Silverado Hybrids

- Highest average fuel economy for an idle-stop vehicle: $43.2 \mathrm{mpg}$ average for the two 2010 Volkswagen Golf Diesels (Imported from Europe)

- Highest charge depleting range at a constant $60 \mathrm{mph}$ for a plug-in hybrid: $31.0 \mathrm{miles}$ for the 2011 Chevrolet Volt

- Highest charge depleting range at a constant $60 \mathrm{mph}$ for a battery electric vehicle: 65.3 miles for the 2011 Nissan Leaf.

Seven (7) vehicles had to abort testing or provided incomplete test results due to catastrophic part failure or accident damage.

157 separate tasks were defined and conducted that generated over 250 reports over the period of performance. 


\section{Recommendations}

As a result of conducting the Advanced Vehicle Testing and Evaluation, Clarity Group, Inc. offers the following recommendations for future advanced vehicle testing;

a) Seven (7) vehicles failed to complete the scheduled testing due to catastrophic part failure or a traffic accident, which "totaled" the vehicle. In one case both vehicles of a model being tested failed to complete the testing and in five (5) other cases, only one vehicle of the model being tested completed the testing.

RECOMMENDATION: More than two samples of an advanced vehicle model should be tested. This would provide a more statistically valid evaluation of the vehicle model and the associated technology's operating costs, fuel economy and durability.

b) Computer technology for data logging and transfer of data collected by loggers has advanced since 2005, and provides greater speed, larger on-board storage, and greater reliability when data is downloaded automatically.

RECOMMENDATION: Update data loggers to systems that are up-to-date technology and able to transfer data remotely (wirelessly via wi-fi or by cellular communication).

c) Throughout the conduct of the AVTA project, Clarity Group, Inc. has relied on only one fleet at a time. Although both fleets used over the project period of performance were reliable, the flexibility to modify mileage accumulation rates, to access vehicles for additional evaluation, adding vehicles to or taking vehicles from the fleet can be problematic when the test fleet makes up a significant portion of the operator's overall fleet.

RECOMMENDATION: Additional fleet operators would increase flexibility for testing and evaluation, and enable the AVTA program to increase the number of vehicles tested.

d) Testing advanced technology vehicles often involved non-traditional transportation fuels and fueling infrastructure (CNG, Hydrogen, Electricity, Propane), and the infrastructure is often an enabler for the advanced vehicle technology.

RECOMMENDATION: Testing and evaluating the fueling infrastructure that supports these advance vehicle technologies would enhance the value to the Advanced Vehicle Testing Activity. Including the evaluation of fueling technologies, especially electric vehicle charging, which can also add an additional level of control on "fuel" consumption aspect of AVTA. 